\title{
SYSTEMATICS OF THE TRAPDOOR SPIDER GENUS ALIATYPUS (ARANEAE: ANTRODIAETIDAE)*
}

\author{
By Frederick A. Coyle \\ Department of Biology, Western Carolina University, \\ Cullowhee, North Carolina, 28723
}

\section{INTRODUCTION}

Aliatypus species are all rather stocky mygalomorph spiders (Figs. 45-49) which construct a burrow with a trapdoor entrance from which they capture prey. In general morphology and behavior, Aliatypus bears striking resemblance to the distantly related trapdoor spider family Ctenizidae, but this similarity is clearly the result of convergent, or at least parallel, evolution; Aliatypus is an atypoid mygalomorph taxon most closely related to Antrodiaetus, Atypoides, and the Mecicobothriidae. Aliatypus species appear to be restricted to California and Arizona (Maps I-4) where they live in ravine banks, road banks, or other slopes in habitats ranging from hot, dry sagebrush scrub communities to wet coast redwood forests and cool California red fir mountain forests. They are among the most abundant trapdoor spiders in California.

Aliatypus has been badly neglected; only one species has been described (Banks, I896; Smith, I908) and little natural history information has been published (Smith, I908; Gertsch, 1949; Coyle, I97I). During the last seven years a concerted collecting effort, largely by Wendell Icenogle and myself, has increased the availability of adult specimens from a dozen to 330 and has thereby made possible this revision. My chief goal in this study has been to define accurately the species limits by means of an analysis of variation. The methods employed are essentially those of my earlier studies (Coyle 1968, 1971) and are summarized in the Methods section of this paper. Discussions of variation patterns are included in order to improve our understanding of geographic variation in mygalomorph spiders and guide future research on Aliatypus. The considerable amount of behavioral and ecological data which has been collected will be published separately in a paper on Aliatypus natural history.

*Manuscript received by the editor January 1, 1975. 
I hope that these studies of Aliatypus will stimulate others to investigate these fascinating spiders. Considerably more collecting is necessary before Aliatypus systematics can be confidently understood. As pointed out in the discussions of variation, small sample sizes and sizeable geographic gaps from which no samples are available have greatly limited the strength of some of my conclusions. The variation discussions, locality records, and distribution Maps 2-4 (Map 4 marks the distribution of unidentifiable Aliatypus specimens.) should help direct future collecting efforts.

\section{Acknowleigements}

Willis Gertsch first recognized the potential diversity within Aliatypus and suggested that I revise the genus. Wendell Icenogle deserves tremendous credit for the hours he labored collecting about 55 percent of the specimens upon which this study is based. He was the first collector of five new species. Without his field work this study would be very incomplete. Jim Horton, my department head during most of this research, provided needed space and release time. I thank the following individuals and institutions for loans of Aliatypus specimens: William Azevedo, Michael Bentzien, Patrick Craig, Willis Gertsch (American Museum of Natural History), Wendell Icenogle, Herbert Levi (Museum of Comparative Zoology), Patrick Marer, Robert Schick (California Academy of Sciences), and Mel Thompson. This research and its publication have been supported by a grant (GB-34I28) from the National Science Foundation.

\section{Evolution}

\section{PHYLOGENY}

Aliatypus, Antrodiaetus, Atypoides, the Mecicobothriidae, and the Atypidae form a distinct monophyletic taxon (Coyle, I97 I). Aliatypus is probably an old group, so that the details of its relationship to these other atypoid mygalomorph taxa are not now clear. The question of whether Aliatypus is more closely related to Antrodiaetus and Atypoides or to the mecicobothriids was discussed earlier (Coyle, 1971), but will remain unresolved until after the completion of a careful comparative study of all atypoid mygalomorphs.

In Figure I I have presented a hypothetical phylogeny of the genus Aliatypus. This speculation is based upon a comparison of character states in living Aliatypus species and related genera. It is 


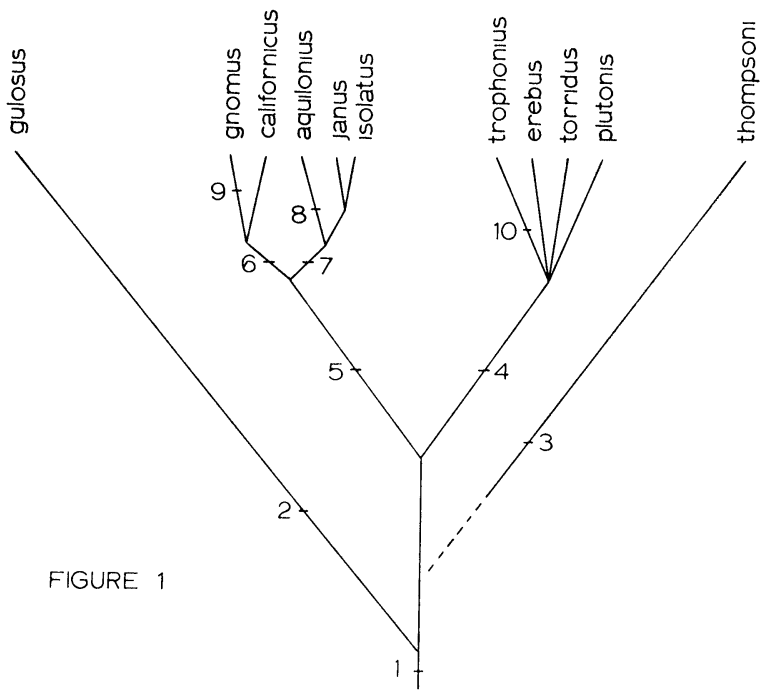

Figure 1: Suggested phylogeny of Aliatypus species. 1. Character states of hypothetical ancestral stock: No ICS keel or OCS keel. Seminal receptacles with moderately long, sinuous, non-tapering stalks and medium sized bulbs. Posterior sigilla small and well separated. Legs of moderate length. Thoracic groove a deep pit. Leg I setation as in majority of species. Moderately large body. 2. Seminal receptacle stalks become short and straight. Legs become proportionately shorter. 3. Posterior sigilla enlarge. Thoracic groove lost. Leg I setation changes. 4. Posterior sigilla enlarge. Legs become proportionately shorter. Become adapted to dryer habitats. 5. Become adapted to more humid and cooler habitats. 6. ICS keel develops. 7. Seminal receptacle stalks become tapered. 8. Conductor tip changes form. Body size reduced. 9. Seminal receptacle stalks become less elongate and less sinuous. Body size reduced. 10. Body size reduced.

meant to be a useful working hypothesis, subject to revision. Characters which were relied upon most heavily are palpus form, seminal receptacle form, and posterior sigilla size and placement. The actual direction of evolution in some characters may well be the reverse of those suggested. It is certain that Aliatypus contains two distinct groups of closely related species - $A$. californicus, $A$. janus, $A$. isolatus, $A$. aquilonius, and $A$. gnomus on the one hand and $A$. trophonius, $A$. erebus, $A$. plutonis, and $A$. torridus on the other - and two distinct species, $A$. gulosus and $A$. thompsoni, each rather distantly related to all the others. 


\section{GEOGRAPHIC VARIATION AND SPECIATION}

As is the case in Antrodiaetus (Coyle, I97 I), Atypoides (Coyle, I968), and probably most other burrowing mygalomorph genera (See, for example, Main, 1957; Loksa, 1966; and Forster and Wilton, 1968.), there is considerable geographic variation in some species of Aliatypus. Detailed descriptions of these geographic variation patterns can be found in the Taxonomy section. My purpose here is to consider some of the causes of these patterns.

The environmental tolerance ranges and dispersal ability of a species are key factors in determining what environmental conditions constitute barriers which can fragment and isolate its populations so that genetic divergence can take place. Little pertaining specifically to Aliatypus dispersal can be added to my earler discussion of dispersal ability in antrodiaetids (Coyle, I97I). In summary, the probability of successful colonization of distant localities by long distance aerial dispersal is extremely low; aquatic rafting, short distance spiderling dispersal, and male wandering are probably the only important means of dispersal under natural conditions. As in Antrodiaetus and Atypoides, environments with very low humidity, such as deserts or semiarid grasslands, are the outstanding barriers to dispersal and thus gene flow in Aliatypus. However, some species of Aliatypus, notably $A$. plutonis and $A$. torridus, are less well restricted by dry barriers than are most other antrodiaetids.

The following discussions, although partly speculation, should, like any working hypotheses, help direct further research. Frequent referral to Map I will help to understand them.

The Central Valley of California, a semiarid grassland in its recent natural state, appears to be a strong barrier to gene flow between coastal and Sierran populations of both Aliatypus californicus and Aliatypus erebus. The genetic discontinuity between these populations may even be great enough to merit calling them incipient species. A similar situation exists in Atypoides riversi (Coyle, I968 and 1971). Apparently, during Pleistocene glacial periods when the climate was wetter and cooler, dispersal of these species occurred across favorable wooded parts of the Central Valley. The recent discovery of isolated $A$. californicus and $A$. riversi populations in the Sutter Buttes of the Central Valley indicates that this was once part of such a corridor allowing gene flow across the valley. Similar dispersals across the Central Valley during Pleistocene glacial periods are also indicated by distribution patterns of the salamander genera Ensatina and Taricha, which, like Aliatypus, require rather mesic habitats (Stebbins, 1949; Riemer, 1958). I suspect that the antro- 


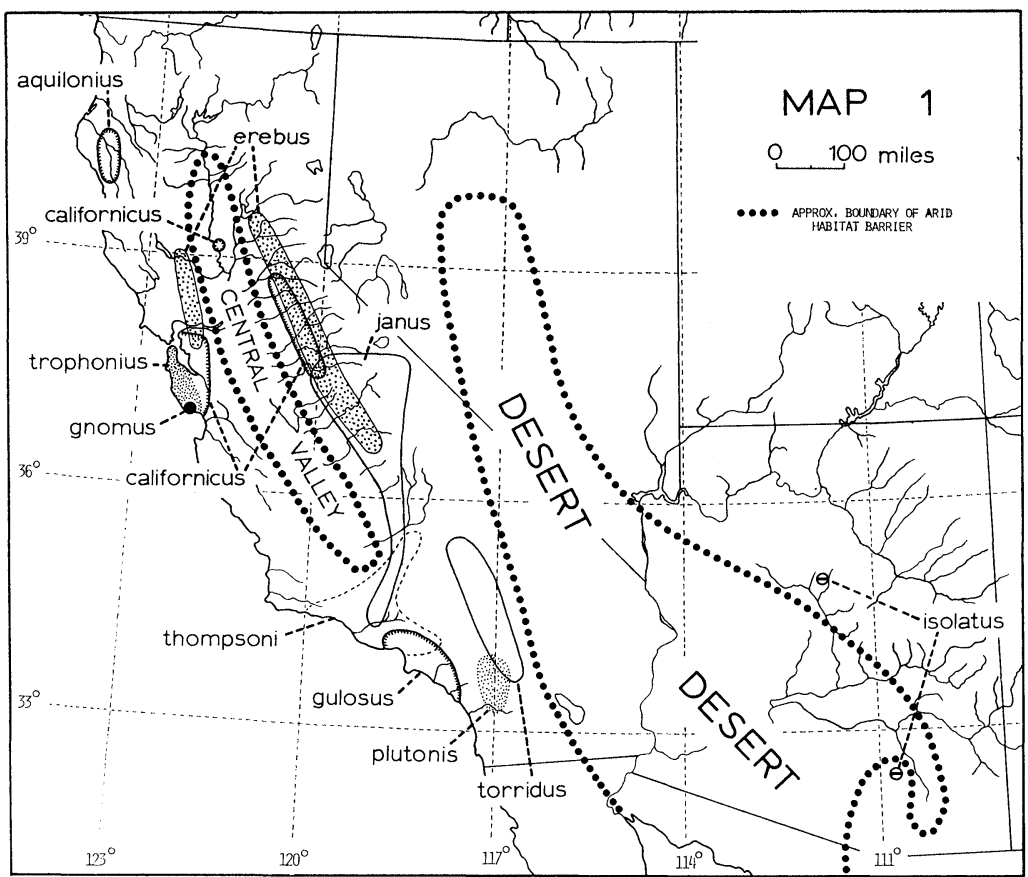

Map 1. Known distribution ranges of Aliatypus species in relation to present major arid habitat barriers which formed during the retreat of the Wisconsin glaciation.

diaetid trans-valley connections existed during the most recent (Wisconsin) glacial period and consequently became severed as recently as I3,000 years ago. Perhaps the $A$. californicus population at Mariposa, which is phenotypically more distinct from the coastal population than is the north Sierran population, was last connected with the coastal population during an earlier glacial period; or perhaps its trans-valley connections were simply severed earlier during the retreat of the last (Wisconsin) glacial period than were those of the north Sierran populations. Perhaps continued expansion of habitat barriers during the present post-glacial period has tended to restrict gene flow between the morphologically divergent northern populations of $A$. erebus and its south Sierran populations.

There is much geographic variation in Aliatypus janus, but the samples are so small and scattered that it is difficult to recognize important barriers to gene flow. The northernmost samples probably 
represent the kind of semi-isolated, genetically divergent, peripheral populations found in many species. Aliatypus thompsoni variant populations are also at the periphery of the species range, where suitable habitats are probably uncommon and semi-isolated. The Tehachapi Mountains apparently provide (or recently provided) an east-west corridor of favorable habitats for the dispersal of $A$. janus and $A$. thompsoni between the southern end of the Sierra Nevada Mountains and the coastal mountain ranges. The morphologically divergent nature of the $A$. thompsoni samples at Tehachapi and in the southern end of the Sierra Nevada Mountains indicates that this corridor is not currently supporting much dispersal.

The phenotypic differences between the two known Aliatypus isolatus populations in Arizona are almost certainly caused by the disruption of gene flow after the recent (Wisconsin) glacial period as desert and grassland barriers expanded all over the Southwest to isolate various mesic mountain habitats. Pollen analyses (Martin and Mehringer, 1965) demonstrate that during the Wisconsin glacial period (which apparently lasted in that area until about 13,000 years ago), woodland and forest habitats favorable for $A$. isolatus extended continuously throughout western and northern Arizona. Thus the similar geographic variation patterns in $A$. isolatus and Antrodiaetus apachecus (Coyle, 197I) probably have a common cause.

The extreme similarity of allopatric Aliatypus janus and Aliatypus isolatus, when viewed with Southwest pollen analyses (Martin and Mehringer, 1965) in mind, leads to the conclusion that these two species were formed when a recent interglacial expansion of the Sonoran and Great Basin Deserts severed a previously widespread ancestral population. Convincing evidence that I7,000 to 23,000 years ago (during the $W$ isconsin glacial period) woodland extended continuously from current $A$. isolatus localities to the present range of $A$. janus, strongly indicates that these sister species may be only I 5,000 years or so old. Indeed, it is possible that genetic divergence has not even progressed far enough for the development of reproductive isolating mechanisms.

There are three other pairs of closely related Aliatypus species $A$. janus and $A$. aquilonius, $A$. californicus and $A$. gnomus, and $A$. erebus and $A$. trophonius - which are not as similar as $A$. janus is to $A$. isolatus. It is possible that each of these pairs originated from a trio of ancestral species fragmented by arid barriers, such as the present Central Valley, during an earlier Pleistocene interglacial. Interestingly, each of these pairs consists of a large and a small species. 


\section{Methods}

\section{COLLECTING METHODS}

Because of their covert behavior, Aliatypus spiders are rarely collected except when one concentrates on special collecting strategies. Banks and slopes of promising habitats (to be described thoroughly in a paper on Aliatypus natural history) are best searched in daylight by carefully examining suitable microhabitat surfaces for the outline of a closed trapdoor. However, whenever the trapdoors are sealed, such as during dry periods, they may become covered with loose soil particles or other debris; carefully shaving away the top layer of soil may then be the only way to locate burrows. Night collecting is usually less satisfactory than daytime collecting since even unsealed Aliatypus doors are only cracked open at night and not easily located with artificial light. At night it is sometimes possible to trap active spiders at their burrow entrances by thrusting a knife blade into the soil and across the burrow lumen just below the spider, but frequently the soil is too hard. More information can be gained by careful excavation of the burrow in daylight. An army trench shovel, a small, chisel-head, rock hammer, a large pocket knife, and pruning shears are all useful for excavating in the often hard and root-bound soil. Penultimate males, easily recognized by their swollen pedipalpal tarsi, will often molt to adulthood if kept in a cool, humid, and dark environment. Just before and during the mating season (usually during the wet fall and winter months) recently matured males may be found in their burrows prior to abandoning them. Wandering males are best collected at night by hand or with pitfall traps in dense burrow aggregations during optimum mating weather.

\section{ANALYSIS OF VARIATION}

I have examined the taxonomy of Aliatypus by means of an analysis of variation nearly identical to the analysis employed in my revisions of Antrodiaetus (Coyle, I97 I) and Atypoides (Coyle, I968). Such an analysis largely overcomes difficulties posed by the relatively simple reproductive anatomy, by the instar heterogeneity of adult female samples, and by heightened geographic variation, difficulties which appear to be common to most mygalomorph spider taxa. The material analyzed consists of 252 adult females and 78 adult males. The sample size for each species is indicated in Tables I and 2.

Initially, variation in a large number of qualitative and quantitative characters was briefly surveyed, and from these characters the diagnostically most promising were selected and their variation studied 
in depth. Variation of the quantitative characters (measurements, meristic characters, and ratios formed from these) was analyzed with the aid of an IBM 36o Model 30 computer. A Fortran IV program directed the computer to calculate the mean and standard deviation of each character for each local population sample of each sex and for certain groupings of local samples into larger infraspecific samples or species samples. The computer then compared these samples pairwise in any desired combination, giving for each character for each comparison a value of the distinctness of the two samples. This "distance" value equals the difference between the means of the two samples divided by the sum of their standard deviations.

This variation analysis was performed with the following number of characters: 23 measurements, one meristic character, and 39 ratios for males; 20 measurements, six meristic characters, and 50 ratios for females. The measurements and meristic characters were defined so as to be clearly delimited. Their abbreviations and definitions are as follows (see Figs. 2-7) :

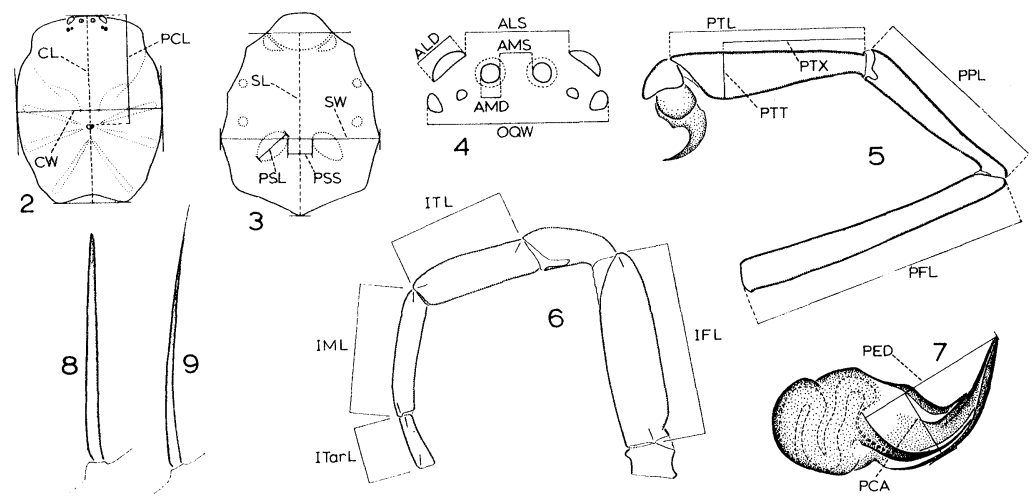

Figures 2-7: Measurements used in Aliatypus revision. See text for definitions. Figures 8-9: Macrosetae types. 8: ensiform. 9: attenuate.

CL Maximum length of carapace measured as distance (along median longitudinal axis) between lines tangent to anteriormost and posteriormost edges of carapace, with lateral border of carapace in horizontal plane.

PCL Length of pars cephalica measured as distance from anterior edge of thoracic groove along median longitudinal line.

$\mathrm{CW}$ Maximum width of carapace along line perpendicular to median longitudinal axis. 
IFL Length of femur I taken as length of straight line connecting the proximal and distal points of articulation. All leg and pedipalp segment length measurements were made in side view along retrolateral surface of appendages after removing them from spider.

ITL Length of tibia I taken as length of straight line connecting proximal and distal points of articulation.

IML Length of metatarsus I taken as length of straight line connecting proximal point of articulation with distalmost point of segment.

ITarL Length of tarsus I taken as length of straight line connecting most proximal exposed point of tarsus with distalmost point of dorsal surface.

IVFL, IVTL, IVML, IVTarL Leg IV segment lengths meassured in same manner as corresponding leg I segments.

PFL Length of pedipalpal femur measured same as IFL.

PPL Length of pedipalpal patella measured as straight line distance from proximal to distal end along dorsal surface.

PTL Length of pedipalpal tibia measured same as ITL.

PTX Distance from proximal point of articulation on tibia to point where PTT line intersects PTL line.

PTT Maximum diameter, taken perpendicular to line defining PTL, of pedipalpal tibia in lateral view.

PED Straight line distance from base of embolus to tip of conductor.

PCA Maximum distance from PED line to outer edge of OCS along line perpendicular to PED line.

SL Maximum length of sternum on line parallel to median longitudinal axis. Anterior border of sternum is its pointed anterior extension lateral to labium.

SW Maximum width of sternum perpendicular to line defining SL.

PSS Minimum distance between posterior sigilla.

PSL Maximum diameter of right posterior sigillum.

OQW Maximum width of eye group (ocular quadrangle) on line perpendicular to median longitudinal axis of carapace. All eye measurements are made in dorsal view with lateral border of carapace horizontal.

ALS Minimum distance between anterior lateral eyes.

ALD Maximum diameter of left anterior lateral eye.

AMS Minimum distance between pupils (light colored saucershaped central area of eye) of anterior median eyes. 
AMD Transverse diameter of left anterior median eye pupil.

EGS Number of epiandrous gland spigots. These are located just anterior to genital opening on abdomen of adult males.

CTP Number of cheliceral teeth in prolateral macrotooth row on left chelicera.

CTR Number of cheliceral teeth in retrolateral row of smaller macroteeth on left chelicera.

CMT Number of cheliceral microteeth between these two rows on left chelicera.

P'TSP Number of ensiform macrosetae on prolateral surface of tarsus of female pedipalp.

PTSR Number of ensiform macrosetae on retrolateral surface of tarsus of female pedipalp.

IMS Number of ensiform macrosetae on metatarsus of leg I of female.

All measurements and counts were performed by myself with the same Wild M-5 stereomicroscope with $20 \times$ eyepieces and an eyepiece micrometer scale. The measurements are accurate to one micrometer unit for each of the three different powers of magnification used. One micrometer unit had the following values for the following characters: $0.0770 \mathrm{~mm}$ for CL; $0.0385 \mathrm{~mm}$ for PCL, CW, SL, SW and all leg and pedipalp segment lengths; and $0.0092 \mathrm{~mm}$ for PTT, PED, PCA, PSS, PSL, and all eye measurements.

A female specimen was included in a population sample only if it was reproductively active (with maturing eggs in abdomen or brood in burrow) or had a longer carapace than the smallest reproductively active female in that sample. Many first adult instar females, a few older adult instar females, and rarely a large immature female make up the portion of a sample which is not reproductively active.

\section{MORPHOLOGICAL TERMINOLOGY}

Setae. Postocular setae form a longitudinal row or longitudinal cluster along the median longitudinal axis of the pars cephalica just behind the eye group. A macroseta is a very large seta. Called spines by many authors, these macrosetae are attached to the exoskeleton proper by means of an obvious socket which allows for some movement. An ensiform macroseta is one which tapers rather abruptly at its terminal end and is therefore rigid for its entire length (Fig. 8). An attenuate macroseta tapers gradually and is therefore very slender distally (Fig. 9). 
Palpus. The conductor of the Aliatypus palpus (Fig. 97) consists of an inner conductor sclerite (ICS) and an outer conductor sclerite (OCS) which lies outside and partly cradles the ICS and the embolus. The ICS base is forked, with the more well developed of the two branches being called the proximal branch.

Female genitalia. In Aliatypus the bursa copulatrix, which opens just anterior and ventral to the uterus opening in the epigastric furrow, is bilobed and weakly sclerotized. The four seminal receptacles (Fig. I63) are functionally paired so that the two on the right side open close to one another into the right lobe of the bursa copulatrix and the other two open together into the left lobe. Each seminal receptacle is weakly sclerotized and consists of a narrow stalk and a distal expanded bulb. The seminal receptacle is either homogeneously sclerotized or the bulb is slightly less sclerotized than the stalk. Aliatypus stalks are usually sinuous, frequently even highly looped or coiled. These loops and coils are not confined to a single plane and are often irregular so that the degree of looping or coiling is very difficult to quantify. It is, however, possible to make a rough quantitative comparison by counting the number of bends per stalk, as is done in Figure $\mathrm{I} 63$, when the stalk is treated as a two-dimensional structure.

Abdominal tergites. The anterior portion of the abdominal dorsum of Aliatypus is provided with one or more segmentally arranged, rather heavily sclerotized patches which are presumably vestigial tergites (Figs.45-49). These tergites are numbered from anterior to posterior, tergite I, tergite II, and tergite III. Tergite II is always present in both sexes and is always larger than tergites I or III.

\section{METHODS OF PRESENTATION}

Type specimens. The holotypes of all species described in this paper are deposited in the Museum of Comparative Zoology. All paratypes are from the type locality and are labeled as paratypes. The paratypes for each species are deposited in about equal numbers in the Museum of Comparative Zoology and the American Museum of Natural History. Quantitative character values are given for each holotype in Table 3.

Key. Whenever quantitative characters are used in the key, the known range of values is used. Proceed cautiously when these ranges are based upon very small samples. Sample size for each species is given in Tables I and 2.

Diagnoses. Each diagnosis lists, in the approximate order of their usefulness, those characters most useful in identifying a given species. 
Proceed cautiously when using diagnoses based upon very small samples. In Tables $I$ and 2 the diagnostically most useful character values are circled for each species or group of species.

Descriptions. The quantitative character values recorded in Tables I and 2 are an essential part of each species description. Each description is a composite of all adult specimens at hand. Only characters of at least some diagnostic value are included. Colors are described from fully sclerotized specimens dead for two months to six years and immersed in alcohol under strong fluorescent light.

Illustrations. Illustrations were carefully drawn in pencil on translucent paper over a squared grid template with the aid of a squared grid reticle in the eyepiece of the Wild M-5 stereomicroscope. The penciled drawings were then traced in ink on heavier paper. Nearly all figures of seminal receptacles are drawn from reproductively active females.

Variation discussions. For each species, variation of all 63 male quantitative characters, all 76 female quantitative characters, and a number of qualitative characters was examined, and all characters which show marked variation are discussed. The sizes of all population samples discussed can be found in the modified Dice-Leraas diagrams or in the records section.

Records. Only specimens which I have examined are listed. Within each county citation, all records from a given locality are separated from those of other localities by a dash. Collection dates are listed only for males. When a male symbol is surrounded by parentheses, it means that the specimen was collected when immature on the date given and matured later in captivity. When no male or female symbol follows a record, this means that only immatures were collected.

\section{TAXONOMY}

\section{ALIATYPUS Smith, I908}

Aliatypus Smith, 1908, Ann. Ent. Soc. Amer., 1(4): 231. Type species by monotypy Atypoidcs californica Banks, 1896, Jour. New York Ent. Soc., 4(4): 88- Bonnet, 1955, Bibliographia Araneorum, 2:225. Coyle, 1971, Bull. Mus. Comp. Zool., 141(6) : 372.

Descriptive diagnosis. Carapace: Figs. 45-53. Thoracic groove a deep pit which varies greatly in shape (from transverse to slightly longitudinal; borders rounded or angular); may be absent or reduced to a shallow depression. A large seta on ocular prominence 
between anterior median eyes. Chelicerae: Figs. 39-40, 45-49. Female with row of 6 to 13 macroteeth on prolateral edge; another row of 2 to 7 smaller macroteeth on retrolateral side of closed fang; and 4 to 68 microteeth between these rows. Male also with retrolateral row of cheliceral teeth. Anterior dorsal outline of chelicerae evenly rounded in both sexes. Female with rastellum. Pedipalps: Figs. 78-9I, 96-1 20. Femur, patella, and tibia of male very elongate. Male tibia swollen at least ventrally near distal end. Embolus very long and slender. Outer (convex) edge of OCS folded over to cradle embolus. ICS extends to but not beyond OCS tip, and is intimately combined distally with OCS. Ridge runs most of length of ICS. Legs: Figs. 92-95. One to 4 (rarely more than I) trichobothria dorsally near distal end of metatarsus IV. Male tibia and metatarsus I each with macrosetae distributed in scattered but consistent pattern ventrally over most of length. Spinnerets: Figs. 43-44. Three pairs (AL, PM, PL); all functional (with spigots). AL spinnerets 2-segmented with at least several spigots clustered at tip of distal segment. PM spinnerets unsegmented. PL spinnerets 3segmented; distal segment shorter than other two together. Genitalia: Figs. I2I-194. Bursa copulatrix bilobed and usually very weakly sclerotized. Seminal receptacles paired, each pair opening into one lobe of bursa copulatrix. Stalks weakly sclerotized and usually relatively elongate and sinuous. Bulbs as sclerotized or slightly less sclerotized than stalks. Behavior: Burrow entrance a trapdoor. Egg sac pendulous and occludes burrow lumen.

The following features of Antrodiaetus and Atypoides readily distinguish them from Aliatypus: Thoracic groove very narrow and longitudinal. No row of large cheliceral teeth on retrolateral side of closed fang. Male pedipalp, especially patella, relatively short. ICS tip distinctly separated from OCS tip. Metatarsus IV with 5 to 2 I trichobothria dorsally near distal end. AL spinnerets absent or unsegmented with at most one spinneret apically. Burrow entrance a collar or turret. Egg sac attached to one side of wall and does not occlude burrow lumen.

The following features of the Mecicobothriidae readily distinguish it from Aliatypus: Thoracic groove very narrow and longitudinal. No single large seta between anterior median eyes. No row of large cheliceral teeth on retrolateral side of closed fang. No rastellum. Male pedipalp, especially patella, relatively short. Metatarsus IV with more than 4 trichobothria dorsally near distal end. PL spinnerets very elongate; distal segment as long or longer than two basal segments combined. Sheet web retreat without trapdoor. 
Discussion. As I have said earlier in this paper and before (Coyle, I97 I), Aliatypus may be as closely related to the Mecicobothriidae as to the other antrodiaetid genera, Antrodiaetus and Atypoides. However, it is best to retain Aliatypus within the family Antrodiaetidae until a careful comparative study of all atypoid mygalomorph taxa demonstrates otherwise.

As discussed earlier, $A$. californicus, $A$. janus, $A$. isolatus, $A$. aquilonius, and $A$. gnomus form a group of closely related species, $A$. trophonius, $A$. erebus, $A$. plutonis, and $A$. torridus form another group of closely related species, and $A . g u l o s u s$ is quite distinct from all other Aliatypus species. I will not formally designate species groups, however, because the placement of $A$. thompsoni, which appears to be intermediate in its relationship to the two groups of species, would be rather arbitrary.

Key to Species of Aliatypus

Males

I. Palpus unique (Fig. I IO) ; sperm reservoir looped very loosely, and embolus base close to ICS base. Pedipapal tibia (Fig. 85) banana shaped and elongate; PTX/PTL $=0.37-0.45$.

gulosus

Palpus otherwise (Figs. 96-I09, I I I-I 20); sperm reservoir much more tightly coiled, and embolus base distant from ICS base. Pedipalpal tibia (Figs. 78-84, 86-9I) not banana shaped; P'TX/PTL $=0.64-0.82$.

2. PSL/PSS $=$ I.28-2.38. CL/IML $=$ I.02-I.24. Tibia and metatarsus I (Fig. 93) with short ensiform macrosetae and strongly appressed background setae. Thoracic groove nearly always absent or shallow.

thompsoni PSL/PSS = 0.I4-I.I7. CL/IML $=$ I.37-2.07. Tibia and metatarsus I (Figs. 92, 94-95) with more elongate macrosetae and suberect or erect background setae. Thoracic groove a deep pit.

3. Weakly sclerotized, finger-like extension at tip of conductor (Fig. 106). PTL/PPL $=$ 1.03-1.06 and $\mathrm{CL} / \mathrm{PSS}=4.8 \mathrm{o}-$ $5 \cdot 31$.

aquilonius

No such extension at tip of conductor (Figs. 96-IO5, IO7-I20). PTL/PPL $=$ I.IO-I.46 or CL/PSS $=5.50-$ IO.34. 4

4. ICS forms at least a weak keel distally (Figs. 96-IOI) 5

Conductor either without a keel (Figs. IO2-II3, II9-I20), or, if keel present, then it is an extension of the OCS and is closer to the conductor tip (Figs. I I4-I I8). 
5. $\mathrm{PFL}=3.07-3.54 \mathrm{~mm} . \mathrm{CL} / \mathrm{PPL}=$ г.66-ı.67. ICS keel weak and conductor tip quite slender (Fig. IOI). gnomus $\mathrm{PFL}=4.08-6.73 \mathrm{~mm}$. CL/PPL $=$ ז.33-г.61. ICS keel stronger and conductor tip not as slender (Figs. 96-IOO).

californicus

6. Distal one-fourth of conductor slender and tapers evenly (Figs. I02-I05, I07-I09), and PTX/PTL $=0.73-0.82$.

Either the distal one-fourth of conductor at least moderately broad and keel-like and tapers suddenly to point at end (Figs. I I 4-i i 8), or P'TX/PTL $=0.64-0.68$.

7. $\mathrm{CL} / \mathrm{ALS}=7.70-8.08$. Known only from Arizona. isolatus $\mathrm{CL} / \mathrm{ALS}=8.70-\mathrm{II} . \mathrm{II}$. Known only from California. janus

8. $\mathrm{PTX} / \mathrm{P} T L=0.64-0.68$. PTL $/ \mathrm{PPL}={ }_{\mathrm{I}} .3 \mathrm{I}-\mathrm{I} .32$. Distal half of pedipalpal tibia venter not much more swollen than proximal half (Fig. 9I). Palpus as in Figs. I 19 and I20. torridus $\mathrm{PTX} / \mathrm{PTL}=0.72-0.78$. PTL $/ \mathrm{PPL}=$ I.02-1.22. Distal half of pedipalpal tibia venter much more swollen than proximal half (Figs. 87-90). Palpus as in Figs. I i 4-I I 8.

9. $\mathrm{CL} / \mathrm{IFL}=$ I.03-1.08.

plutonis

$\mathrm{CL} / \mathrm{IFL}=\mathrm{I} .25-\mathrm{I} .33$

IO

ı. $\mathrm{CL} / \mathrm{PCA}=6.64-6.96 . \mathrm{CL} / \mathrm{AMD}=21.7-22.5 . \mathrm{CL}=2.9-$ $3.7 \mathrm{~mm}$. Palpus as in Fig. I 6 . trophonius $\mathrm{CL} / \mathrm{PCA}=$ 9.17-9.56. $\mathrm{CL} / \mathrm{AMD}=25.2-34.8 . \mathrm{CL}=4.4-$ $6.6 \mathrm{~mm}$. Palpus as in Figs. I I 4-I I 5 .

erebus

\section{Females}

I. Seminal receptacle stalks straight and short (Figs. I5I-I54).

gulosus

Seminal receptacle stalks sinuous (Figs. I 2 I-I 50, I 55-I94). 2

2. Thoracic groove absent or only a shallow depression (Figs. 5253). $\mathrm{IMS} / \mathrm{PSS}=33.3$ - I 6.6.

thompsoni

Thoracic groove a deep pit (Figs. 47,49 ). IMS/PSS $=6.1$ 34.7

3. $\mathrm{CL} / \mathrm{IVT} \mathrm{TL}=2.29-2.86 . \mathrm{SW} / \mathrm{PSL}=6.19-20.00 . \mathrm{PSL} / \mathrm{PSS}$ $=0.13-0.67$.

$\mathrm{CL} / \mathrm{IVTL}=2.88-3.52 . \mathrm{SW} / \mathrm{PSL}=3.8 \mathrm{I}-6.56$. PSL $/ \mathrm{PSS}$

$$
=0.55^{-2.00} \text {. }
$$

4. $\mathrm{AMD} / \mathrm{AMS}=$ I.36-I.7 I. Seminal receptacle stalks weakly sinuous (Figs. I 49-I5O). gnomus AMD/AMS $=$ 0.39-1.06. Seminal receptacle stalks strongly sinuous (Figs. I2I-I 48 ). 
5. Known only from Arizona. isolatus

Known only from California.

6. IFL/IVFL $=0.96-1.02$. ITarL $=0.46-0.80$.

IFL/IVFL $=$ I.02-I.I3. IT $\operatorname{IrL}=0.92-$ - .38 .

aquilonius

7. Seminal receptacle stalks about equal diameter throughout length (Figs. I2I-I3I). californicus

Seminal receptacle stalks usually much thicker basally than at distal end (Figs. 132-143).

8. IVFL/IVML $=$ I.02-1.08.

IVFL/IVML $=$ I.II-I.23.

janus

plutonis

9. $\mathrm{IFL}=$ 1.84-2.84. $\mathrm{CL} / \mathrm{PTSR}=$ 0.98-г.3 $\mathrm{I}$. Seminal receptacle stalks proportionately long and with $3-5$ bends; bulbs small to medium sized (Figs. I72-173).

trophonius

$\mathrm{IFL}=3.27-5.38 . \quad \mathrm{CL} / \mathrm{PTSR}=\mathrm{I} .39-3.03$. Seminal receptacle stalks proportionately shorter, with $\mathrm{I}-3$ bends; bulbs medium sized to very large (Figs. I74-187, 192-194). I0

Iо. $\mathrm{CMT}=4$-I I. $\mathrm{CL} / \mathrm{OQW}=3.43-3.99 \quad$ torridus

$\mathrm{CMT}={ }_{\mathrm{I}} \mathrm{I}-68 . \mathrm{CL} / \mathrm{OQW}=4.05-4.93$.

erebus

\section{Aliatypus californicus (Banks)}

Figures IO-I 7, 39, 45-48, 54, 65, 78-79, 92, 96-го0, І 2 I-131. Map 2.

Atypoides californica Banks, 1896, Jour. New York Ent. Soc., 4(4): 88. Holotype a penultimate male from Black Mountain, California, 23 October, in Museum of Comparative Zoology; examined.

Aliatypus californicus: Smith, 1908, Ann. Ent. Soc. Amer., 1(4): 232.Comstock, 1912, The Spider Book, p. 251. - Gertsch, 1949, American Spiders, p. 132. - Bonnet, 1955, Bibliographia Araneorum, 2: 225.Coyle, 1971, Bull. Mus. Comp. Zool., 141(6): 372. - Kaston, 1972, How to Know the Spiders, p. 60.

Comments on the type locality and previous descriptions. Banks ( I 896) wrote only "Black Mtn., Calif." for the type locality. Other species described in the same paper were collected by the same collector (R. W. Doane) from the Palo Alto area. This implies that the type locality of $A$. californicus is Black Mountain in northwestern Santa Clara County. Smith (1908), who knew Doane well, states confidently that the type was collected on Monte Bello Ridge of this mountain. The following species description is based partly upon a male and a female collected on Montebello Road, presumably very close to the type locality.

Banks' (1896) description is based upon an immature specimen, is brief, and does not include characteristics which distinguish $A$. californicus from some other Aliatypus species. Smith's ( 1908) de- 
scription is more thorough, includes illustrations, and describes a crucial diagnostic feature, the ICS keel. This shows up in Fig. 4a of Smith's Plate XV. Although Smith correctly states that the pedipalpal tibia is longer than the patella, he erred in drawing it shorter (Smith's Fig. 3, Plate XV). The specimens upon which Smith based his description were placed in the Stanford University collection but have since been lost. Having closely examined the type specimen and Smith's description, I am confident that the material upon which the following description is based is conspecific with that described by Banks and Smith.

Diagnosis. Males: The presence of a keel on the ICS together with the shape of the conductor tip (Figs. 96-IOO) distinguish this species from all others. Closely related $A$. janus differs from $A$. californicus in the ratio IML/ITarL (Table I). A. isolatus, also closely related, is distinguished by the ratios IML/ITarL, PPL/ PFL, and PTL/PPL (Table I). Any of the other species can be separated from $A$. californicus with the appropriate ratio selected from the following: CL/IML, CL/PSL, and PTL/PPL (Table I). Females: $A$. californicus females are difficult to distinguish from those of $A$. janus and $A$. isolatus. A. californicus seminal receptacle stalks are of about equal diameter throughout (Figs. I2I-I3I), unlike those of $A$. janus (Figs. I32-I43) and $A$. isolatus (Figs. I44I46) which are much narrower distally than at the basal end. In $A$. isolatus the postocular row of cephalic setae extends to a point one-half or more of the distance from the anterior edge of the carapace to the thoracic groove; in $A$. californicus it extends to a point less than one-half the distance to the thoracic groove. A. aquilonius and $A$. gnomus, both closely related to $A$. californicus, can be distinguished from the latter by their small body size (Table 2; especially ITarL). $A$. aquilonius has distinctively smaller CL/PTSR and IFL/IVFL values (Table 2) and seminal receptacles with more swollen stalk bases (Figs. I47-I 48) than $A$. californicus (Figs. I2 II3I). $A$. gnomus has a distinctively larger AMD/AMS value (Table 2) and shorter, less sinuous seminal receptacles (Figs. I49I 50) than $A$. californicus (Figs. I2I-I3I). All other species can be separated from $A$. californicus by either seminal receptacle form or appropriate ratios chosen from the following (Table 2): CL/IFL, CL/ITL, CL/IML, SW/PSL, and PSL/PSS.

Description. See Tables I-3.

Male: Carapace. Figs. 45-46. Thoracic groove a deep pit; usually rounded anteriorly, elongate, and tapering posteriorly; sometimes nearly circular or triangular. Postocular setae form a narrow longi- 
tudinal row. Sternum. Fig. 54. Posterior sigilla small to medium sized and well separated. Pedipalps. Figs. 78-79, 96- гоo. Tibia strongly swollen ventrally near distal end. Embolus base well separated from ICS base. ICS ridge distally develops into thin keel which then disappears so that conductor tip is pointed. Inner (concave) edge of OCS nearly smooth to rough. Leg $I$. Fig. 92. Tibia and metatarsus with ventral, suberect, mostly attenuate macrosetae. Rest of metatarsus setae mostly long, slender, and suberect. Abdomen. Figs. 45-46. Tergites I and III reduced to small patches or spots at bases of macrosetae. Coloration. Pars thoracica light yellow to pale yellow-brown. Pars cephalica darker; light brown to medium brown; darkest along margin and median longitudinal line. Chelicerae like pars cephalica. Pedipalpal femur and patella dorsally a darker orange-brown or red-brown.

Females: Carapace. Figs. 47-48. Thoracic groove a relatively small deep pit of varying shape; usually rounded anteriorly and tapered posteriorly; sometimes circular, elongate-oval, transverseoval, or triangular. Postocular setae form narrow row which extends back to a point $1 / 3$ to almost $1 / 2$ of distance from anterior edge of carapace to thoracic groove. Sternum. Fig. 65. Posterior sigilla small to medium sized and well separated. All or nearly all peripheral sternal setae slender; a few may be moderately stout. Longest setae scattered all over sternum, but more abundant anteriorly. Chelicerae. Figs. 39, 47-48. Genitalia. Figs. I2I-I3I. Seminal receptacle stalks weakly sclerotized, nearly constant diameter throughout length, long, and with 3 to 9 bends (usually 6 to 9 bends). Bulbs relatively small to medium sized, slightly less sclerotized than stalks. Coloration. Pars thoracica light yellow to light grey-yellow. Pars cephalica darker; often especially dark around margin and median longitudinal line; darker parts medium brown to darker redbrown; lighter parts light yellow-brown to orange-brown. Chelicerae match darker parts of pars cephalica.

Variation. Males: The coastal population samples average considerably larger in body part dimensions than the Sierran population samples, with the sharpest discontinuity being in PED, PTT, and ITarL (Fig. IO). Somewhat discontinuous geographic variation is found in the ratios CL/PPL (Fig. II), CL/PTX (Fig. I2), and PPL/PFL. This and weaker variation in other characters show a recurrent pattern: some phenotypic discontinuity between the rather homogeneous coastal populations on the one hand and the Sierran populations on the other; considerable discontinuity between the two Sierran populations, with the coastal populations more similar to the 

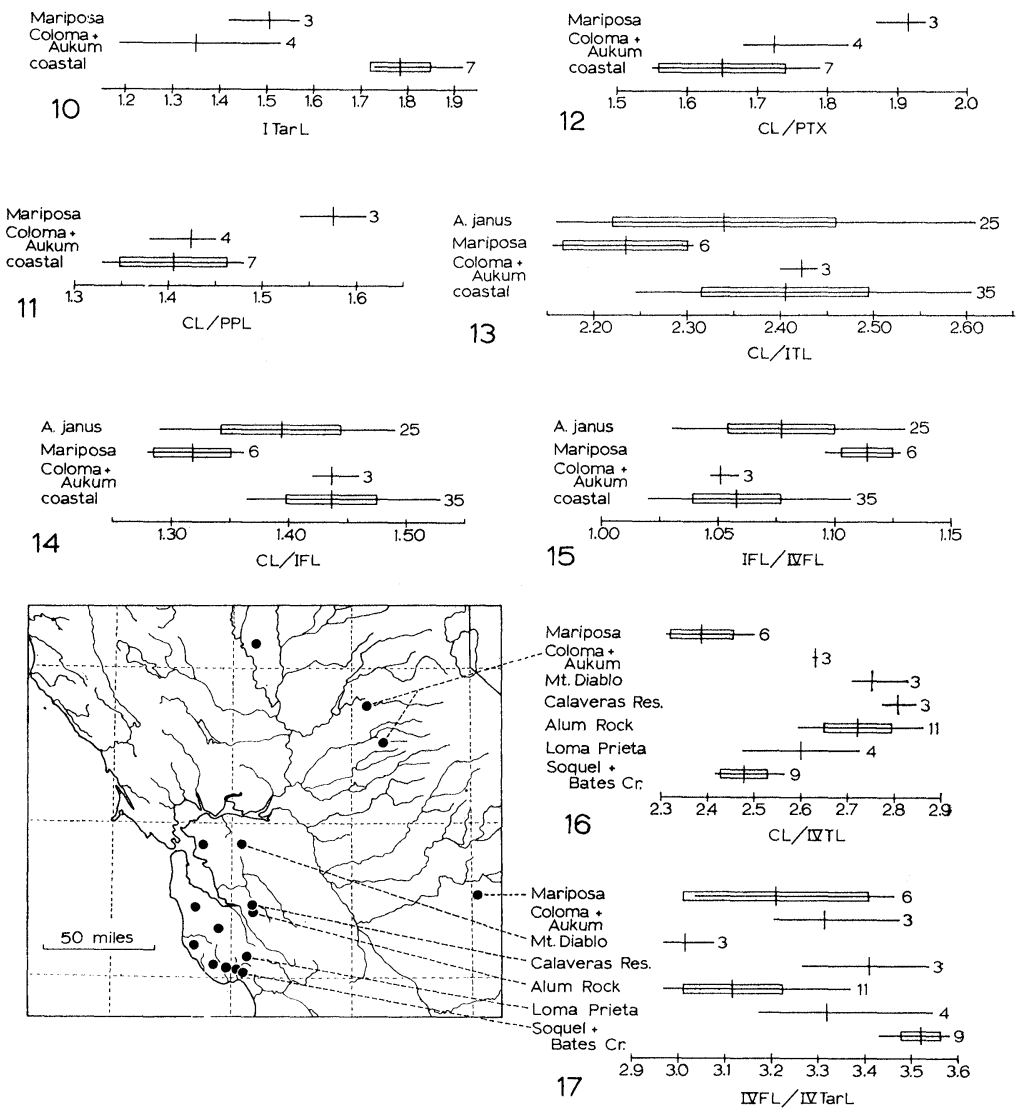

Figures 10-17: Geographic variation of Aliatypus californicus. Map of sample localities and modified Dice-Leraas diagrams. (Horizontal line represents the observed range, vertical line the mean, open rectangle the standard deviation, and number to right of range line the sample size.) 10-12: males. 10: ITarL (in $\mathrm{mm}$ ) variation. 11: CL/PPL variation. 12: CL/PTX variation. 13-17: females. 13-15: A comparison of coastal $A$. californicus, Sierran $A$. californicus, and $A$. janus. 13: CL/ITL variation. 14: CL/IFL variation. 15: IFL/IVFL variation. 16: CL/IVTL variation. 17: IVFL/IVTarL variation. 
northern Sierran (Coloma-Aukum) population than to the Mariposa population.

Noteworthy geographic variation also occurs in thoracic groove shape, pedipalpal femur shape, and conductor form. Almost all coastal specimens have an elongate thoracic pit which narrows posteriorly (Fig. 45). The Coloma-Aukum specimens have roughly circular or slightly transverse pits. The Mariposa specimens have slightly elongate pits which narrow posteriorly and have a roughly triangular shape. Coastal specimens have rather strongly bowed pedipalpal femurs (Fig. 79), Mariposa pedipalpal femurs are less strongly bowed, and Coloma-Aukum ones are nearly straight (Fig. 78). Most of the Sierran specimens have less well developed ICS keels and relatively wider conductor tips (Figs. 98-IOO) than do coastal specimens (Figs. 96-97). However, there is considerable variation among Sierran populations, with Coloma males having a rather well developed keel and narrow conductor tip (Fig. 98), and Mariposa males having smaller keels and proportionately wider conductor tips (Figs. 99-IOO).

Females: There is a moderate amount of geographic variation among the coastal populations. Although some individual population samples (especially the Mt. Diablo and Soquel area samples) are quite different from another sample in a few ratios (Figs. I6-I7), no population sample is distinct from the rest of the entire coastal sample in any character. The three northern Sierran (ColomaAukum) specimens are quite similar to the coastal populations in all characters with the exception of seminal receptacle form. Variation in the number of stalk bends in the northern Sierran receptacles (Figs. I27-129) spans the gap between the more sinuous coastal stalks (Figs. I2 I-I 25) and the less sinuous Mariposa stalks (Figs. I30-I3I). Northern Sierran females tend to have proportionately large receptacle bulbs (Figs. I28-129). The Mariposa sample differs rather strongly from the coastal samples in four characters (Figs. I3-I5) : IFL/IVFL, IVFL/IVTL, CL/IFL, and CL/ITL. It likewise differs markedly from the northern Sierran sample in these plus a fifth, CL/IVTL (Fig. I6).

In summary, male and female variation patterns indicate that there is little, if any, gene flow between coastal and Sierran populations across the unfavorable Central Valley, that there is little gene flow between the northern and more southern Sierran populations, and that the coastal population is genetically more similar to the northern Sierran populations than to the Mariposa population. I do not feel that the variation discontinuities between coastal populations and the 
Coloma-Aukum population are great enough to indicate that reproductive isolation would develop if the populations were brought together. The recent discovery in the Sutter Buttes area of the Central Valley of a moderately large immature female $A$. californicus (Fig. I26) supports this conclusion by suggesting that gene flow could have occurred rather recently across the Central Valley.

The female sample from Mariposa is quite divergent from all other A. californicus samples. However, without an analysis of more and larger Sierran samples, I am reluctant to conclude that this Mariposa population is a different species. It is possible but unlikely that this Mariposa female sample is conspecific with $A$. janus. The computer analysis shows that this sample is more similar to $A$. janus than to the rest of the entire $A$. californicus sample. If this population is conspecific with $A$. janus, its variation patterns shown in Figures I3-I 5 could be the result of character displacement with the sympatric $A$. californicus population. However, the collection of three $A$. californicus males in the same location with the Mariposa females argues strongly against this possibility.

Distribution. Mountains and foothills of the San Francisco Bay region, western foothills of the Sierra Nevada Mountains, and at least one area in the Central Valley (Map 2).

Records. California. coastal populations: Contra Costa Co.: 0.5 mi. E of South Gate of Mt. Diablo St. Pk., I 300 ft., 3 ․ - Orinda Village. San Mateo Co.: Butano State Park, ㅇ․ - Huddart Park, . . Santa Clara Co.: Montebello Rd., 4 mi. W of junc. with Stevens Canyon Rd., $2300 \mathrm{ft}$., Io Oct. I97I, ot, o . - Mt. Loma Prieta, $9 \mathrm{mi}$. W of Morgan Hill, I800 ft., Io Oct. 1970, $0^{\star}, 49$. - Marsh Rd., 0.5 mi. S of Calaveras Reservoir, $900 \mathrm{ft}$., 7 Oct. I970, $20^{\star}, 3$ ㅇ. - Alum Rock Park, 600 ft., II Oct. 1970, $0^{\pi}$, 9 ; 23 Oct. I970, O, 3 우 ; 7 ㅇ․ Santa Cruz Co.: 4.5 mi. N of Soquel Center, $300 \mathrm{ft} .$, I 2 Oct. I97 I, $0^{x}, 4$; ; 29 . - Bates Creek, 3 mi. NE of Soquel, 200 ft., 3 + . - Henry Cowell St. Pk., Redwood Loop Nature Trail, $250 \mathrm{ft}$., $9 .-\mathrm{I} .7 \mathrm{mi}$. W of Felton on Felton Empire Rd., Iooo ft., 9 . $-4.3 \mathrm{mi}$. W of Felton on Ice Cream Grade Rd., i6oo ft. Sierran populations: El Dorado Co.: Omo Ranch Rd., I.5 mi. NE of Aukum, 2200 ft., 9 Nov. 1972, $0^{7}, 2$ 9 . - 0.5 mi. SE of Coloma, 750 ft., 8 Nov. 1972, 30, 9 . Mariposa Co.: 0.5 mi. NW of Mariposa on rt. 49, 2000 ft., 14 Oct. I969,

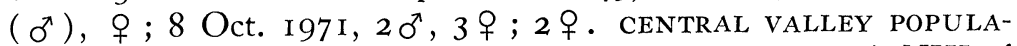
TION: Sutter Co.: Moore Canyon of Sutter Buttes, $4.5 \mathrm{mi}$. NW of Sutter, $200 \mathrm{ft}$. 
Aliatypus janus new species

Figures I8-24, 55, 66, 83-84, IO2-105, I32-143. Map 2.

Type specimens and etymology. Holotype male from $5 \mathrm{mi}$. south of Hume Lake, Fresno Co., California, I6 October I973 (W. R. Icenogle). One male and three female paratypes. Janus was the Latin god of gates and doors.

Diagnosis. Males: $A$. janus is very similar to $A$. isolatus; CL/ ALS (Table I) is useful in separating these two allopatric species. $A$. janus is distinct from closely related $A$. californicus in the absence of an ICS keel (Figs. IO2-IO5) and in IML/ITarL (Table I). $A$. janus is distinct from $A$. aquilonius in palpus tip form (Figs. I02ro5), SW/PSS, CL/PSS, and CL/ALS (Table I). $A$. janus differs from $A$. gnomus in CL/ALS, CL/AMD, and body size (Table I). Sympatric $A$. erebus differs from $A$. janus in CL/ PTT, PSL/PSS, CL/IFL (Table I), and palpus form (Figs. IO2-IO5). A thomproni, also sympatric with $A$. janus, is distinct in PSL/PSS, CL/IML (Table I), thoracic groove form, and leg I setation. Other species can be separated from $A$. janus with an appropriate ratio from the following (Table I): CL/ALS, PTX/PTL, and PTT/PTL. Females: The only really helpful character to use in separating $A$. janus from closely related $A$. isolatus is SL/SW (Table 2). Only seminal receptacle form appears useful in separating $A$. janus from closely related $A$. californicus (See $A$. californicus diagnosis). $A$. janus has a larger IFL/IVFL, longer ITarL, and more IMS (Table 2) than does $A$. aquilonius. A. janus is distinct from $A$. gnomus in AMD/ AMS, IFL/IVFL, body size (Table 2), and seminal receptacle form (Figs. 132-I43). $A$. janus is distinct from sympatric $A$. erebus in seminal receptacle form (Figs. I32-I 43), CL/PSL, SW/ PSL, and IFL/IVFL (Table 2). A. janus is distinct from sympatric $A$. thompsoni in thoracic groove form, seminal receptacle form (Figs. I32-I 43), CL/PSS, and PSL/PSS (Table 2). The remaining Aliatypus species can be separated from $A$. janus by either CL/IFL or IFL/IVFL (Table 2), and by seminal receptacle form (Figs. 132-1 43).

Description. See Tables I-3.

Males: Carapace. Thoracic groove a deep pit; usually roughly triangular or T-shaped. Postocular setae form moderately long narrow row. Sternum. Fig. 55. Posterior sigilla small to medium sized and well separated. Pedipalps. Figs. 83-84, 102-105. Tibia markedly swollen ventrally near distal end. Embolus base distant from ICS 
base. Conductor tapers evenly to narrow tip which is sharp or angularly truncate; tip may be bent or straight. Inner (concave) edge of OCS smooth to somewhat rough. Leg. I. A few to all ventral macrosetae on tibia and metatarsus are ensiform; background setae long, slender, not appressed, and very densely distributed. Abdomen. Tergites I and III reduced to small patches or spots at bases of macrosetae. Coloration. Pars thoracica pale yellow to light brown. Pars cephalica markedly darker; medium to dark red-brown or chestnut. Chelicerae usually slightly darker red-brown than pars cephalica. Dorsal surface of pedipalpal patella and tibia same as chelicerae or darker.

Females: Carapace. Thoracic groove a deep pit; usually roughly triangular or $\mathrm{T}$-shaped; rarely a transverse furrow, transversely oval, or circular. Postocular setae form a very narrow longitudinal row. Sternum. Fig. 66. Posterior sigilla medium sized and well separated. Great majority of peripheral sternal setae slender; usually a few to many stout ones on anterior-lateral margins. Longest setae scattered over most of sternum, but slightly more abundant anteriorly. Genitalia. Figs. 132-143. Stalks of seminal receptacles very weakly to moderately heavily sclerotized; almost always much thicker at base than at distal end; weakly to strongly sinuous (3-9 bends). Bulbs small to medium sized; less sclerotized than stalks. Coloration. Pars thoracica pale yellow to rather dark yellow-gray. Pars cephalica slightly to much darker; pale brown to chestnut; median longitudinal band and posterior border darker than rest. Chelicerae orangebrown, red-brown, or chestnut; slightly darker than dark part of pars cephalica.

Variation. Males: Although the male population samples are very small, they should provide at least an indication of the geographic variation patterns within this species. The strongest geographic variation occurs in pedipalpal tibia shape and conductor tip form. As Figures $18,21,83$, and 84 indicate, the Yosemite and Briceburg specimens have markedly more elongate and slender pedipalpal tibiae than do the other samples. However, because of a relatively short pedipalpal patella, the Hume Lake and Sequoia specimens exhibit a PTL/PPL ratio similar to the Yosemite and Briceburg specimens and distinct from the other samples (Fig. 19). Although conductor tip shape varies considerably, the variation is rather continuous and clinal (Figs. I02-I05). The Yosemite conductor tips (Fig. IO3) are rounded in ventral view and strongly bent dorsad. The Briceburg conductor tip is very similar except that it is not as strongly bent dorsad. The Benton Station conductor tip is like the Yosemite tips. 

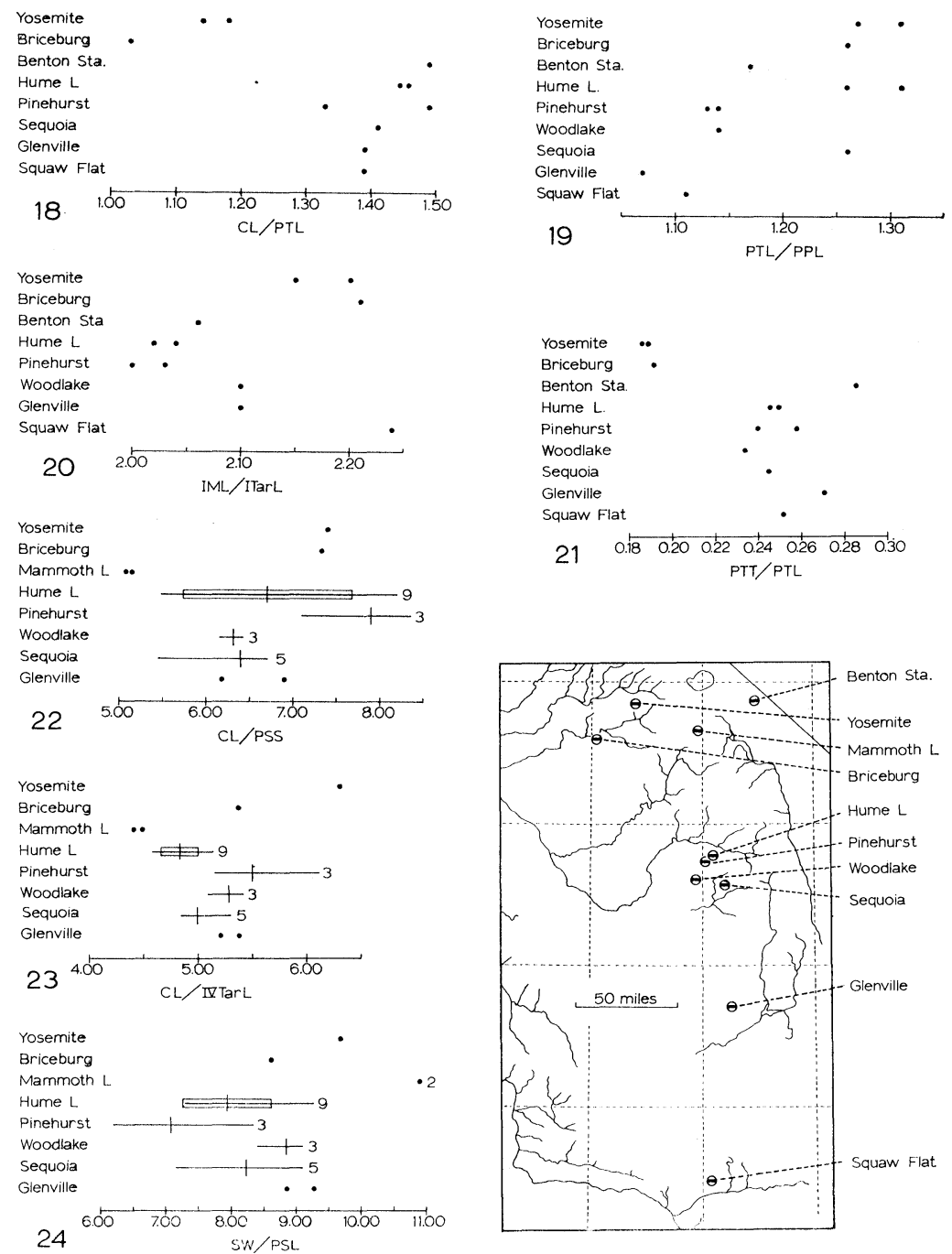

Figures 18-24: Geographic variation of Aliatypus janus. Modified DiceLeraas diagrams and map of sample localities. 18-21: males. 18: CL/PTL variation. 19: PTL/PPL variation. 20: IML/ITarL variation. 21: PTT/ PTL variation. 22-24: females. 22: CL/PSS variation. 23: CL/IVTarL variation. 24: SW/PSL variation. 
The Hume Lake conductor tips (Fig. IO2) are blunt or slightly angularly truncate, and bend dorsad almost as strongly as the Yosemite conductor tips. The Pinehurst conductor tips (Fig. IO4) are slightly broader and thicker, are angularly truncate, and bend only very slightly dorsad. The Woodlake, Glenville (Fig. I05), and Squaw Flat conductor tips are similar to those at Pinehurst, but are more angularly truncate and completely unbent.

Rather strong variation occurs in the ratio IML/ITarL (Fig. 20), with Yosemite and Briceburg specimens distinct from Hume Lake and Pinehurst specimens. Tibia and metatarsus I setation varies geographically with Yosemite, Briceburg, Benton Station and Hume Lake specimens having Io to 50 percent of the ventral macrosetae ensiform and relatively long densely distributed background setae. All other specimens have 70 to IOO percent of the ventral macrosetae ensiform, and shorter, less erect, less densely distributed background setae. The Yosemite and Briceburg specimens differ from the rest in that the pars thoracica is not markedly lighter than the pars cephalica. The Yosemite and Benton Station specimens differ from the rest in that the postocular setae extend back to a point at one-half or more of the distance from the anterior edge of the cephalothorax to the thoracic groove.

Females: The female population samples also show a considerable amount of geographic variation, which is not surprising for such a widespread species. The chief variation pattern is that most samples (Hume Lake, Pinehurst, Woodlake, Sequoia, and Glenville) are quite similar, but that the northern samples (Yosemite, Briceburg, and Mammoth Lakes) do not form as homogeneous a grouping and each differs almost distinctively from most other samples in a few characters. The very small sample sizes limit the strength of any conclusions.

Discontinuous geographic variation in quantitative characters involves those ratios incorporating PSS and PSL (Figs. 22 and 24). In these ratios the Mammoth Lakes population, with its smaller, more widely spaced posterior sigilla, is quite divergent. CL/IVTarL (Fig. 23) exhibits rather strong geographic variation with the Yosemite specimen very divergent. Other quantitative characters exhibit less geographic variation.

Variation in seminal receptacle form is illustrated by Figures 132I43. All samples except those from the Yosemite-Briceburg area have very similar seminal receptacles. In both the Yosemite and Briceburg specimens, the stalk base is not much thicker than the distal end, a condition similar to that of $A$. californicus. Additional 
noteworthy variation among female samples is as follows: the Mammoth Lakes, Pinehurst, Woodlake, and Glenville specimens are lighter colored than most specimens from other localities; the Woodlake and Glenville specimens have zero to two stout peripheral sternal setae (nearly all other specimens have many more) and fewer postocular setae than nearly all other specimens.

Variation in both sexes indicates, not surprisingly, that gene flow is restricted in portions of this species' geographic range. Gene flow between the more northern populations (Yosemite, Briceburg, Benton Station, and Mammoth Lakes) and those to the south may be especially restricted. Possible competition or hybridization with $A$. californicus in the area of sympatry around Mariposa may have an important effect upon the genetics of these northern populations. The Yosemite and Briceburg specimens are especially divergent and may eventually prove to represent a distinct species. Obviously, more and larger samples must be collected in order to obtain an accurate picture of geographic variation and of factors affecting gene flow within this species.

Distribution. Central and southern Sierra Nevada Mountains and part of the Coast Range Mountains north of Los Angeles (Map 2).

Records. California. Fresno Co.: Loop road 5 mi. S of Hume Lake, $6000 \mathrm{ft.}$, I6 Oct. 1973, $2 \sigma^{*}, 99 .-\mathrm{Hwy} .245$, I mi. E of Pinehurst, $4300 \mathrm{ft.}$, I 8 Oct. I973, $20^{\pi}, 3$. . Kern Co.: Glenville, I5 Nov. 1969, ơ. - Io mi. SW of Glenville, 2 9. Madera Co.: $7 \mathrm{mi}$. W of Mammoth Lakes, $8700 \mathrm{ft} .2$ ㅇ. Mariposa Co.: near Briceburg, I $300 \mathrm{ft} ., 0^{x}$. $-4 \mathrm{mi}$. $\mathrm{N}$ of Briceburg on Hwy. I4O, I $300 \mathrm{ft} .$, O . - Yosemite Nat'l Pk., $3.4 \mathrm{mi}$. E of Yosemite Cr. bridge on Hwy. I 20, about $8000 \mathrm{ft}$., Io Aug. 1972, $20^{\top}$. - Yosemite Nat'l Pk., 20 mi. E of Crane Flat on Hwy. I 20, about $8000 \mathrm{ft}$,, 오. Mono Co.: Benton Station, 26 Oct. 1941, $0^{\lambda}$. Tulare Co.: Sequoia Nat'l Pk., Congress trail near General Sherman Tree, 6800 ft., I3-I 4 Aug. I972, $0^{\pi}, 5$ \% . - I4 mi. N of Woodlake on Hwy. 69, I 200 ft., Io Nov. I972, $0^{x}, 3$.. Ventura Co.: $5.5 \mathrm{mi}$. S of Squaw Flat, 29 Nov. 1970, $0^{\star}$.

\section{Aliatypus isolatus new species}

Figures 56, 67, 80, 107-109, I44-I46. Map 3.

Type specimens and etymology. Holotype male from Cave Springs Campground, about $9 \mathrm{mi}$. north of Sedona in Oak Creek Canyon, Coconino Co., Arizona, I9 August 1972 (F. A. Coyle). One male and four female paratypes. The specific name is a Latin adjective meaning isolated. 
Diagnosis. The geographic range of this species (Map 3) is well separated from those of all other Aliatypus species. Males: Because of its proportionately long metatarsus I, short tarsus I, and short pedipalpal patella, $A$. isolatus is best distinguished from most of its congeners by the ratios IML/ITarL, PPL/PFL, and PTL/PPL (Table I). The palpus structure (Figs. I07-IO9) of $A$. isolatus is distinctly different from that of most species. CL/ALS (Table I) is the best character for distinguishing $A$. isolatus from closely related $A$. janus. Females: $A$. isolatus is extremely similar to $A$. janus and A. californicus; refer to diagnoses of these species. A . isolatus differs from similar $A$. aquilonius in having a transverse thoracic pit rather than a rounded or elongate one, and in its larger body size (especially longer tarsi; Table 2). A. isolatus can be separated from $A$. gnomus by seminal receptacle form (Figs. I44-I 46 ), AMD/AMS and CL/AMD (Table 2), and body size (Table 2). CL/IVTL, $\mathrm{CL} / \mathrm{IFL}$, and PSL/PSS (Table 2) clearly distinguish $A$. isolatus from all other species.

Description. See Tables I-3.

Males: Carapace. Thoracic groove a deep transverse pit or groove. Postocular setae form a relatively long narrow row. Sternum. Fig. 56. Posterior sigilla small and far apart. Pedipalp. Figs. 8o, I07-I09. Tibia swollen ventrally near distal end. Embolus base distant from ICS base. Conductor tapers rather evenly to narrow, sharp, angularly truncate tip which is bent. Inner (concave) edge of OCS smooth. Leg I. Tibia and metatarsus with all or nearly all ventral macrosetae attenuate; background setae elongate, slender. densely distributed, and not appressed. Abdomen. Tergite I small. Tergite III absent. Coloration. Pars cephalica and chelicerae light brown to dark brown; much darker than light grey-yellow pars thoracica. Pedipalps darker than pars cephalica; medium orangebrown to dark red-brown.

Females: Carapace. Thoracic groove a deep transverse pit or groove. Postocular setae row extends to point at least one-half of distance from anterior edge of carapace to thoracic groove. Sternum. Fig. 67. Posterior sigilla small and far apart. Peripheral setae slender. Longest setae scattered all over sternum. Genitalia. Figs. I 44-I 46. Seminal receptacles weakly sclerotized. Base of stalk relatively thick and nearly straight. Stalk becomes much narrower distally; long; 4-7 bends; often very irregularly looped. Bulbs small. Coloration. Pars thoracica pale yellow to pale yellow-brown. Pars cephalica darker; light yellow-brown to medium brown. Chelicerae slightly darker than pars cephalica. 
Variation. Males: A comparison of the two small samples of two males each indicates rather strong geographic variation. The Oak Creek Canyon sample has a markedly larger body size $(\mathrm{CL}=4.8$ $\mathrm{mm}, .4 .9 \mathrm{~mm}$ ), a proportionately longer pedipalpal patella (CL/ $\mathrm{PPL}=\mathrm{r} .53, \mathrm{r} .64)$, and darker coloration than the Santa Catalina Mountain sample $(\mathrm{CL}=3.5 \mathrm{~mm}, 3.8 \mathrm{~mm} ; \mathrm{CL} / \mathrm{PPL}=\mathrm{I} .75$, I.77). The conductor tip is proportionately a bit narrower and is bent more strongly (Figs. I07-IO9) in the Oak Creek Canyon males. Females: No marked geographic variation occurs in any of the ratio characters. The Oak Creek Canyon sample averages larger in body size, but the ranges of the two samples overlap. Seminal receptacle stalks are more irregularly sinuous in the Santa Catalina Mountain sample than in the Oak Creek Canyon sample (Figs. I 44-I 46). The two samples show broadly overlapping color variation.

Distribution. Arizona (Map 3).

Records. Arizona. Coconino Co.: 0.2 mi. S of Manzanita Campgrd. in Oak Creek Canyon about $6 \mathrm{mi}$. N of Sedona, $4400 \mathrm{ft}$., $q$. - Cave Springs Campgrd. in Oak Creek Canyon about 9 mi. $\mathbf{N}$ of Sedona, 4900 ft., 19 Aug. 1972, $20^{x}, 4$ o . Pima Co.: Molino Basin Campgrd. in Santa Catalina Mtns., $4500 \mathrm{ft}$. - I.5 mi. below Bear Cr. Picnic Area along Hwy. to Mt. Lemon, $5400 \mathrm{ft}$., 27 March 1970, $2\left(\sigma^{x}\right), 5$ o . - Bear Cr. Picnic Area in Santa Catalina Mtns., $5800 \mathrm{ft}$. - General Hitchcock Picnic Area in Santa Catalina Mtns., $6000 \mathrm{ft}$.

Aliatypus aquilonius new species

Figures 57, 68, 8I, I06, I47-I48. Map 2.

Type specimens and etymology. Holotype male from Grizzly Creek Redwoods State Park, Humboldt Co., California, 8 August I972 (F. A. Coyle). One male and I4 female paratypes. The specific name is a Latin adjective meaning northern.

Diagnosis. Males: The weakly sclerotized, finger-like extension at the tip of the palpus (Fig. IO6) is distinctive. The pedipalpal patella is proportionately long (Fig. 8I), so that appropriate ratios from among the following distinguish $A$. aquilonius from any other species (Table I): PTL/PPL, PPL/PFL, CL/PPL, CL/ PSS, SW/PSS. A. aquilonius males are markedly smaller than those of coastal $A$. californicus and some other species (Table I). Females: The following characters best distinguish $A$. aquilonius from similar species: smaller AMD/AMS (Table 2) and more strongly coiled seminal receptacle stalks (Figs. 147-I48) than in 
A. gnomus; smaller CL/PTSR and IFL/IVFL (Table 2) than in A. californicus; smaller IFL/IVFL and fewer IMS (Table 2) than in $A$. janus; fewer IMS and smaller CL/ITL (Table 2) than in $A$. isolatus. Because of its small widely spaced posterior sigilla (Fig. 68) and proportionately long tibia IV, A. aquilonius is easily separated from the rest of the species by the following characters (Table 2): CL/IVTL, CL/PSS, CL/PSL, SW/PSS, SW/PSL, and PSL/PSS.

Description. See Tables I-3.

Males: Carapace. Thoracic groove a deep longitudinal groove or a deep rounded pit. Postocular setae form a relatively short and narrow longitudinal band. Sternum. Fig. 57. Posterior sigilla faint, small, and far apart. Pedipalp. Figs. 8I, I06. Distal half of tibia ventrally moderately swollen. Embolus base distant from ICS base. Palpus tipped with weakly sclerotized finger-like extension. Inner (concave) edge of OCS smooth. Leg I. Tibia and metatarsus with most of ventral macrosetae attenuate; background setae long, slender, erect, and rather sparsely distributed. Abdomen. Tergites I and III reduced to small patches or spots at bases of macrosetae. Coloration. Cephalothorax and chelicerae nearly homogeneous light yellow-brown. Pedipalps slightly darker.

Females: Carapace. Thoracic groove a deep pit; circular, irregular, or longitudinal. Postocular setae few; form a moderately long, roughly single row. Sternum. Fig. 68. Posterior sigilla small and far apart. Peripheral setae slender. Longest setae absent from large central area. Genitalia. Figs. I47-I 48. Seminal receptacles very weakly sclerotized. Base of stalk relatively thick, elongate, and nearly straight. Stalk long, becomes much narrower distally, 3-6 bends. Bulbs very small. Coloration. Cephalothorax homogeneous light yellow-brown. Chelicerae darker light brown to medium brown.

Variation. There is very little variation among the four males. Females: The Grizzly Creek sample $(\mathrm{n}=\mathrm{I} 2)$ has a markedly larger mean body size $(C L=4.60 \pm .74 \mathrm{~mm}$; range $=3.4 \mathrm{~mm}-5.8 \mathrm{~mm})$ than the Redway sample $(\mathrm{n}=\mathrm{I} 4)(\mathrm{CL}=3.40 \pm .4 \mathrm{I} \mathrm{mm}$; range $=2.8 \mathrm{~mm}-4.1 \mathrm{~mm})$. Generally, the larger the specimen the more heavily sclerotized and elongate the posterior sigilla; the posterior sigilla are round in the smallest specimens and twice as long as wide in the largest specimens. There is continuous variation in the degree of coiling of seminal receptacles; all specimens fall between, or are similar to, the conditions illustrated by Figures I 47 and I 48 .

Distribution. Humboldt Co. in northwestern California (Map 2). 
Records. California. Humboldt Co.: Grizzly Creek Redwoods St. Pk., 400 ft., 8 Aug. 1972, 2( $\left.0^{t}\right)$, 12 \% . - I.4 mi. W of Redway on road to Briceland, $400 \mathrm{ft} ., 7 \mathrm{Aug}$. $1972,\left(\sigma^{4}\right), \mathrm{I} 4$ \% . $-2 \mathrm{mi}$. W of Briceland, $400 \mathrm{ft} ., 15$ Sept. 1971, $0^{x}$, + .

\section{Aliatypus gnomus new species}

Figures 49, 58, 69, 82, IOI, I49-I 50. Map 2.

Type specimens and etymology. Holotype male from Henry Cowell Redwoods State Park, Santa Cruz Co., California, 3 August 1972 (F. A. Coyle). One male and four female paratypes. The specific name is a Latin noun meaning dwarf.

Diagnosis. Males: At least one of the following ratios (Table I) will separate this species from any one of the other species: CL/PPL, CL/PSL, PSL/PSS, and PTL/PPL. The palpus, with an ICS keel and a slender conductor tip (Fig. IOI), is quite distinct from that of all species. The ICS keel is narrower and the conductor tip more slender than in closely related $A$. californicus. These palpus features, CL/PPL, CL/PSL, and body size (Table I) are the best characters for separating $A$. gnomus from $A$. californicus. In all of these characters, $A$. gnomus is more distinct from coastal $A$. californicus populations than from the Sierran $A$. californicus populations. Females: A. gnomus has distinctively large, close set AME's, so that one ratio, AMD/AMS (Table 2), clearly separates this species from all other species. Also, the weakly sinuous seminal receptacles (Figs. I49-I 50) are distinctive. A. gnomus is distinctively smaller (Table 2) than most other species.

Description. See Tables I-3.

Males: Carapace. Thoracic groove a deep rounded pit. Postocular setae form rather short narrow row which is broadest anteriorly. Sternum. Fig. 58. Posterior sigilla small and far apart. Pedipalp. Figs. 82, IоI. Distal half of tibia ventrally swollen. Embolus base distant from ICS base. ICS with a thin narrow keel distally. Conductor tip slender and tapers evenly to fine point. Inner (concave) edge of OCS smooth. Leg I. Tibia and metatarsus with most of ventral macrosetae attenuate; background setae long, slender, moderately densely distributed and more or less appressed on tibia but suberect on metatarsus. Abdomen. Tergites I, II, and III all well developed; II largest. Coloration. Pars cephalica and chelicerae pale brown. Pars thoracica pale yellow. Pedipalps darker than pars cephalica. 
Females: Carapace. Fig. 49. Thoracic groove a deep circular or longitudinally oval pit. Three or four large postocular setae form single, moderately long, row; sometimes additional tiny setae. AME's relatively large and separated by less than diameter. Sternum. Fig. 69. Posterior sigilla small and far apart. Peripheral setae slender. Longest setae less common centrally than toward the periphery. Genitalia. Figs. I49-I 50. Seminal receptacle stalks extremely weakly sclerotized, weakly sinuous ( I-4 weak bends), and same diameter throughout length. Bulbs almost transparent and proportionately small to medium sized. Coloration. Pars thoracica pale yellow. Pars cephalica and chelicerae a darker pale brown.

Distribution. Known only from the type locality (Map 2).

Record. California. Santa Cruz Co.: Henry Cowell Redwood St. Pk., along Hwy. 9, 3.3 mi. S of Felton center, $400 \mathrm{ft}$., 3 Aug. I $972,2\left(\sigma^{7}\right), 4$ ㅇ.

\section{Aliatypus gulosus new species}

Figures 25-26, 59, 70, 85, I IO, I5I-I54. Map 2.

Type specimens and etymology. Holotype male from Salt Creek, I.5 miles north of Dana Point, Orange Co., California, 6 December I968 (W. R. Icenogle). Three males and I 7 female paratypes. The species name is a Latin adjective meaning gluttonous.

Diagnosis. Males: The palpus (Fig. I IO) of A. gulosus is distinctively different from that of all other species. The very loosely looped sperm reservoir, the closeness of the embolus base to the ICS base, the jagged, serrate inner (concave) edge of the OCS, and the evenly tapered conductor tip are some of the more distinctive palpus features. The distinctive, long banana shape of the pedipalpal tibia (Fig. 85) is expressed quantitatively by the excellent diagnostic ratios (Table I) PTX/PTL and PTL/PPL. Females: The seminal receptacles (Figs. I5I-I54) of $A$. gulosus are distinctively different from those of all other species. The stalks are short and straight and the bulbs are relatively large. The appropriate ratio selected from among the following will clearly distinguish $A$. gulosus from any other species (Table 2): CL/IFL, CL/IML, CL/PSS, SW/PSS, SW/PSL, PSL/PSS, and IMS/PSS. Any of the last five ratios distinguish $A$. gulosus, with its small, widely spaced posterior sigilla, from the other southern California species ( $A$. thompsoni, $A$. plutonis, and $A$.torridus).

Description. See Tables I-3. 


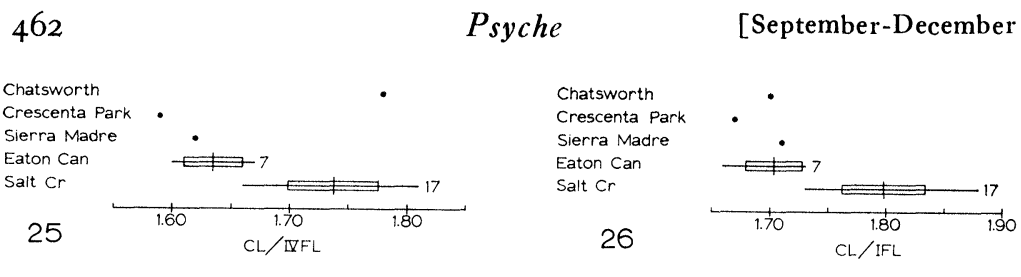

Figures 25-26: Geographic variation of Aliatypus gulosus females. Modified Dice-Leraas diagrams. 25: CL/IVFL variation. 26: CL/IFL variation.

Males: Carapace. Thoracic groove a deep, roughly circular pit. Postocular setae form a roughly triangular grouping. Sternum. Fig. 59. Posterior sigilla small and well separated. Pedipalps. Figs. 85, I IO. Tibia banana shaped. Sperm reservoir large and loosely looped. Embolus base very close to ICS base. Distal half of conductor tapers evenly to tip. Inner (concave) edge of OCS with minute jagged serrations. Leg. I. Very similar to A. plutonis leg I in proportions and setation. Most ventral macrosetae on tibia and metatarsus are ensiform. Abdomen. Tergites I, II, and III all well developed; II largest and I smallest; sometimes II and III are fused together or nearly so. Coloration. Carapace light yellow-brown to medium red-brown; margins of pars cephalica often slightly darker. Chelicerae like lightest parts of carapace or slightly darker. Pedipalps dorsally like lightest parts of carapace or lighter.

Females: Carapace. Thoracic groove a deep transverse pit; slightly to much wider than long. Postocular setae form a roughly double row. Sternum. Fig. 7o. Posterior sigilla rather small and far apart. Usually, all or most peripheral sternal setae slender; stout setae most likely found near anterior-lateral margins of sternum. Longest setae scattered rather evenly over sternum. Genitalia. Figs. I 5I-I54. Seminal receptacles very weakly sclerotized. Stalks short and straight. Bulbs relatively large. Coloration. Pars thoracica pale yellow to medium brown. Pars cephalica centrally about same color; darker (light brown to chestnut brown) around margin. Chelicerae like darker portion of pars cephalica.

Variation. While the total male sample (one male from Eaton Canyon and five from Salt Creek) is remarkably homogeneous in all characters, the female samples exhibit patterns of geographic variation which indicate some limitation to gene flow between the Salt Creek and the Los Angeles area populations. Females: Three characters exhibit marked geographic variation. The Salt Creek and Eaton Canyon samples differ somewhat markedly in two ratios, CL/IFL and CL/IVFL (Figs. 25-26). Also, Salt Creek specimens possess 
fewer stout peripheral sternal setae than most Los Angeles area specimens; a few of the latter possess many stout setae scattered along the entire sternal margin. The Chatsworth specimen is markedly variant. All its peripheral sternal setae are stout, the very long sternal setae are almost completely limited to the anterior half of the sternum, the sternum is exceptionally wide $(\mathrm{SL} / \mathrm{SW}=\mathrm{I} . \mathrm{O} 2)$, and femur $\mathrm{I}$ is longer than femur IV (IFL/IVFL $=$ r.05). Some minor and non-geographic variation occurs in the relative positions of the seminal receptacles (Figs. I 5 I-I 54).

Distribution. The Los Angeles Basin of southern California (Map 2).

Records. California. Los Angeles Co.: Eaton Canyon Park, 3 Jan. 1965, ơ ; 7 우. - Sierra Madre, Bailey Canyon, 우. Crescenta Valley Park, ㅇ. - Chatsworth, 우. Orange Co.: Salt Creek, I.5 mi. N of Dana Point, $60 \mathrm{ft} ., 6$ Dec. I968, $20^{7}, 4$; ; 5 Sept. 1969, ơ ; 12 Nov. 1969, ơ ; 13 ㅇ․

\section{Aliatypus thompsoni new species}

Figures 27-33, 40-44, 50-53,60, 7I-73, 86, 93, III-II3, I55-I 7I. Map 4.

Type specimens and etymology. Holotype male from Chatsworth, Los Angeles Co., California, 25 November i967 (M. E. Thompson). Three male and 15 female paratypes. This species is named after Mel Thompson, who has collected most of the male specimens studied.

Diagnosis. Males: $A$. thompsoni is distinct from all other species in two ratio characters (Table I), PSL/PSS and CL/IML. The posterior sigilla are large, faint, and closely spaced (Fig. 6o) and metatarsus I is relatively long (Fig. 93). The relatively short ventral macrosetae, all of which are ensiform, and the appressed background setae of tibia and metatarsus I (Fig. 93) are also distinctive. The thoracic groove is nearly always absent or shallow (Figs. 50-5I). Females: Unlike all other species, $A$. thompsoni females either have no thoracic groove or only a shallow vestige (Figs. 52-53). The small PSS (Table 2; Figs. 7I-73) distinguishes this species from all others except $A$. trophonius. The large numbers of PTSR and IMS (Table 2) distinguish this species from many others. An appropriate ratio from among the following will distinguish $A$. thompsoni from any other species: CL/PSS, SW/PSS, and IMS/PSS (Table 2). A. thompsoni seminal receptacles (Figs. I55-I7I), with their long, many-looped, non-tapered stalks and relatively small to medium sized bulbs, are diagnostically useful.

Description. See Tables I-3. 
Males: Carapace. Figs. 50-5I. Thoracic groove absent, a slight double longitudinal depression, or a shallow double longitudinal pit. Postocular setae form a short narrow longitudinal row. Sternum. Fig. 6o. Posterior sigilla faint, large, and close to one another. Pedipalps. Figs. 86, I I I-II3. Tibia strongly swollen ventrally near distal end. Embolus base distant from ICS base. Conductor tip shaped like knife blade tip. Inner (concave) edge of OCS smooth to moderately rough. Leg $I$. Fig. 93. Tibia and metatarsus with ventral, erect to suberect, relatively short, ensiform macrosetae; nearly all rest of setae appressed. Abdomen. Tergites I and III much smaller than tergite II; usually reduced to small patches or spots at bases of macrosetae. Coloration. Pars thoracica pale yellow to pale yellow-brown. Pars cephalica darker; pale brown to medium brown. Chelicerae dorsally similar to or slightly darker than pars cephalica. Pedipalps dorsally vary from pars thoracica color to cheliceral color; sometimes with orange or red tint.

Females: Carapace. Figs. 52-53. Thoracic groove absent or vestigial; if latter, it is usually a shallow depression or rarely a shallow rounded pit. 2-5 postocular setae form a very narrow longitudinal row. Sternum. Figs. 7I-73. Posterior sigilla faint, often irregularly shaped, large, and very close together. Peripheral sternal setae all slender; sometimes a few to many anterior-lateral ones stout. Longest setae scattered over most of sternum. Chelicerae. Fig. 40. Genitalia. Figs. I 55-I7I. Seminal receptacles extremely weakly sclerotized. Stalks very long, nearly same diameter throughout length and strongly looped (4-I I bends), sometimes irregularly. Bulbs small to medium sized. Coloration. Pars thoracica pale yellow to yellow. Pars cephalica darker (at least around margins and median longitudinal line); light yellow to light brown. Chelicerae darker than pars cephalica; light brown or light orange-brown to medium redbrown.

Variation. Males: Several male characters show strong geographic variation. Two variation patterns are common: often the Sierra Madre and Henninger Flats samples are similar to one another and divergent from the rest; sometimes the Tehachapi Mountain sample is divergent.

The Henninger Flats males are smaller than any others and the Tehachapi Mountain sample exhibits the largest body size average, but body size values in the other samples fill the gap between these two extremes (Fig. 27). The sternum is markedly broader (Fig. 30) and the pars cephalica is distinctly more elongate (Figs. 28, 50-5I) in the Sierra Madre and Henninger Flats samples than in all others. 

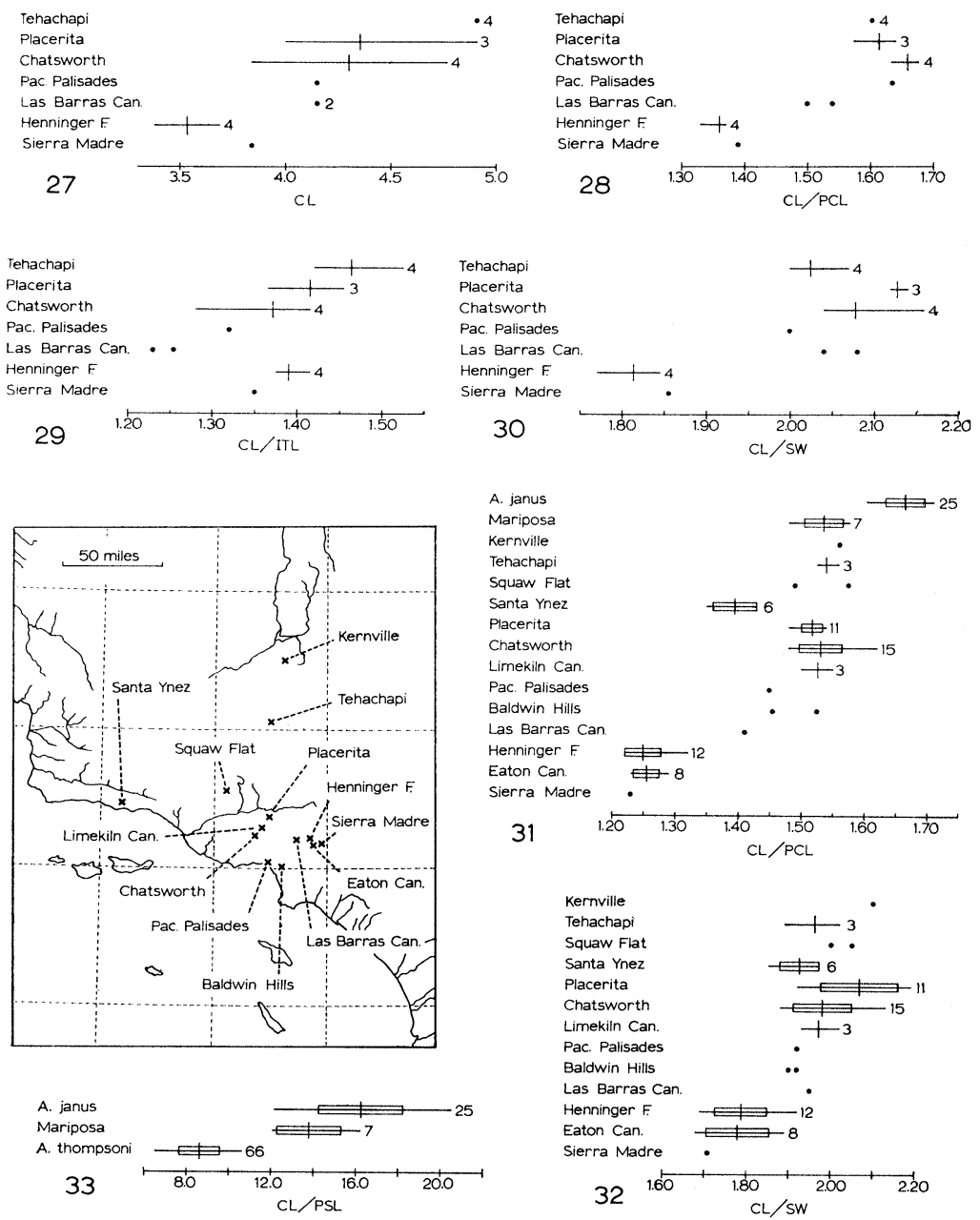

Figures 27-32: Geographic variation of Aliatypus thompsoni. Modified Dice-Leraas diagrams and map of sample localities. 27-30: males. 27: CL (in $\mathrm{mm}$ ) variation. 28: $\mathrm{CL} / \mathrm{PCL}$ variation. 29: CL/ITL variation. 30: CL/SW variation. 31-32: females. 31: CL/PCL variation compared with that of $A$. janus and the enigatic Mariposa population. 32: CL/SW variation. Figure 33: Modified Dice-Leraas diagram showing CL/PSL variation of females of Aliatypus thompsoni, $A$. janus, and the enigmatic Mariposa population. 
Thoracic groove form is correlated with pars cephalica shape. Those specimens (Sierra Madre and Henninger Flats) with an exceptionally elongate pars cephalica lack any vestige of a thoracic groove (Fig. 5I). Specimens with a more normal pars cephalica possess at least a vestigial thoracic groove in the form of a shallow depression (Fig. 50). Tehachapi Mountain specimens have slightly to markedly deeper thoracic grooves than other specimens.

Tehachapi Mountain males have two or three trichobothria dorsally near the distal end of metatarsus IV. All other A. thompsoni males as well as all other Aliatypus males have only one trichobothrium in that position. Variation in palpus conductor tip form is illustrated by Figures I I I to II3. The Tehachapi Mountain conductor tips (Fig. III) are slightly but consistently different from those in all other samples. Tehachapi Mountain males tend to have a darker pars cephalica and chelicerae, and redder pedipalps than do other specimens. The Las Barras Canyon specimens have noticeably more elongate legs (Fig. 29) than most others.

Females: A few female characters exhibit strong geographic variation. These are characters which also vary strongly in the male sample, and the geographic patterns of these variations are like those in the male sample.

The pars cephalica is markedly more elongate in the Sierra Madre, Eaton Canyon, and Henninger Flats samples than in all other samples (Figs. 3I, 52-53). These same three southeastern samples have on the average a considerably broader sternum than most other samples (Figs. 32, 7I-73). The thoracic groove is completely absent in these three samples with an elongate pars cephalica (Fig. 53), and is only a faint depression (slightly more heavily sclerotized than its immediate surroundings) (Fig. 52) in all other samples except the Tehachapi Mountain and Kernville samples. These latter specimens have a slightly deeper depression or a shallow pit.

The Tehachapi Mountain and Kernville specimens have two to four trichobothria dorsally near the distal end of metatarsus IV. All other females of $A$. thompsoni and all other Aliatypus species have only one such trichobothrium. Variation in seminal receptacle form is illustrated by Figures 155 to I7I. The Tehachapi Mountain and Kernville specimens have shorter receptacle stalks and fewer loops per stalk than other specimens elsewhere. The centrally located populations (Baldwin Hills, Pacific Palisades, Las Barras Canyon, Limekiln Canyon, Chatsworth, and Placerita) all have a dense cluster of short stout setae at the anterior median edge of the carapace, while 
all other populations have at most only a few very small or moderately stout setae here.

The similar geographic variation patterns for both sexes of $A$. thompsoni indicate two areas of reduced gene flow; one between the northeastern populations (Tehachapi Mountain and Kernville) and the rest of the species, and the other between the southeastern populations (Sierra Madre, Eaton Canyon, and Henninger Flats) and the rest of the species. In the former area it is likely that there is a paucity of suitable habitats. It is not as apparent why there might be reduced gene flow in the latter area. One female that was collected with the Tehachapi Mountain population looks suspiciously like a product of interbreeding between $A$.thompsoni and $A$.torridus or $A$. plutonis. If hybridization has occurred in this area, it could be responsible for some of the variant nature of the Tehachapi and Kernville populations.

A possible central Sierran population of A. thompsoni. Seven Aliatypus females with only a faint depression for a thoracic groove were collected at Mariposa, California ( $0.5 \mathrm{mi}$. north of town limits on Hwy. 49). These are similar to A. thompsoni in all characters execpt posterior sigilla size and separation and PTSR. The posterior sigilla of the Mariposa sample are markedly smaller (Fig. 33) and farther apart than in $A$. thompsoni. The PTSR of the Mariposa sample ranges from four to six with a mean of 4.3 , while that of $A$. thompsoni ranges from five to eight with a mean of 6.2. Except for CL/PCL (Fig. 3I) and the condition of the thoracic groove, this sample is even more similar to the sympatric species, $A$. janus. It is less similar to sympatric $A$. californicus and very unlike sympatric $A$. erebus.

There are a number of possible explanations for this situation. Perhaps this Mariposa sample is conspecific with $A$. thompsoni. Perhaps it is a reproductively isolated northern derivative of $A$. thompsoni. Perhaps it is a variant population of $A$. janus which has undergone a drastic shift in pars cephalica and thoracic groove structure. Perhaps it is a product of hybridization between $A$. thompsoni and $A$. janus. Intensive field work in the Mariposa area is required to solve this problem.

Distribution. Foothills of the Los Angeles area north into the Santa Ynez Mountains in the west and the southern end of the Sierra Nevada Mountains in the east (Map 4).

Records. California. Kern Co.: Piute Mtns. S of Kernville, o . - along Water Canyon Rd., 4500-5500 ft., Tehachapi Mtns. S of 
Tehachapi, 7 Sept. 1967, ( $\left.0^{x}\right)$; 1o Oct. 1968, $20^{x}, 2$; 16 Jan. I970, ơ ; 9 . Los Angeles Co.: Sierra Madre, 900 ft., 4 Feb. I973, $\sigma^{7}$; ․ - Eaton Canyon Park near Altadena, 8 우. - Henninger Flats near Altadena, 15 Nov. 1968, $20^{\pi}, 2$ o ; IO Jan. 1968, $\sigma^{\pi}$; i6 Jan. I970, $\sigma^{x}$; 10 o . - Las Barras Canyon, 2 mi. SE of Tujunga, 1500 ft., 12 Oct. 1972, $20^{x}$, 우. - Baldwin Hills, 2 우. - Pacific Palisades, Feb. 1945, $\sigma^{\star}$, o . - Chatsworth, I000-1 200 ft., 2 Oct. I966, $0^{x} ; 9$ Oct. 1966, $0^{x}, 2$ o ; 28 Oct. 1967, $0^{x}$, $9 ; 25$ Nov. 1967, ox, 3 우 ; 9 ㅇ. — Limekiln Canyon, 2.5 mi. NW of Granada Hills, I 300 ft., 3 o. - Placerita Canyon St. Pk., 31 Oct. 1968, 3 o, 5 ㅇ ; 6 ㅇ. Santa Barbara Co.: Santa Ynez Mtns., Stagecoach Rd., 200 yds. W of junc. with Hwy. I 54, 2200 ft., 5 o . - Santa Ynez Mtns., Paradise Rd. 2.I mi. E of junc. with Hwy. 154, 우. Ventura Co.: 5 mi. S of Squaw Flat, 2 오.

\section{Aliatypus trophonius new species \\ Figures 61, 74, 87, 95, I16, I72-173. Map 4.}

Type specimens and etymology. Holotype male from $4.5 \mathrm{mi}$. north of Soquel, Santa Cruz Co., California, I3 October I97 I (W. R. Icenogle). One male and nine female paratypes. Trophonius was a Boetian oracular god who snatched inquirers underground to give them revelations.

Diagnosis. Males: The palpus of this species (Fig. II6) is quite different from that of all other species, except $A$. erebus and $A$. plutonis. The OCS is quite broad to near the tip where it suddenly tapers to a fine point. Because of proportionately short appendage articles, a strongly swollen pedipalpal tibia (Fig. 87 ), and relatively large close-set anterior median eyes, any one of the following ratios (Table I) will separate $A$. trophonius from nearly all other species: CL/IFL, CL/ITL, CL/IML, CL/PPL, PTT/PTL, CL/PTT, CL/AMD. A trophonius is small, so that many dimensions, especially PFL and PTL (Table I) are useful diagnostically. The most similar species, $A$. erebus, can be separated from $A$. trophonius best with the following ratios (Table I) CL/PCA, CL/ITarL, and CL/AMD. Also, A trophonius has a proportionately shorter proximal branch of the ICS base (Fig. II6) and a relatively broader conductor just proximal to the conductor tip than does $A$. erebus. Females: $A$. trophonius has relatively short leg I articles and relatively large, close spaced, posterior sigilla, so that it can be separated from any species by using the appropriate ratio from among the following (Table 2) : IFL/IVFL, CL/IFL, CL/ITL, CL/IML, 
SW/PSS, SW/PSL, and PSL/PSS. Small $A$. trophonius is easily separated from large species by IFL, ITL, and IML (Table 2). Closely related $A$. erebus can be distinguished from $A$. trophonius by the ratios (Table 2) CL/IMS, CL/AMD, and CL/PTSR, by body size ( $\mathrm{CL}$ and other measurements in Table 2 ), and by the proportionately longer $A$. trophonius seminal receptacle stalks with more bends and relatively smaller bulbs (Figs. i72-I73). A trophonius seminal receptacles are also markedly different from those of several other species.

Description. See 'Tables I-3.

Males: Carapace. Thoracic groove a deep circular to elongateoval pit. Postocular setae form roughly triangular grouping. Sternum. Fig. 6I. Posterior sigilla medium sized and rather well separated. Pedipalps. Figs. 87, iा6. Articles relatively short. Tibia greatly swollen ventrally, especially near distal end. Embolus base well separated from ICS base. OCS broad to near its tip where it suddenly tapers to fine point. Inner (concave) edge of OCS smooth. Leg I. Fig. 95. Majority of ventral macrosetae on tibia and metatarsus are ensiform; background setae fairly sparse, long and slender. more erect on metatarsus. Abdomen. Tergites I and III reduced to spots at bases of macrosetae. Coloration. Pars thoracica pale yellow. Pars cephalica darker; light brown to medium brown around margins and along median longitudinal line, lighter elsewhere. Chelicerae and pedipalps dorsally like pars cephalica.

Females: Carapace. Thoracic groove a deep pit; roughly circular or slightly transverse. Postocular setae form longitudinal triangular band. Sternum. Fig. 74. Posterior sigilla moderately large and somewhat elongate. Peripheral sternal setae slender. Longest setae scattered rather evenly over sternum. Genitalia. Figs. I72-I 73. Stalks of seminal receptacles very weakly sclerotized, only slightly more sclerotized than bulbs. Stalks moderately long and slender; about same diameter throughout length; with 3 to 5 bends. Bulbs proportionately small to medium sized. Coloration. Pars thoracica pale yellow to pale yellow-brown. Pars cephalica darker; light brown to medium red-brown around margins and along median longitudinal line, lighter elsewhere. Chelicerae like darkest part of pars cephalica.

Distribution. Known only from the low foothills of the Coast Range just west and south of San Francisco Bay (Map 4).

Records. California. San Francisco Co.: San Francisco, o . Santa Cruz Co.: $4.5 \mathrm{mi}$. N of Soquel center on Soquel-San Jose Rd., $300 \mathrm{ft} .$, I 3 Oct. I97 I, $20^{*}, 9$ 오. 
Aliatypus erebus new species

Figures 34-38, 62, 75, 88, I I4-I I5, I74-I87. Map 4.

Type specimens and etymology. Holotype male from Fossil Ridge on south side of Mt. Diablo, Alameda Co., California, 24 November to 5 December, 1970 (W. E. Azevedo). Three male and two female paratypes. Erebus was the Latin god of darkness.

Diagnosis. Males: The ratios CL/PED and CL/PCA (Table I) will separate $A$. erebus males from those of the closely related species, $A$. trophonius, $A$. plutonis, and $A$. torridus. For other characters useful in separating $A$. erebus from each of these species, see their diagnoses. A. erebus' conductor form (Figs. II4-I I5) and strongly swollen pedipalpal tibia (Fig. 88) are distinct from that of most other species. The ratios PTT/PTL, CL/ITarL, CL/IFL, CL/ PED, and CL/PSL (Table I) best distinguish $A$. erebus from the less closely related species. Females: $A$. erebus' seminal receptacles, with large bulbs and short stalks with normally only two (at most three) bends (Figs. I 74-I 87 ), are distinct from those of all species except $A$. torridus. CL/PSL, SW/PSL, or PSL/PSS (Table 2) will separate $A$. erebus specimens nicely from distantly related species. CL/IMS, IMS/PSS, CL/PTSR, PTSR, or IMS (Table 2) distinguish $A$. erebus from $A$. thompsoni. CL/IMS, CL/AMD, CL/PTSR, CL, and IVTarL (Table 2) distinguish $A$. erebus from closely related $A$. trophonius. IVFL/IVML and CMT (Table 2) best distinguish $A$. erebus from closely related $A$. plutonis. CMT, $\mathrm{CL} / \mathrm{OQW}, \mathrm{CL} / \mathrm{CMT}$, and IMS/CMT (Table 2) are the most helpful characters when separating $A$. erebus specimens from those of very similar $A$. torridus.

Description. See Tables I-3.

Males: Carapace. Thoracic groove a deep circular or elongate oval pit; somewhat narrowed posteriorly. Postocular setae numerous and form a roughly triangular grouping. Sternum. Fig. 62. Posterior sigilla large and well separated. Pedipalps. Figs. 88, II4-I I5. Pedipalpal tibia robust; greatly swollen ventrally near distal end. Embolus base well separated from ICS base. Proximal branch of ICS base elongate. OCS rather broad to near its end where it quickly tapers to a fine point. Inner (concave) edge of OCS smooth to very rough. Leg I. Ventral tibia and metatarsal macrosetae attenuate and ensiform; background setae rather elongate and not closely appressed. Abdomen. Tergites I and III reduced to patches or spots at bases of macrosetae. Coloration. Pars thoracica greyyellow. Pars cephalica markedly darker; medium brown to dark 
red-brown. Chelicerae match pars cephalica. Pedipalps dorsally like or slightly lighter than pars cephalica.

Females: Carapace. Thoracic groove a deep pit; elongate or transverse; rounded or triangular. Postocular setae numerous; form an elongate, roughly triangular grouping. Sternum. Fig. 75. Posterior sigilla large and rather well separated. Stout setae usually distributed around entire periphery of sternum; always common along anterior lateral margins. Most of central setae extremely elongate. Genitalia. Figs. I74-187. Seminal receptacles very weakly sclerotized. Stalks rather short; with I to 3 strong bends; same diameter throughout length. Bulbs large to very large. Coloration. Pars thoracica greyyellow to pale brown. Pars cephalica darker; pale brown to dark chestnut brown; darkest along margins and median longitudinal line. Chelicerae light brown to dark chestnut brown.

Variation. Males: The two male samples, which are separated by the Central Valley, differ considerably in body size and EGS number but are very similar in most ratio characters. The male from Tuolumne Co. is markedly larger $(\mathrm{CL}=6.6 \mathrm{~mm})$, has a proportionately longer pedipalpal patella $(\mathrm{CL} / \mathrm{PPL}=\mathrm{r} .57 ; \mathrm{PTL} / \mathrm{PPL}$ $=\mathrm{r} .02)$ and metatarsus $\mathrm{I}(\mathrm{CL} / \mathrm{IML}=\mathrm{r} .76 ; \mathrm{IML} / \mathrm{IT}$ arL $=$ I.96), and proportionately closer posterior sigilla $(\mathrm{SW} / \mathrm{PSS}=5.4 \mathrm{I})$ than does the Mt. Diablo sample $(\mathrm{CL}=4.4 \mathrm{~mm}-4.9 \mathrm{~mm}$; CL/

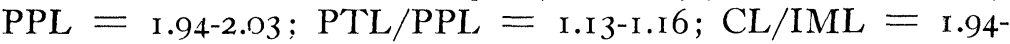
2.07; IML/ITarL $=$ I.66-1.7 $;$ SW/PSS $=3.30-4.35)$. The only marked difference in palpus form is in conductor tip shape (Figs. I I 4-I I 5 ).

Females: The four population samples from the southern half of the Sierra Nevada Mountains (Sonora, Mariposa, Shaver Lake, and Pinehurst-Miramonte) are similar in all characters. Each of the other three samples (Mt. Diablo, Wilbur Springs, and Nevada City) are divergent from this homogeneous south Sierra grouping in some characters. Of these divergent samples, the Mt. Diablo sample is less divergent than either the Wilbur Springs or Nevada City samples.

The Mt. Diablo sample is divergent from the south Sierra grouping in body size (Fig. 34), IFL/IVFL, and IFL/ITarL, and is somewhat divergent from all samples in CL/CMT (Fig. 35) and IMS/ CMT. The Wilbur Springs sample is divergent from the south Sierra grouping in body size (Fig. 34), CL/SL (Fig. 38), CL/SW, ITL/IML, and IMS/PSS (Fig. 36), and is divergent from all samples in CL/SL (Fig. 38), CL/SW, and IMS/PSS (Fig. 36). The Nevada City sample is divergent from the south Sierra group- 

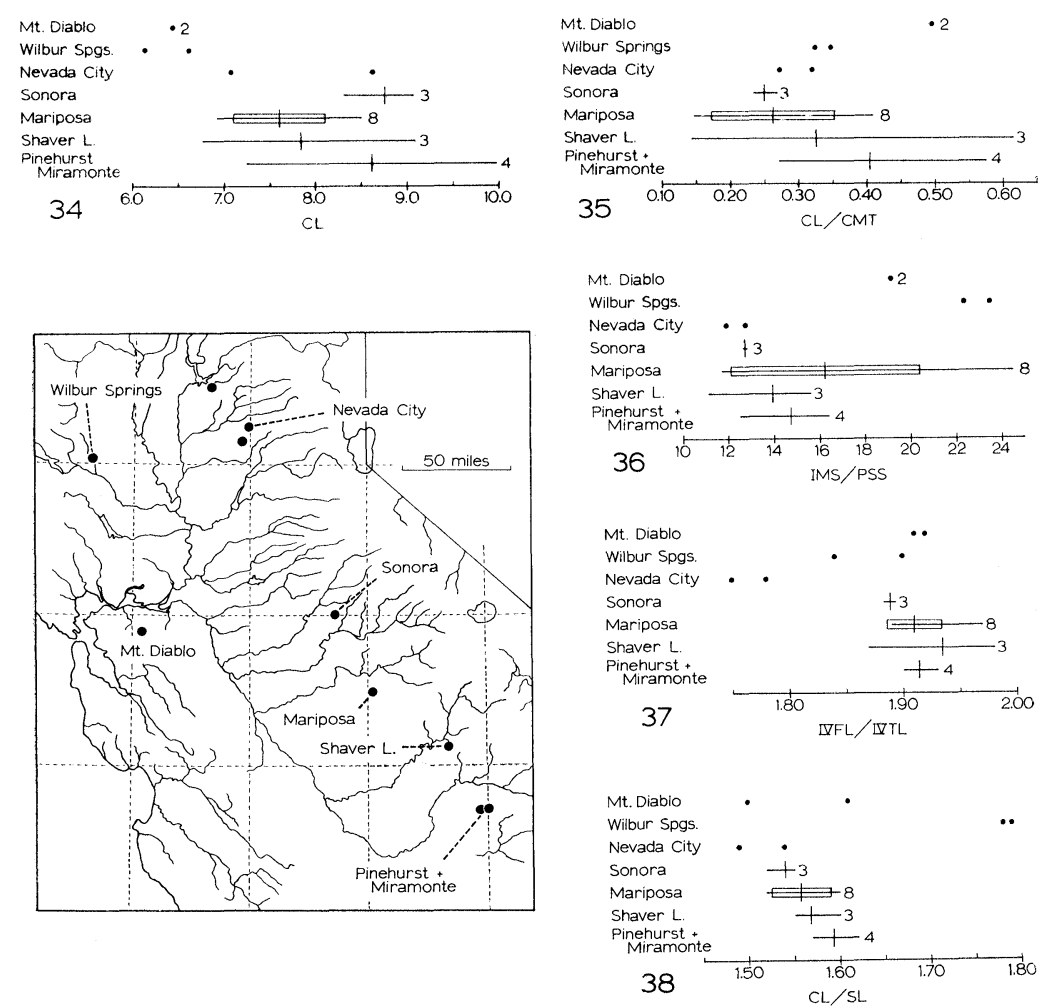

Figures 34-38: Geographic variation of Aliatypus erebus females. Modified Dice-Leraas diagrams and map of sample localities. 34: CL (in $\mathrm{mm}$ ) variation. 35: CL/CMT variation. 36: IMS/PSS variation. 37: IVFL/ IVTL variation. $38: \mathrm{CL} / \mathrm{SL}$ variation.

ing in IVFL/IVTL (Fig. 37), IFL/IVFL, IVTL/IVML, and ITL/IML, and is divergent from all samples in IVFL/IVTL (Fig. 4) and ITL/IML. Mt. Diablo, Sonora, Mariposa, Pinehurst, and (two of three) Shaver Lake specimens have stout setae distributed all around the margins of the sternum. The Wilbur Springs, Nevada City, Miramonte, and (one of three) Shaver Lake specimens have only a few stout marginal setae, and these only at the anterior lateral sternal margins. In addition, the Wilbur Springs specimens are unique in not having short stout setae scattered over the periphery of the central region of the sternum. The range of color variation is considerable, with the Sonora specimens darkest, the Pinehurst and 
Miramonte specimens a bit lighter, and all other specimens noticeably lighter than these. Variation in seminal receptacle form (Figs. I74I87) is continuous with no divergent populations. Bulb size and stalk diameter seem to be the most variable aspects of seminal receptacle form.

More and larger samples are needed before firm conclusions can be made about the genetic relationships of these populations. I feel that the best working hypothesis suggested by this analysis of variation is that the Mt. Diablo, Wilbur Springs, and Nevada City populations are, because of distance and ecological barriers to gene flow, markedly different genetically from the south Sierra populations, but that this isolation is either incomplete or has not been of long enough duration for reproductive isolating mechanisms to develop. A thorough search for more populations is especially needed in central and northern California in the eastern part of the Coast Range, the Central Valley, and the western foothills of the Sierra Nevada Mountains.

Distribution. Eastern edge of the Coast Range in central California and western slope of the Sierra Nevada Mountains (Map 4).

Records. California. Butte Co.: in mi. E of Oroville on Lumpkin Rd., I $300 \mathrm{ft}$., ㅇ. Colusa Co.: $3 \mathrm{mi}$. SE of Wilbur Spgs. on Bear Cr. Rd., I250 ft., 2 9. Contra Costa Co.: south side of Mt. Diablo, Fossil Ridge, 3I Oct.-6 Nov. I970, ơ; 24 Nov.-5 Dec. I970, $20^{x} ; 5$ Dec. 1970-20 Feb. 197I, $0^{x}$. - - $0.5 \mathrm{mi}$. E of South Gate of Mt. Diablo St. Pk., I 300 ft., 2 ㅇ. Fresno Co.: Shaver Lake, 2 ㅇ. - Hwy. I68, I.5 mi. S of Dinkey Cr. Rd., near Shaver

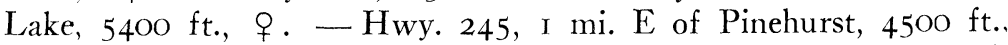
3 9 . - Mt. Miramonte, q. Mariposa Co.: $0.5 \mathrm{mi}$. NW of Mariposa along Hwy. 49, 2000 ft., 8 \%. Nevada Co.: Hwy. 49, 10.7 mi. S of Grass Valley, I300 ft. - Hwy. 20, 2 mi. NE of Nevada City, $3000 \mathrm{ft} ., 2$ 9. Tuolumne Go.: Draper Mine Rd., 6 mi. E of Sonora, $2700 \mathrm{ft} ., 39$. - probably near Sonora, summer 1968, $0^{*}$.

Aliatypus plutonis new species

Figures 63, 76, 89-90, 94, гі7-гі 8, г88-г9г. Map 4.

Type specimens and etymology. Holotype male from University of California at Riverside campus, Riverside Co., California, 3i October 1968 (W. R. Icenogle). One male and four female paratypes. 'The specific name is the genitive of Pluto, the Latin god of the nether world.

Diagnosis. Males: A. plutonis can be distinguished best from closely related and sympatric $A$. torridus by pedipalp and palpus 
characters. The pedipalpal patella of $A$. plutonis is distinctively more elongate (Figs. 89-90; PPL/PFL and PTL/PPL in Table $\mathrm{I}$ ), its pedipalpal tibia has a distinctively different shape (Figs. 89-90; PTX/PTL in Table $\mathrm{I}$ ), and its OCS is drawn out into a broad thin lateral keel just below the tip (Figs. II7-II8). $A$. plutonis can be distinguished from closely related but allopatric $A$. erebus by the following characters (Table I) : CL/PCA, CL/PED, CL/IFL, and the broad, thin OCS keel (Figs. II7-I 8 ). The following ratios will separate $A$. plutonis specimens from those of the other species: PSL/PSS, CL/PSL, CL/ITL, and CL/PPL (Table I). Females: A. plutonis females are distinct from those of all other species by virtue of their low IVFL/IVML value (Table 2). This is the best character to use in separating $A$. plutonis from its closest relatives, $A$. erebus and $A$. torridus. The seminal receptacle stalks of $A$. plutonis are more elongate and more slender (Figs. I88-19I) than those of $A$. torridus or A. erebus. SW/PSS and PSL/PSS (Table 2) are useful in separating $A$. plutonis from most of the other species.

Description. See Tables I-3.

Males: Carapace. Thoracic groove a deep pit, longer than wide; anterior border rounded; narrow posteriorly. Postocular setae usually form a double row anteriorly. Sternum. Fig. 63. Posterior sigilla large and moderately well separated. Pedipalps. Figs. 89-90, I I7I I8. Tibia strongly swollen ventrally near distal end; slightly swollen more proximally. Embolus base distant from ICS base. Conductor tip very sharp. Thin lateral keel-like extension of conductor (OCS) just proximal to tip so that conductor is markedly narrower just proximal of this keel. Inner (concave) edge of OCS smooth to slightly rough. Leg I. Fig. 94. Tibia and metatarsus with ventral, erect, elongate, attenuate and ensiform macrosetae; background setae elongate and not closely appressed. Abdomen. Tergites I and III reduced to small patches or spots at bases of macrosetae. Coloration. Pars thoracica grey-yellow to light brown. Pars cephalica darker, at least along margins and median longitudinal line; pale brown to medium brown. Chelicerae match lighter or darker portion of pars cephalica. Pedipalps dorsally like pars thoracica.

Female: Carapace. Thoracic groove a large deep pit; usually roughly triangular with front wall straight or procurved. Postocular setae distribution variable; single or roughly double longitudinal row or long narrow triangular grouping. Sternum. Fig. 76. Posterior sigilla large and moderately well separated. Stout setae distributed around entire periphery of sternum. Most of central setae 
extremely elongate. Genitalia. Figs. I 88-19i. Seminal receptacles very weakly sclerotized. Stalks rather short, with a few strong loops (3-5 bends), moderately thick, and same diameter throughout length. Bulbs rather large. Coloration. Pars thoracica grey-yellow. Pars cephalica darker; light brown to medium brown; darkest along margins and median longitudinal line. Chelicerae match darkest parts of pars cephalica.

Variation. Males: Both Riverside males have a more slender pedipalpal tibia (Fig. 90) than all other specimens, which are all similar to Figure 89. The palpus form of most specimens is like Figure I I 8 or intermediate between this and the Palomar Mountain specimen (Fig. I I7). Females: As illustrated (Figs. I88-I9I), there is a small amount of largely intrapopulation variation in bulb size and stalk diameter.

Distribution. Southwestern California south of the San Bernardino Mountains (Map 4).

Records. California. Riverside Co.: U. of Calif. at Riverside campus, $1250 \mathrm{ft} ., 27$ Oct. I967, $\sigma^{\top} ; 3$ I Oct. I968, $\sigma^{\star} ; 4$ 으 - S of Banning on Hwy. 243, $5.4 \mathrm{mi}$. S of junc. with I-IO, $3300 \mathrm{ft} ., 2 \mathrm{I}$ Aug. I968, (20 ), 우; 3 ㅇ․ San Diego Co.: Hwy. 395, 4 mi. E of Fallbrook, $800 \mathrm{ft}$; 20 Sept. I97 I, $\sigma^{7}$. - Palomar Mtn., Nate Harrison Grade Rd., $2350 \mathrm{ft}$., 6 Jan. I972, $\sigma^{\star}$.

\section{Aliatypus torridus new species}

Figures 64, 77, 91, I I9-120, I92-I94. Map. 4.

Type specimens and etymology. Holotype male from Mountain Center, Riverside Co., California, 3 October I968 (W. R. Icenogle). One male and four female paratypes. The specific name is a Latin adjective meaning dry and hot.

Diagnosis. Males: The pedipalpal tibia (Fig. 9I) of this species has a distinctive shape and the pedipalpal patella is relatively short so that PTX/PTL and PTL/PPL (Table I) together distinguish A. torridus from all other species. For other characters which also distinguish $A$. torridus from closely related $A$. trophonius, $A$. erebus, and $A$. plutonis, see these species' diagnoses. Females: A. torridus is difficult to distinguish from $A$. erebus; CMT number, CL/OQW, CL/CMT, and IMS/CMT ('Table 2) are the most helpful diagnostic characters. $A$. torridus is distinguished from closely related and sympatric $A$. plutonis by IVFL/IVML, PSL/PSS (Table 2), and its shorter, thicker seminal receptacle stalks (Figs. I92-I94). Among the following characters can be found at least one that will 
distinguish $A$. torridus from any one of the other Aliatypus species (Table 2) : PSL/PSS, CL/PSL, CL/IFL, and seminal receptacle form (Figs. I92-I94).

Description. See Tables I-3.

Males: Carapace. Thoracic groove a deep pit with front wall broad and procurved; transverse to slightly longer than wide; narrowed posteriorly. Postocular setae grouped in form of narrow triangle. Sternum. Fig. 64. Posterior sigilla rather large and well separated. Pedipalp. Figs. 9I, I I9-I20. Tibia swollen ventrally over most of its length. Embolus base distant from ICS base. Inner (concave) edge of OCS smooth to slightly rough. Leg I: Tibia and metatarsus setation very similar to that of $A$. plutonis. Abdomen. Tergites I and III reduced to small spots at bases of macrosetae. Coloration. Pars thoracica grey-yellow to pale brown. Pars cephalica darker; light brown to medium brown; darkest along margin and median longitudinal line. Chelicerae match either lighter or darker portion of pars cephalica. Pedipalps dorsally like pars thoracica.

Females: Carapace. Thoracic groove a large, deep, roughly triangular pit with transverse anterior wall; usually wider than long. Postocular setae form a long slender triangular grouping. Sternum. Fig. 77. Posterior sigilla large and well separated. Stout setae distributed around entire periphery of sternum. Most of central setae extremely elongate. Genitalia. Figs. I92-I94. Seminal receptacles weakly to very weakly sclerotized. Stalks short, with I to 3 bends, thick, and same diameter throughout length. Bulbs rather large. Coloration. Pars thoracica pale yellow to pale brown. Pars cephalica darker; grey-yellow to medium brown; darkest along margins and median longitudinal line. Chelicerae medium brown.

Variation. Males: Considering the large geographic distance separating the two population samples, there is surprisingly little difference in pedipalp and palpus form (Figs. I I9-I20). Moderately strong differences between these two small samples show up only in the following ratios: CL/ALS (El Paso Mountain sample with higher mean), CL/ITL (Mountain Center mean higher), and IFL/ITarL (El Paso Mountain mean higher).

Females: Seminal receptacle form is remarkably similar throughout all three population samples (Figs. I92-I94). Noteworthy geographic variation occurs in five ratio characters. The Yucaipa sample $(\mathrm{n}=2)$ has markedly smaller mean values of IMS/CTP and $\mathrm{CL} / \mathrm{C} T \mathrm{P}$ than both the Mountain Center $(\mathrm{n}=4)$ and El Paso Mountain $(n=2)$ samples. In three other characters, CL/OQW, 
CL/AMD, and IFL/ITL, the Mountain Center and El Paso samples are markedly different from one another and the Yucaipa sample is intermediate.

Distribution. Interior southern California from the San Jacinto Mountains north to the southern Sierra Nevada Mountains (Map 4).

Records. California. Kern Co.: NE edge of El Paso Mtns., I mi. W of Hwy. 395, $3800 \mathrm{ft}$., 3 Jan. 1969, $20^{*} ; 2$. . - NE of El Paso Mtns., spring 1963, $\sigma^{*}$. Riverside Co.: Mountain Center, 300 yds. W of junc. of Hwys. 243 and 74, $4400 \mathrm{ft} ., 3$ Oct. I968, $20^{7} ; 4$ ㅇ․ San Bernardino Co.: Yucaipa, $2800 \mathrm{ft} ., 2$ 우.

\section{Literature Cited}

BANKs, N.

1896. New Californian spiders. J. New York Ent. Soc., 4(4) : 88-91. COYLe, F. A.

1968. The mygalomorph spider genus Atypoides (Araneae: Antrodiaetidae). Psyche, 75: 157-194.

1971. Systematics and natural history of the mygalomorph spider genus Antrodiactus and related genera (Araneae: Antrodiaetidae). Bull. Mus. Comp. Zool., 141 (6) : 269-402.

FORSTER, R. R., AND WiLton, C. L.

1968. The spiders of New Zealand. Part 2. Otago Mus. Bull. No. 2: 1-180.

GerTsCH, W. J.

1949. American Spiders. Princeton, D. Van Nostrand Co., 285 pp. LoKSA, I.

1966. Nemesia pannonica O. Herman (Araneae: Ctenizidae). Ann. Univ. Sci. Budapest, Sect. Biol., 8: 155-171.

MaIN, B. Y.

1957. Biology of aganippine trapdoor spiders (Mygalomorphae: Ctenizidae). Australian J. Zool., 5(4): 402-473.

Martin, P. S. and Mehringer, P. J., JR.

1965. Pleistocene pollen analysis and biogeography of the Southwest. Pp. 433-451. In H. E. Wright and D. G. Frey (eds.), The Quaternary of the United States. Princeton, Princeton Univ. Press.

Riemer, W. J.

1958. Variation and systematic relationships within the salamander genus Taricha. Univ. of California Publ. Zool., 56: 301-390.

SMITh, C. P.

1908. A preliminary study of the Araneae Theraphosae of California. Ann. Ent. Soc. America, 1 (4) : 207-249.

Stebbins, R. C.

1949. Speciation in salamanders of the plethodontid genus Ensatina. Univ. of California Publ. Zool., 48: 377-526. 


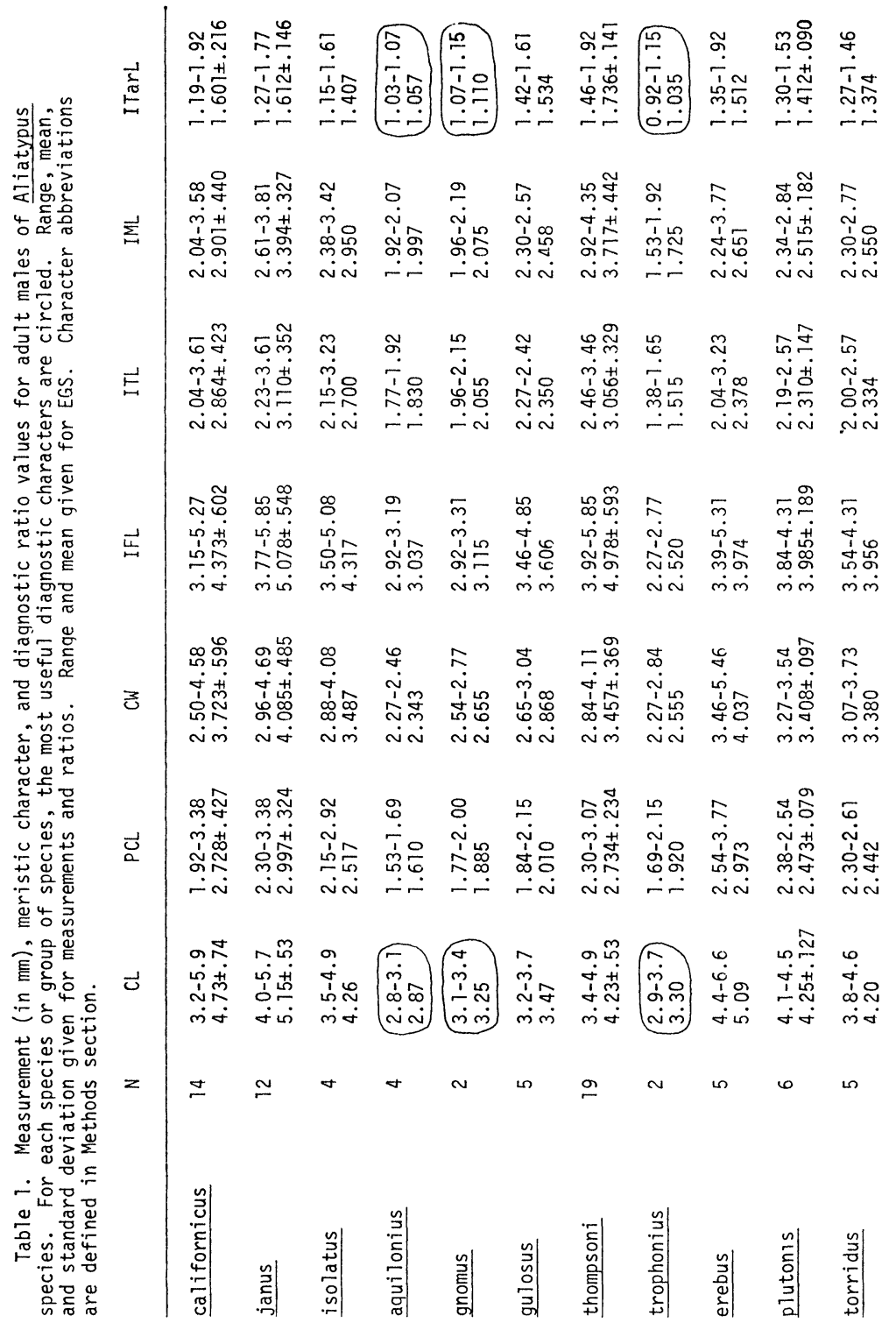




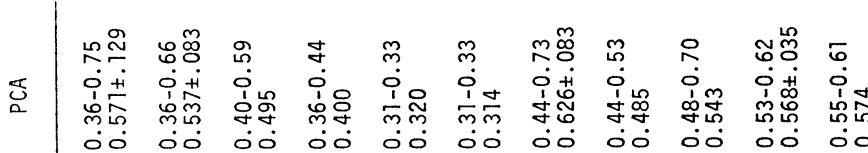

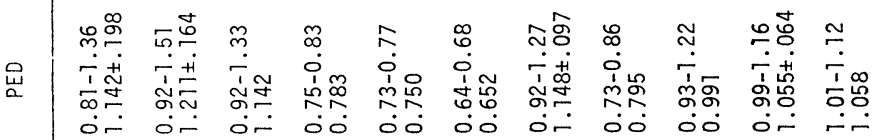

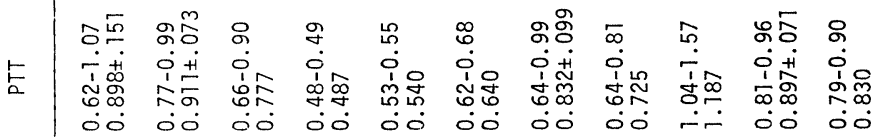

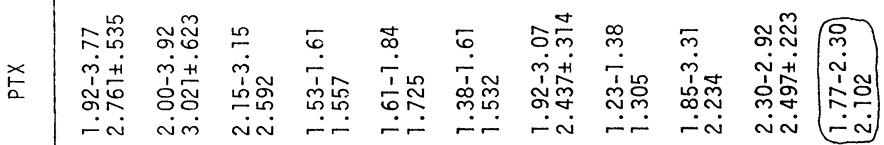

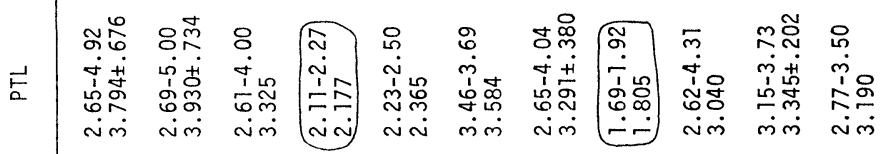

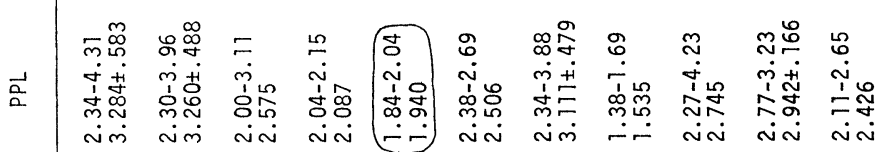

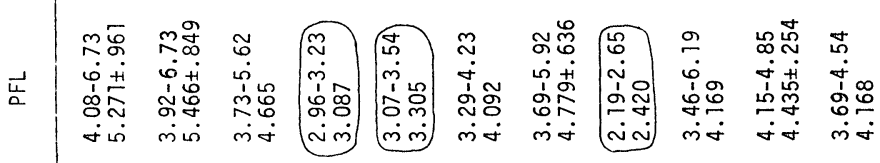

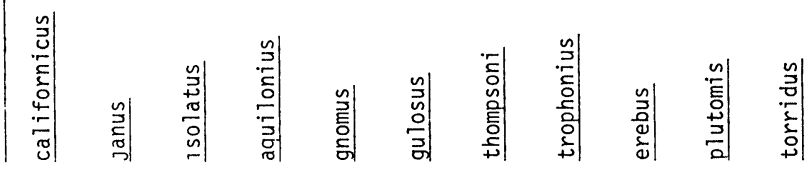




\begin{tabular}{|c|c|c|c|c|c|c|c|c|c|c|c|}
\hline$\frac{9}{\alpha}$ & 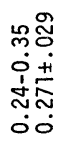 & 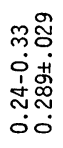 & 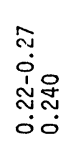 & 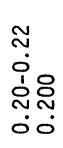 & 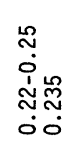 & 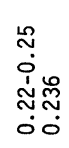 & 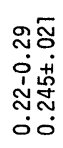 & $\begin{array}{l}\stackrel{2}{0} \\
\vdots \\
1 \\
\infty \\
\infty \\
0 \\
0 \\
0\end{array}$ & 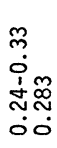 & 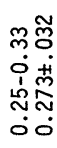 & 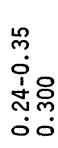 \\
\hline$\tilde{z}$ & 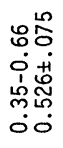 & 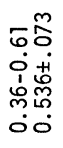 & 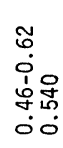 & 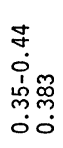 & 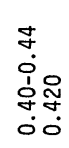 & 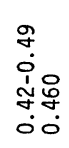 & 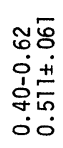 & 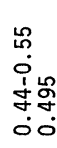 & 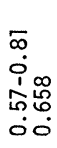 & 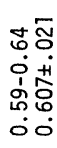 & 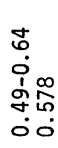 \\
\hline 긍 & 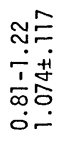 & 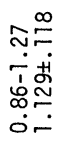 & 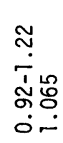 & 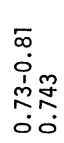 & $\begin{array}{l}\infty \\
\infty \\
\dot{0} \\
\dot{0} \\
\infty \\
\infty \\
0 \\
0\end{array}$ & 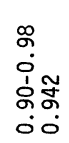 & 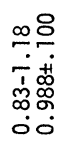 & $\begin{array}{l}\infty \\
\stackrel{0}{0} \\
\dot{1} \\
1 \\
\infty\end{array}$ & 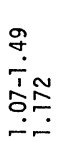 & 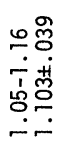 & 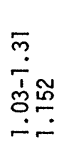 \\
\hline$\vec{\Omega}$ & 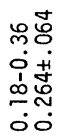 & 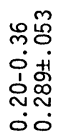 & 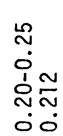 & 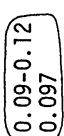 & 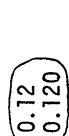 & 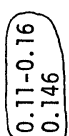 & 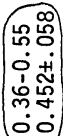 & 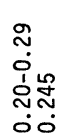 & 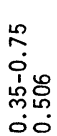 & 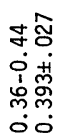 & 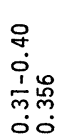 \\
\hline$\widetilde{ૂ}$ & 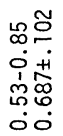 & 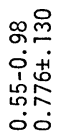 & 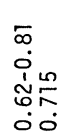 & 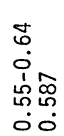 & 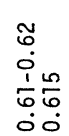 & 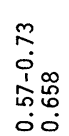 & 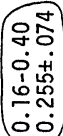 & 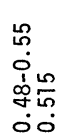 & $\begin{array}{l}\text { ț } \\
\dot{0} \\
\dot{1} \\
\dot{0} \\
0 \\
0 \\
0 \\
0\end{array}$ & 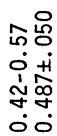 & 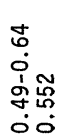 \\
\hline z & 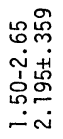 & 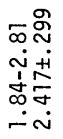 & 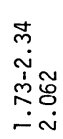 & 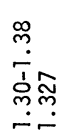 & 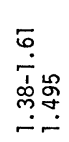 & 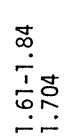 & 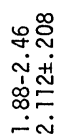 & 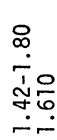 & 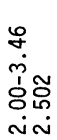 & 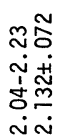 & 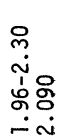 \\
\hline$\vec{\omega}$ & 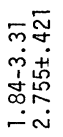 & 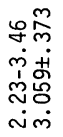 & 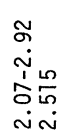 & 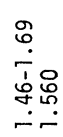 & 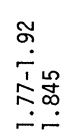 & 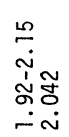 & 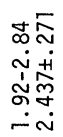 & 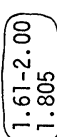 & 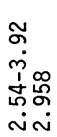 & 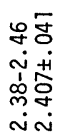 & 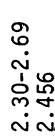 \\
\hline & 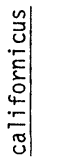 & 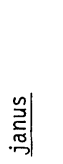 & 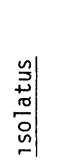 & 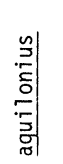 & $\begin{array}{l}\text { ב्ञ } \\
\text { 혐 }\end{array}$ & 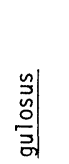 & 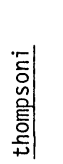 & $\begin{array}{l}\text { ज्ञ } \\
\vdots \\
0 \\
0 \\
0 \\
0 \\
\vdots\end{array}$ & 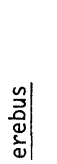 & $\begin{array}{l}0 \\
\stackrel{0}{0} \\
0 \\
\frac{3}{0}\end{array}$ & 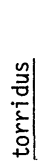 \\
\hline
\end{tabular}




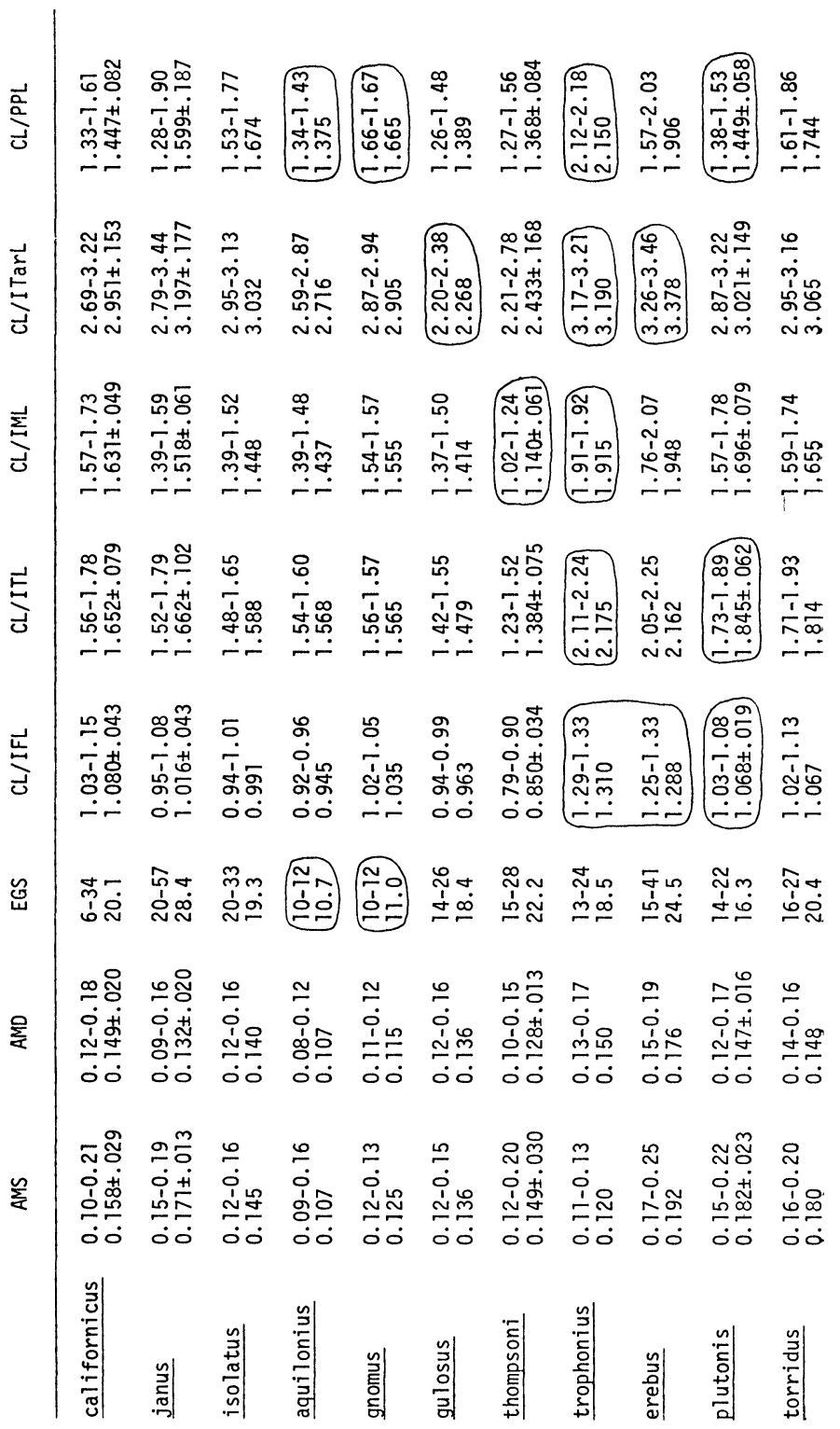




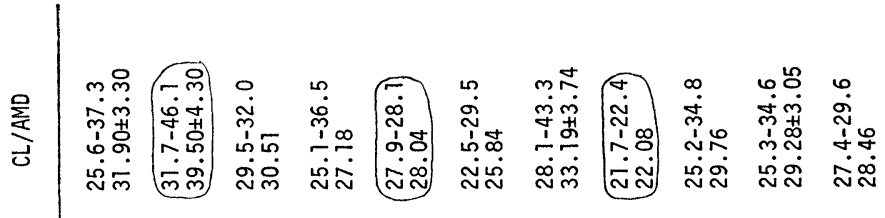

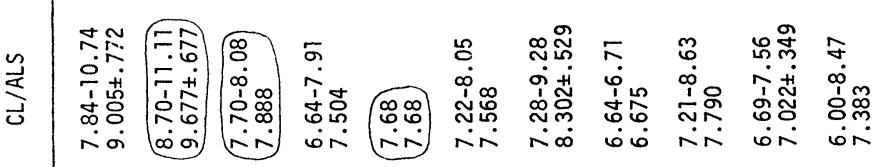

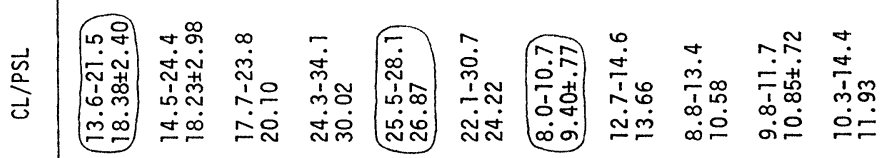

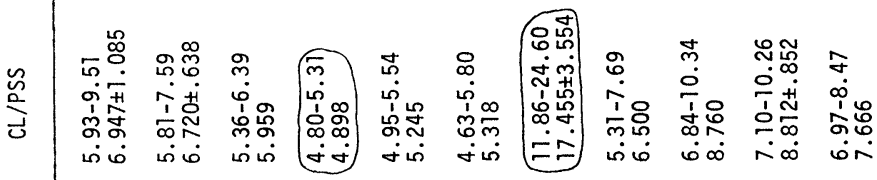

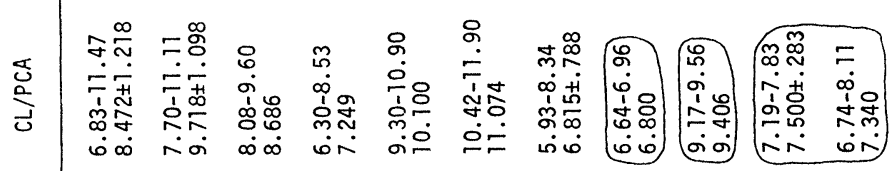

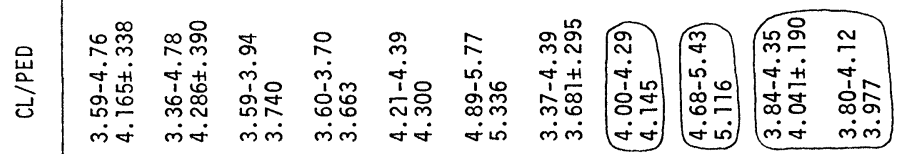

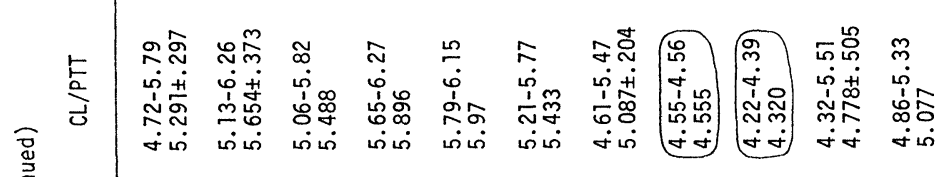

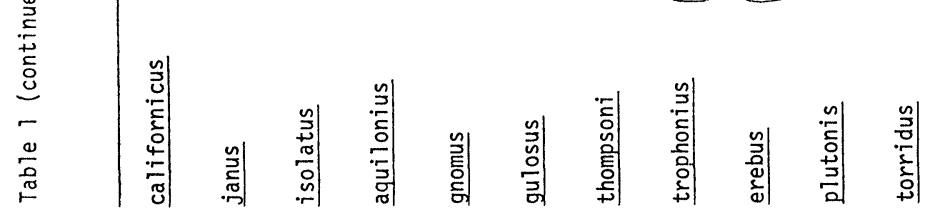




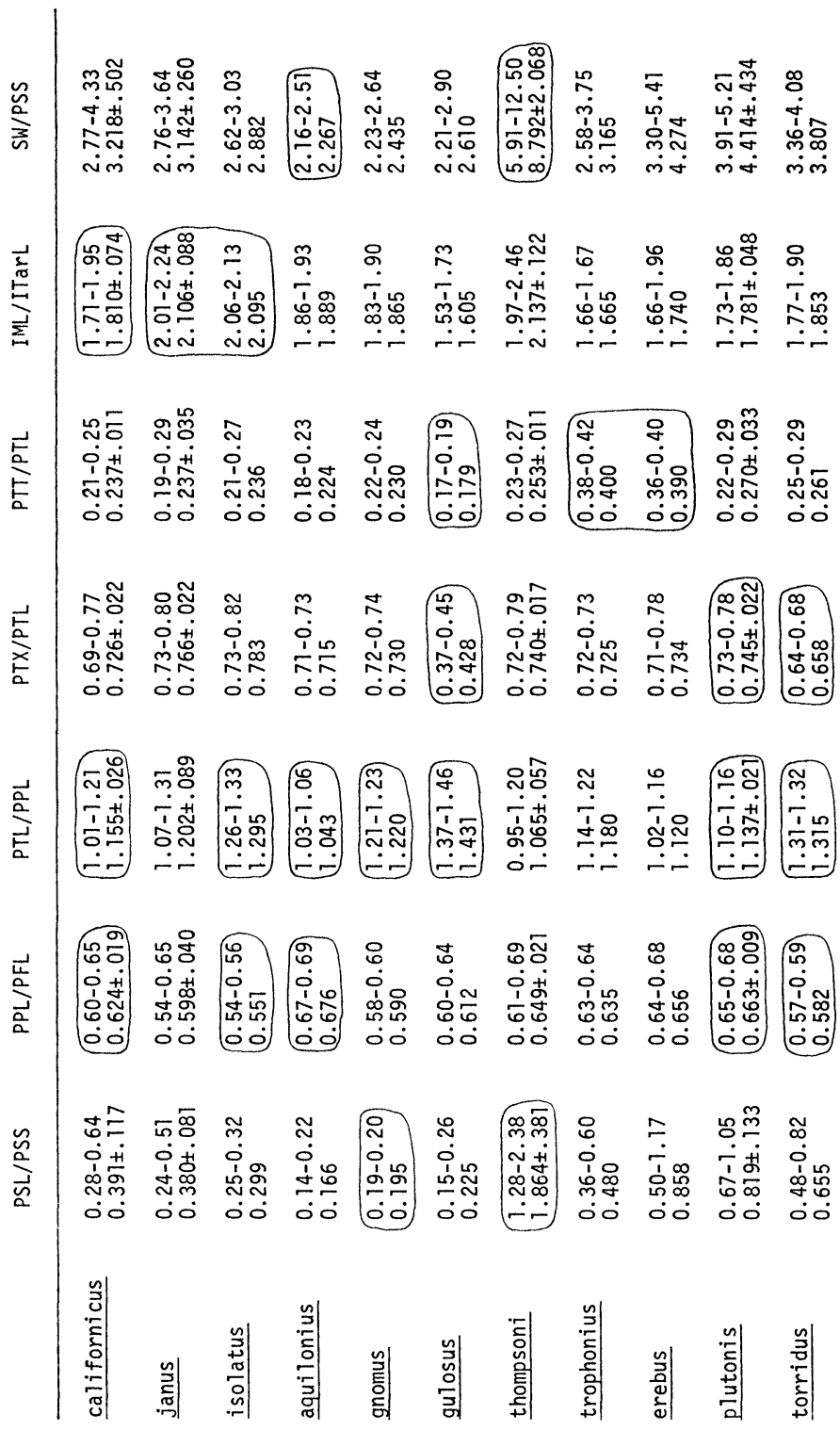




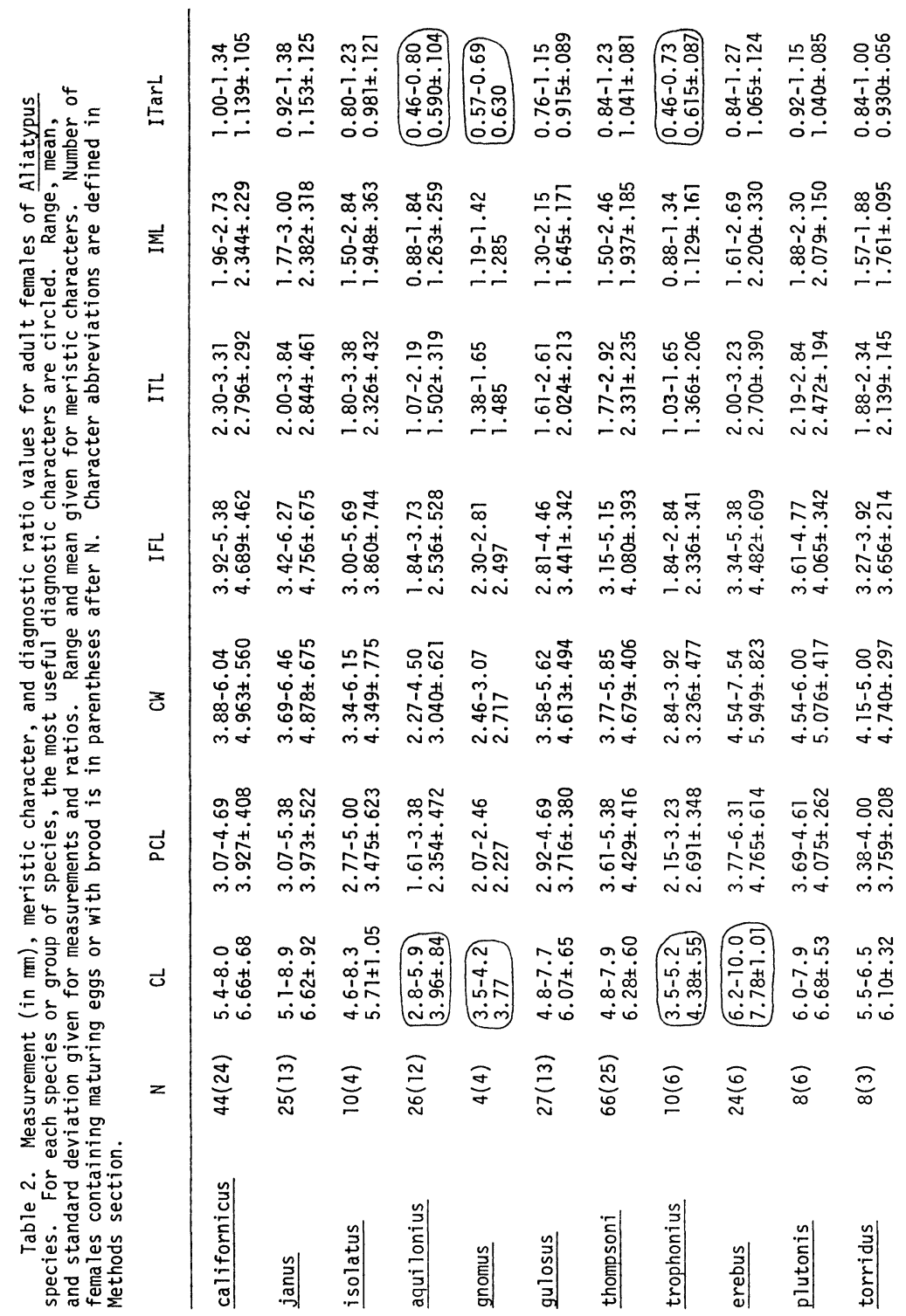




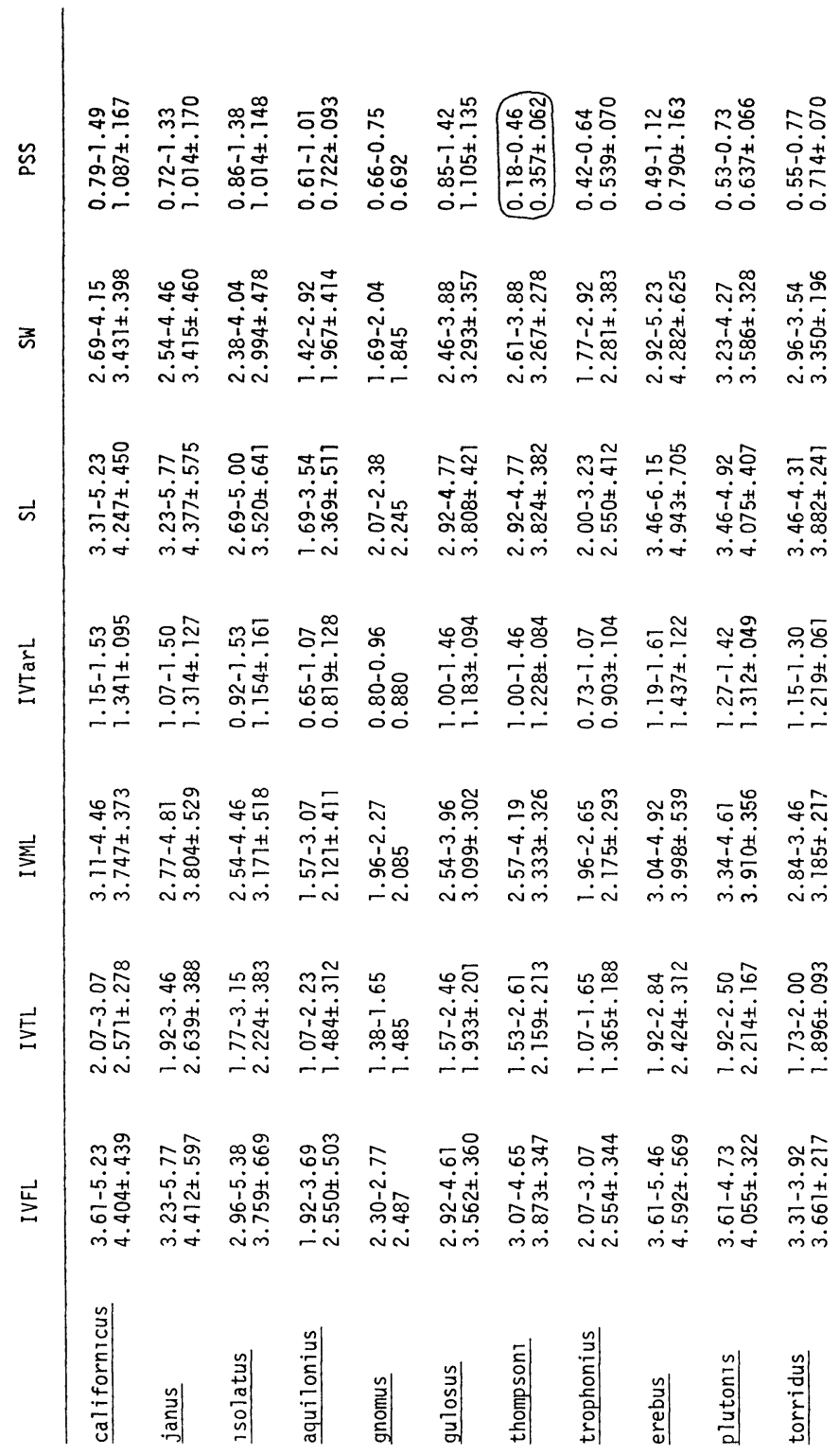




\begin{tabular}{|c|c|c|c|c|c|c|c|c|c|c|c|}
\hline 点 & 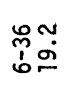 & 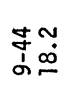 & $\begin{array}{l}\text { సิ̃o } \\
\text { İo }\end{array}$ & 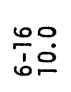 & $\bar{r}$ & ָָָּ & 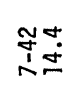 & 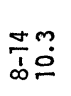 & 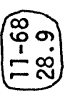 & $+\infty$ & 90 \\
\hline 舀 & & $\stackrel{p}{\dot{m}} \stackrel{m}{\dot{m}}$ & 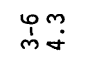 & $\stackrel{\substack{\varphi \\
m}}{m}$ & मेंm & 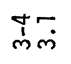 & 㒸 & $\stackrel{m}{2} \stackrel{2}{\sim}$ & 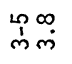 & में & मू \\
\hline in & $\infty$ & 음 & $\stackrel{\sim}{1} \tilde{\infty}$ & יִ & $\stackrel{\circ}{r}$ & am & 号 & $\hat{0}$ & $\frac{m}{i}-\dot{\infty}$ & 足 & $\stackrel{0 m}{a ! m}$ \\
\hline & & 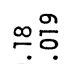 & 웅. & $\simeq \bar{o}$ & $\stackrel{0}{?}$ & $\because \stackrel{0}{0}$ & $\because \overline{0}$ & $\because \frac{0}{\sigma}$ & ๓ం్రి & $\because \tilde{0}$ & $\approx \overline{0}$ \\
\hline 命 & 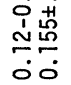 & 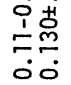 & 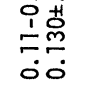 & 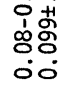 & 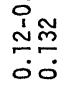 & 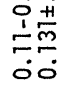 & $\begin{array}{l}\frac{i+}{4} \\
\frac{1}{0} \\
\dot{0}\end{array}$ & 足芯 & 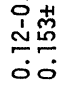 & 品苦 & 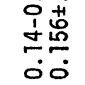 \\
\hline & & 舫 & 迎藏 & స్ి & - & 잉 & นึ์ & 웡 & 옹 & 녕 & ஜ్ల్ \\
\hline$\sum_{\Sigma}^{n}$ & 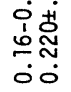 & 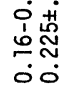 & 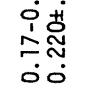 & \begin{tabular}{l}
$\frac{i}{i}$ \\
$=$ \\
\hdashline$\dot{0}$ \\
0
\end{tabular} & $\begin{array}{l}\text { io } \\
\text { ஸेo } \\
\vdots 0\end{array}$ & 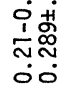 & $\begin{array}{l}\dot{i}+ \\
\text { ÑN } \\
\text { io }\end{array}$ & 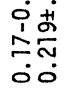 & 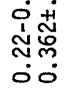 & 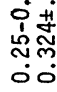 & 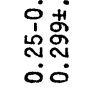 \\
\hline & ஜू & $\infty_{m}^{\infty}$ & ణ్లి & జ్రి & $\stackrel{\sim}{\sim}$ & চ్లి & 0 & m్లి & 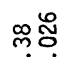 & గ్ర్ర & ஜீ్ \\
\hline$\frac{0}{\alpha}$ & 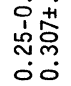 & 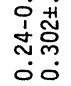 & 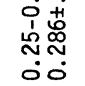 & 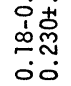 & 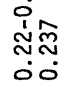 & $\begin{array}{l}\text { ì } \\
\text { స̃. } \\
\text { iั }\end{array}$ & 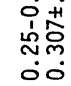 & 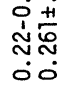 & 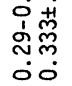 & 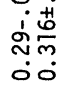 & $\begin{array}{l}\text { ì } \\
\text { șస్ల } \\
\vdots 0\end{array}$ \\
\hline & $\stackrel{J}{=}$ & $\iota_{\infty} \overline{0}$ & $\sigma^{\infty} \stackrel{\infty}{\frac{0}{\tau}}$ & $\approx \mathscr{0}$ & ณ & 응응 & & ఐ & $q^{\circ}$ & 응호 & $\approx \widehat{\mathscr{o g}}$ \\
\hline בั) & 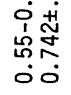 & 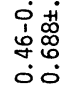 & 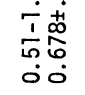 & 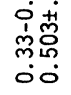 & 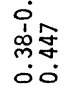 & 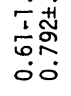 & 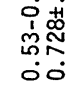 & 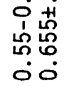 & 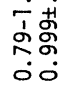 & 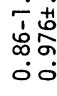 & 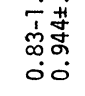 \\
\hline & $\approx \bar{n}$ & 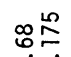 & 요 & $\hat{N} \stackrel{m}{=}$ & $\stackrel{\infty}{\circ}$ & ఐ & $\mathscr{\infty}$ & 웜듬 & $\stackrel{2}{N}$ & ㅁํㅇ & 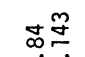 \\
\hline 홍 & 客芯 & 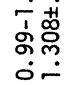 & 官芯 & 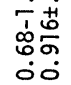 & 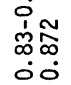 & 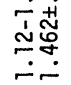 & & 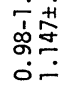 & 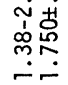 & 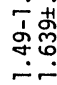 & 守荌 \\
\hline & ํํㅇ & 용 & ळ్లి & నิธి & $\approx$ & ํํำ & $\therefore \underset{ }{ }$ & 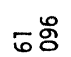 & & 용 & న。 \\
\hline बूँ & 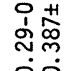 & 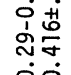 & 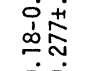 & $\begin{array}{l}\text { ít: } \\
\text { ô은 }\end{array}$ & 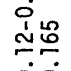 & 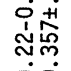 & 它芒 & 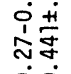 & 它芯 & 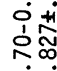 & 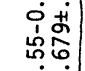 \\
\hline & & & & & & & & & & & \\
\hline & $\begin{array}{l}0 \\
0 \\
0 \\
0 \\
0 \\
0 \\
0\end{array}$ & 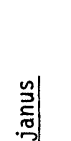 & 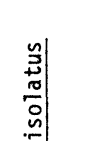 & 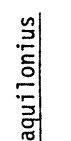 & 흘 & 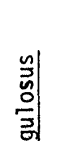 & $\begin{array}{l}0 \\
0 \\
0 \\
0 \\
0 \\
\vdots\end{array}$ & 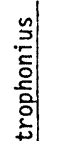 & 滒| & 点 & 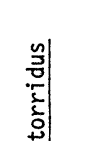 \\
\hline
\end{tabular}




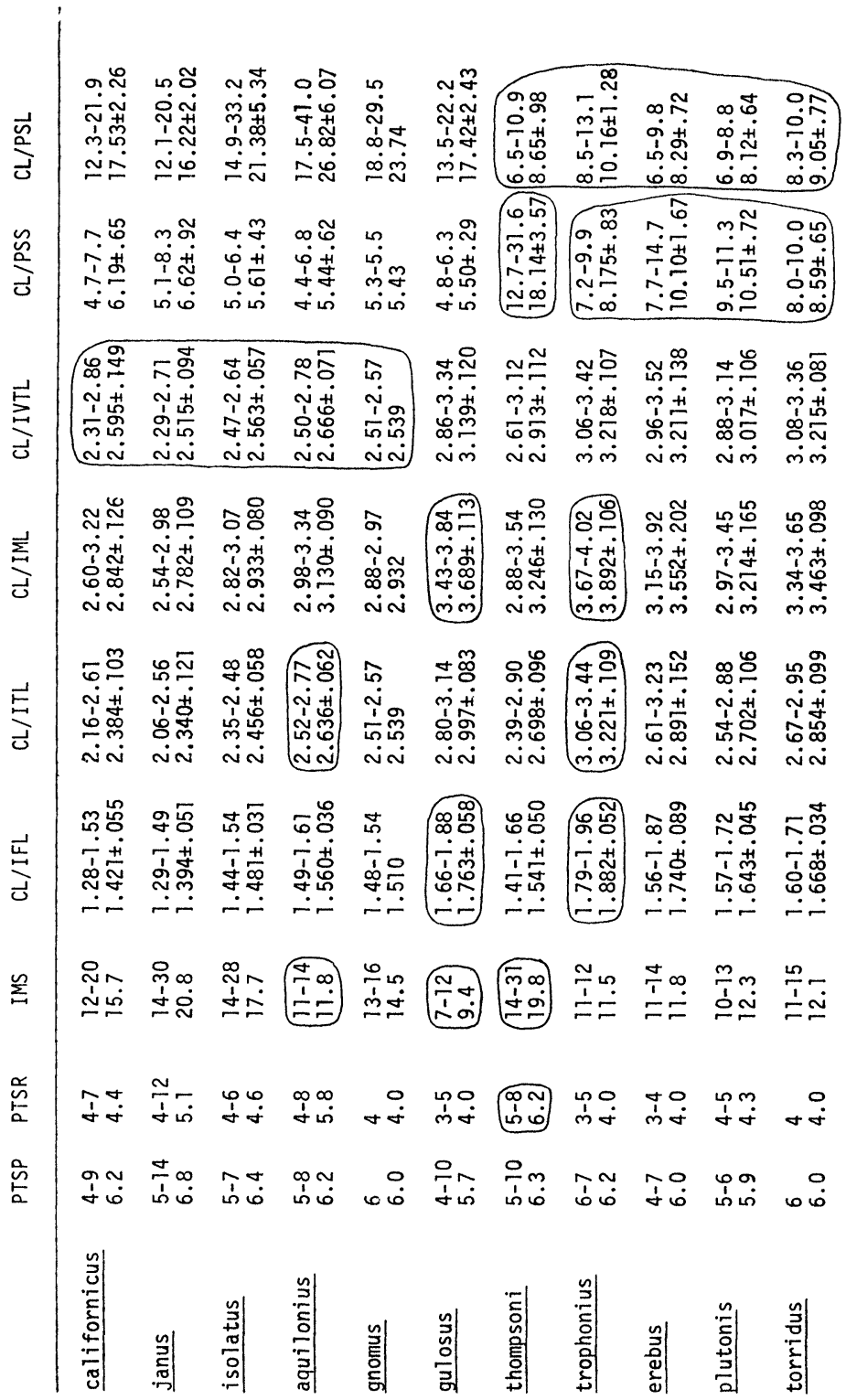




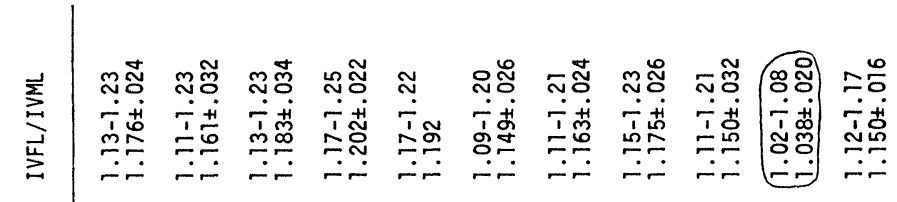

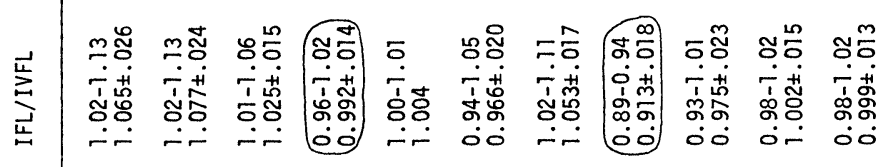

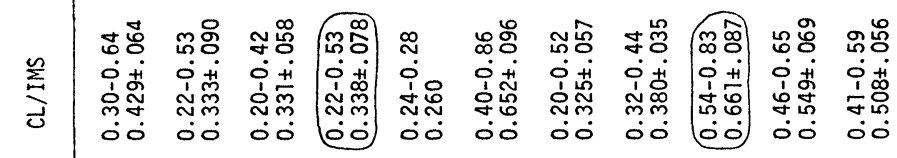

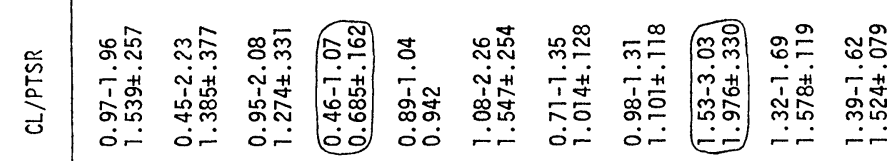

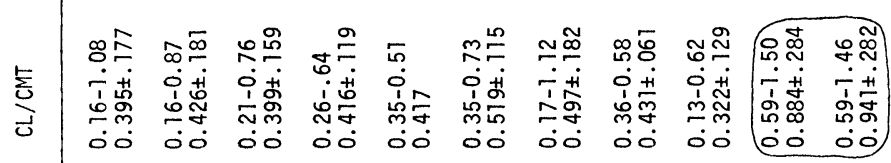

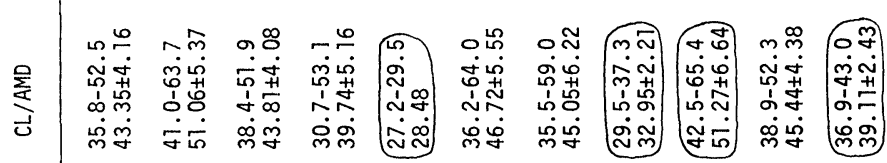

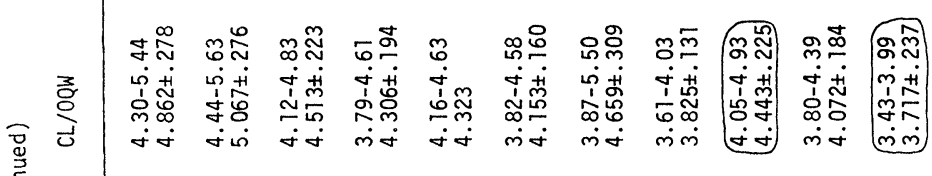

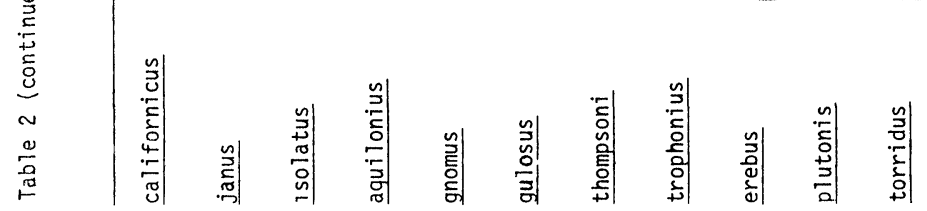




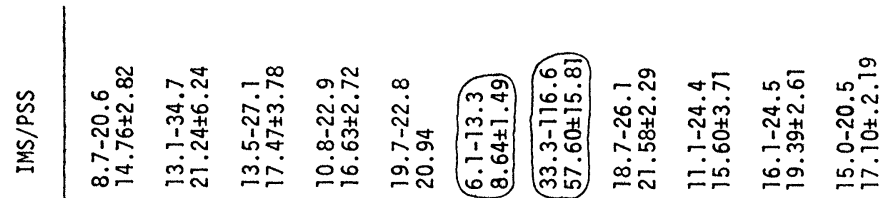

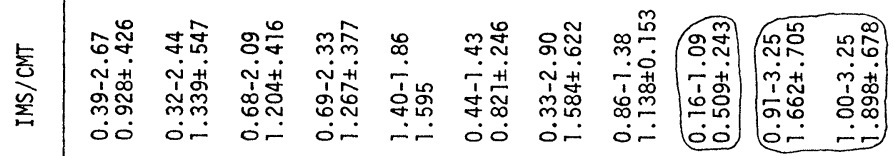

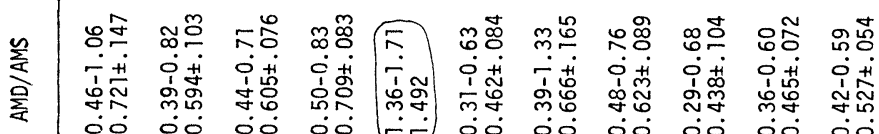

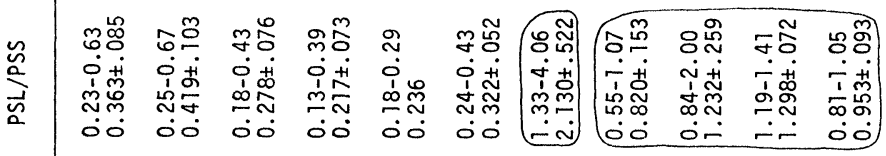

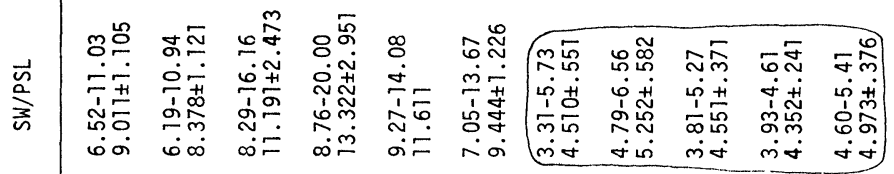

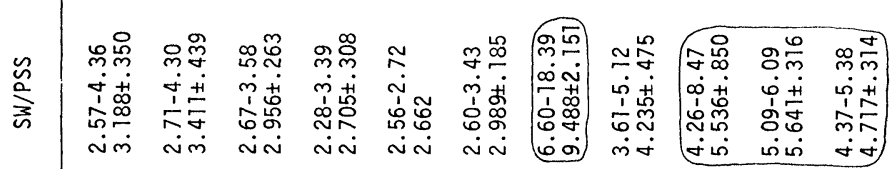

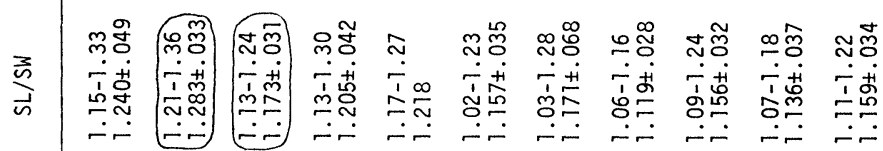

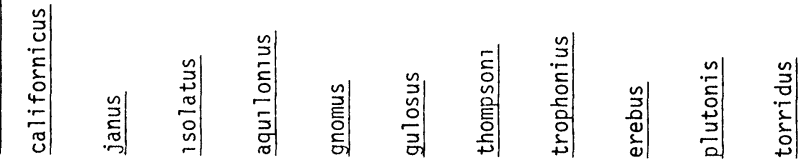


os

임

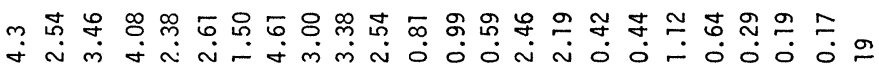

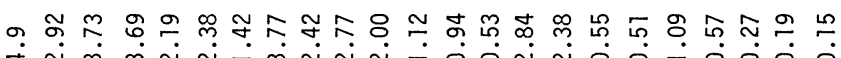

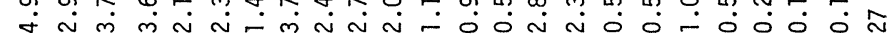

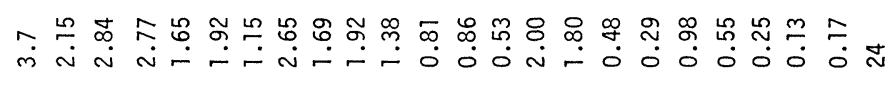

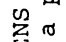

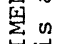

鼠迹

일 엉

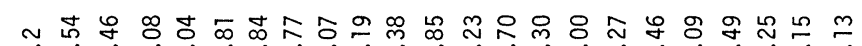

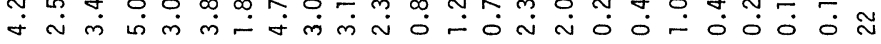

요요

落

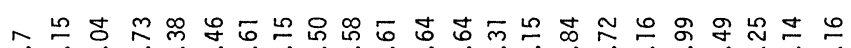

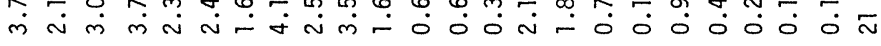

क्ष

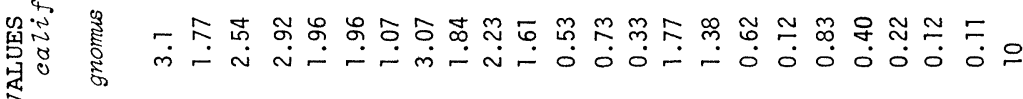

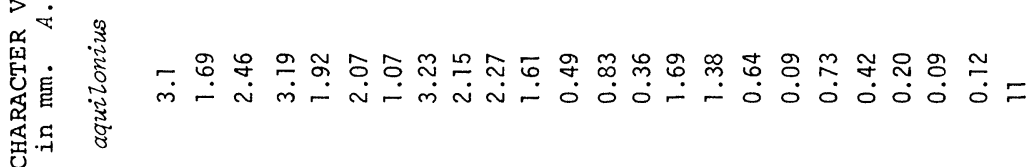

监

胥

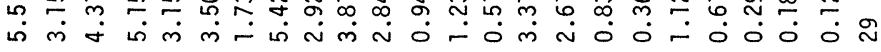
国点䍃

in

m

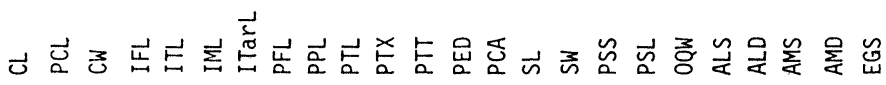




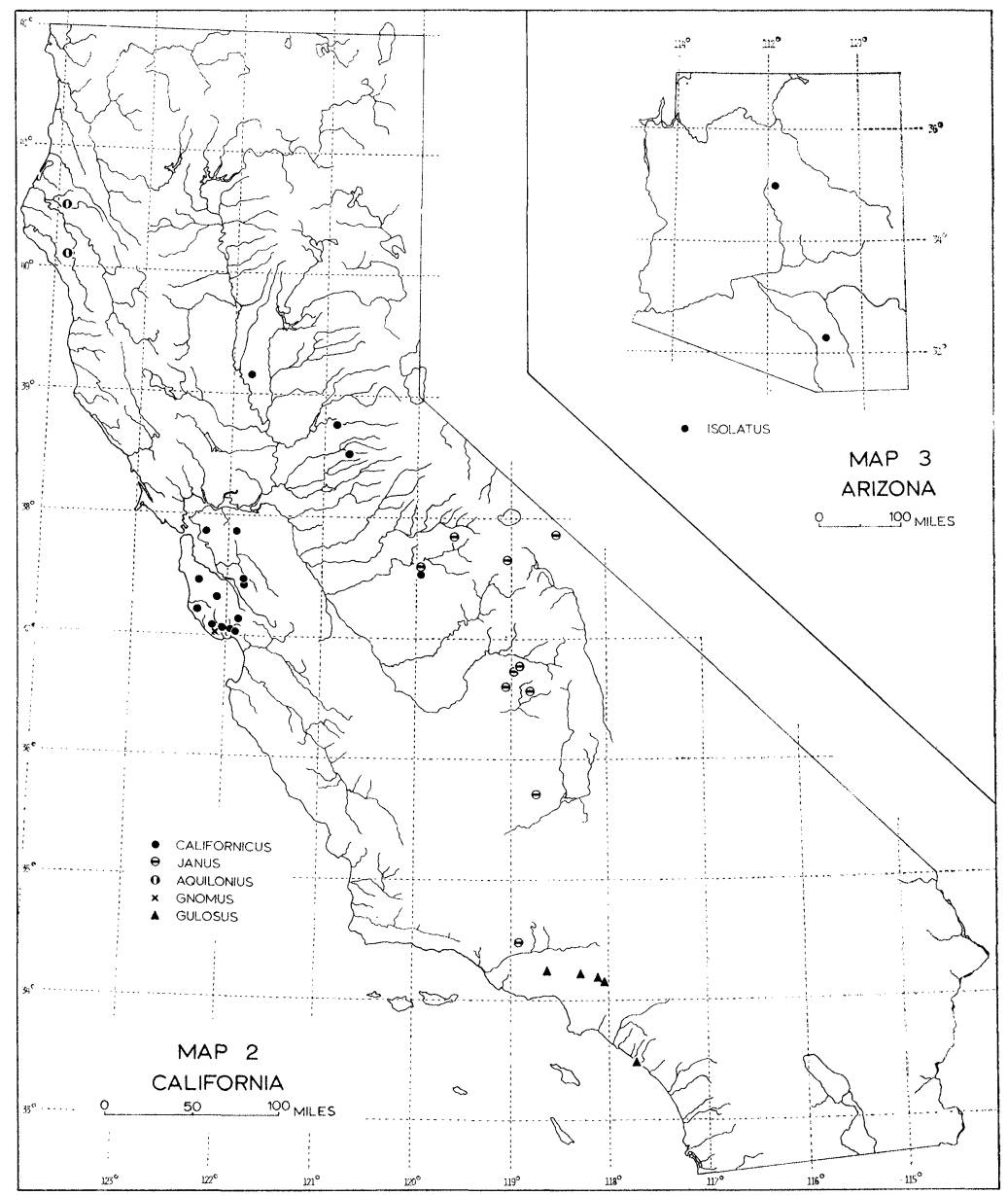

Maps 2-3. Distribution of Aliatypus species. 


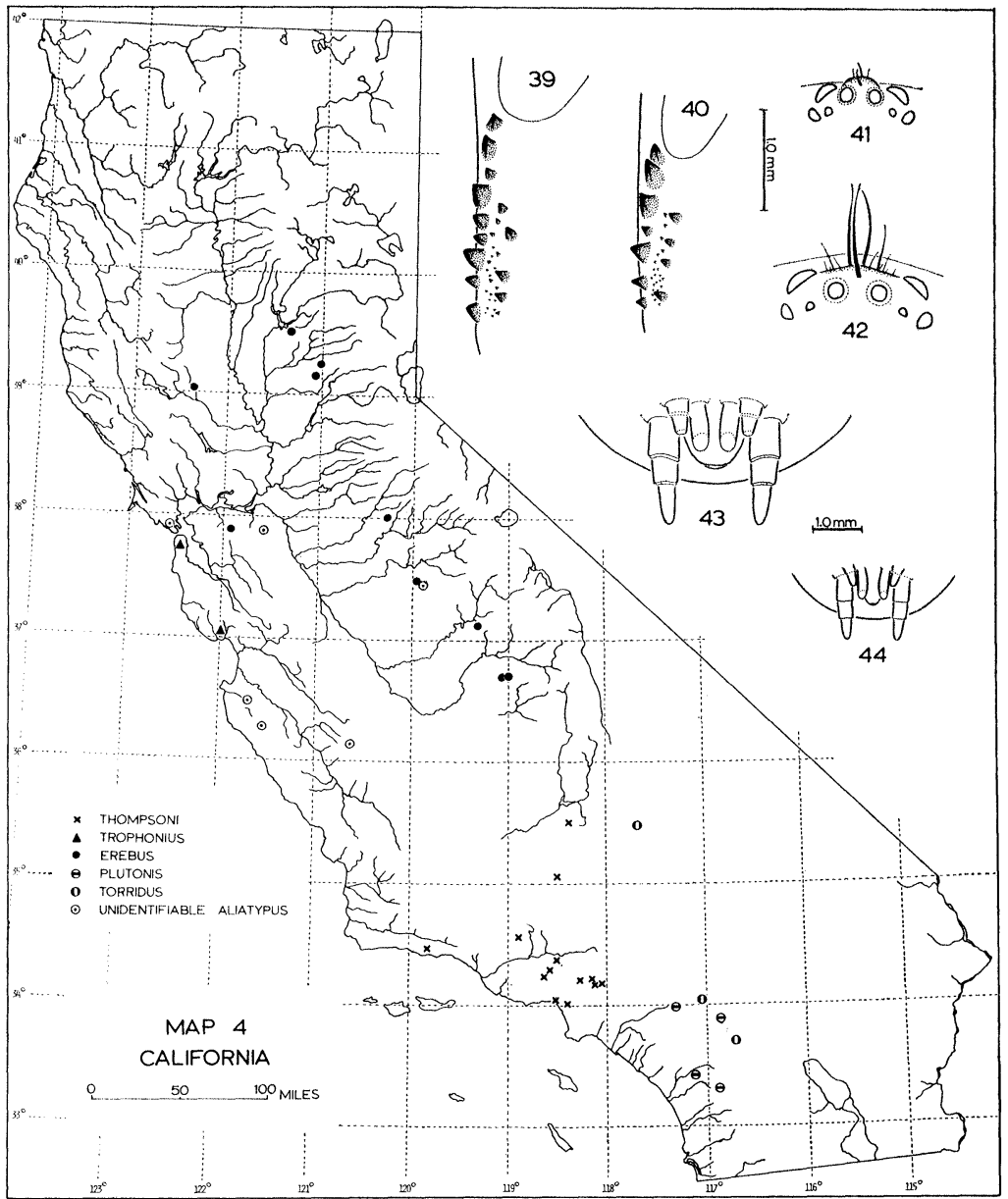

Map 4. Distribution of Aliatypus species. (Unidentifiable specimens are immatures and females which cannot be assigned to any recognized species.) Figures 39-40: Cheliceral teeth of Aliatypus females. (Ventral view of left chelicera.) 39: $A$. californicus, Soquel. 40: $A$. thompsoni, paratype. Figures 41-42: Eyes of Aliatypus thompsoni (Dorsal view with lateral border of carapace horizontal.) 41: male, holotype. 42: female, paratype. Figures 43-44: Spinnerets of Aliatypus thompsoni. (Ventral view.) 43: female, paratype. 44: male, paratype. 

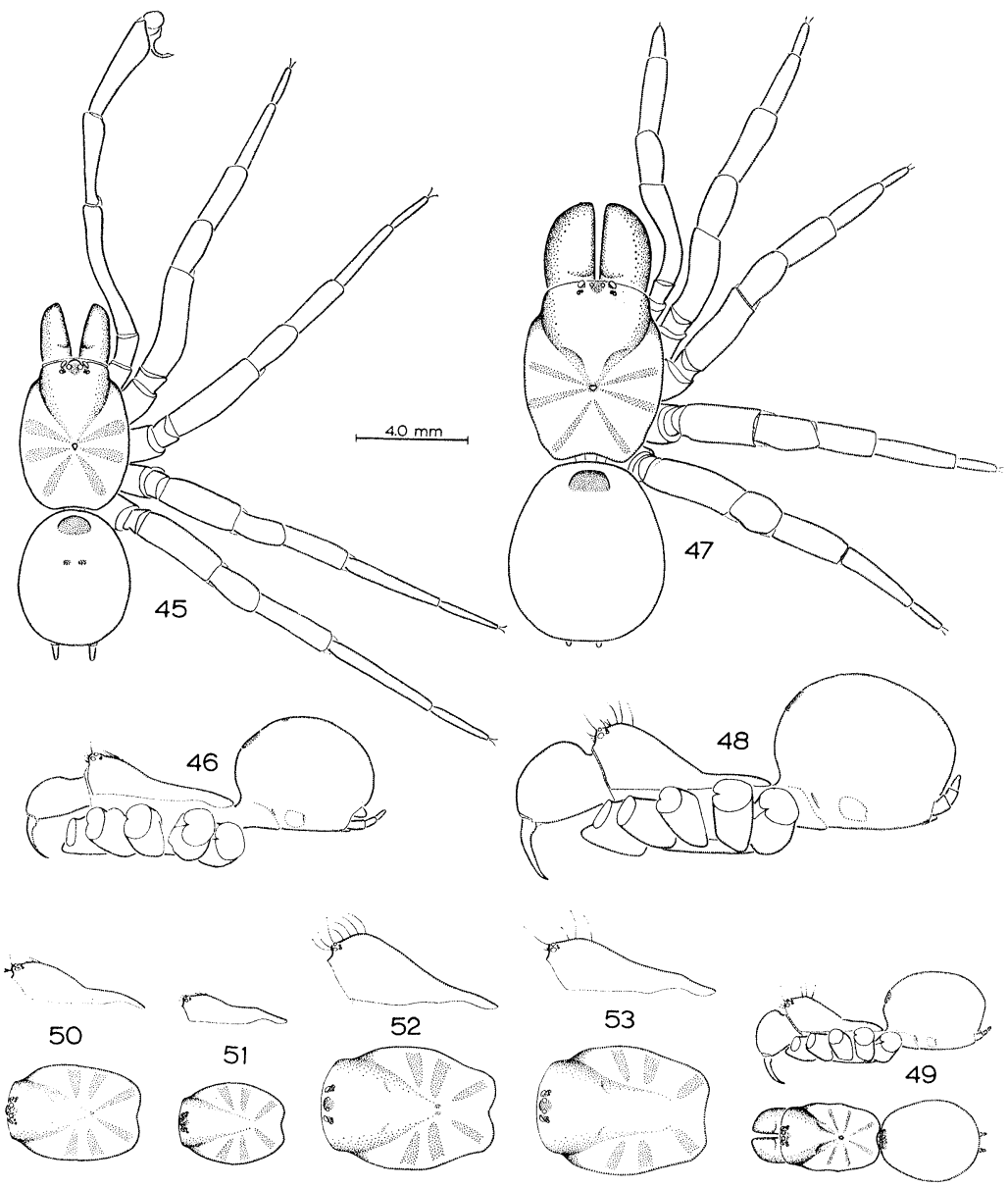

Figures 45-53: Whole body and carapace views of Aliatypus. 45-48: $A$. californicus. 45-46: male, Calaveras Reservoir. 47-48: female, Soquel. 49: A. gnomus female, paratype. 50-53: A. thompsoni. 50-51: males. 50: Placerita Canyon. 51: Henninger Flats. 52-53: females 52: Placerita Canyon. 53: Henninger Flats. 


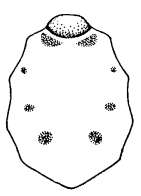

54

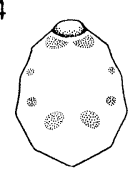

60

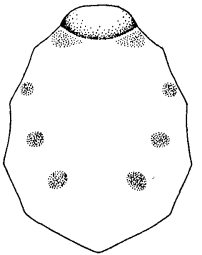

65

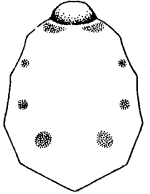

55

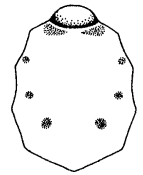

56<smiles>c1ccccc1</smiles>

57<smiles>c1ccccc1</smiles>

58

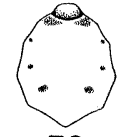

59

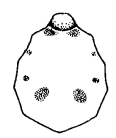

61

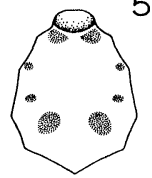

62

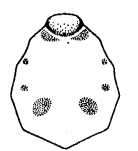

63

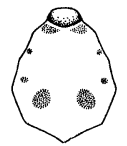

64

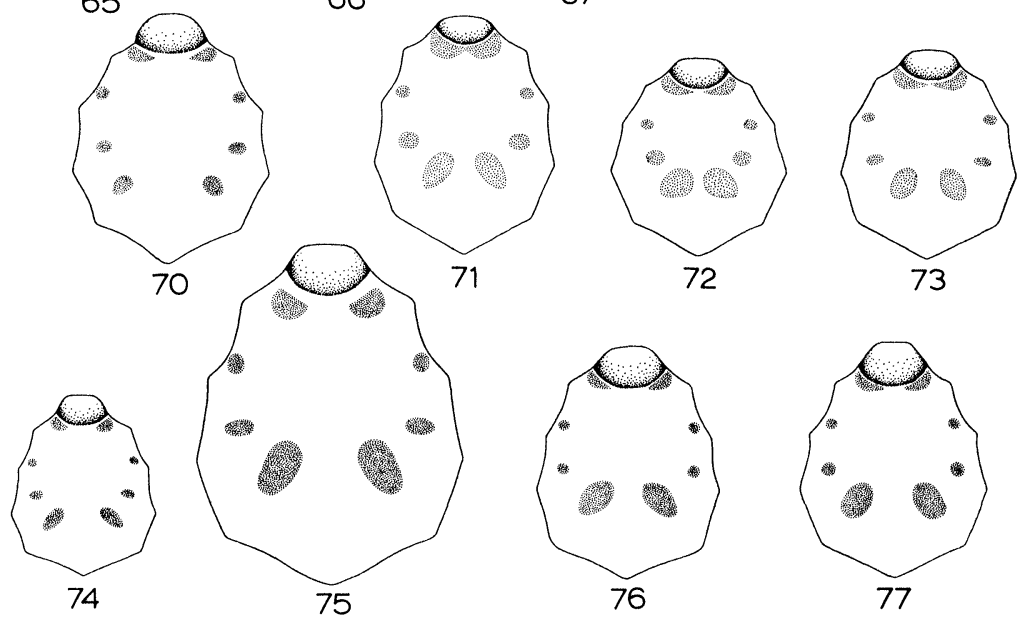

Figures 54-77: Sternum, labium, and sigilla of Aliatypus species. 54-64: males. 54: $A$. californicus, Alum Rock Park. 55: $A$. janus, holotype. 56: $A$. isolatus, paratype. 57: A. aquilonius, holotype. 58: A. gnomus, holotype. 59: $A$. gulosus, holotype. 60: $A$. thompsoni, paratype. 61: $A$. trophonius, holotype. 62: A. erebus, holotype. 63: A plutonis, Banning. 64: $A$. torridus, holotype. 65-77: females. 65: $A$. californicus, Montebello Rd. 66: $A$. janus, paratype. 67: $A$. isolatus, paratype. 68: $A$. aquilonius, paratype. 69: $A$. gnomus, paratype. 70: $A$. gulosus, paratype. 71-73: $A$. thompsoni. 71: paratype. 72-73: Eaton Canyon. 74: $A$. trophonius, paratype. 75: A. erebus, Sonora. 76: A. plutonis, Banning. 77: A. torridus, paratype. 


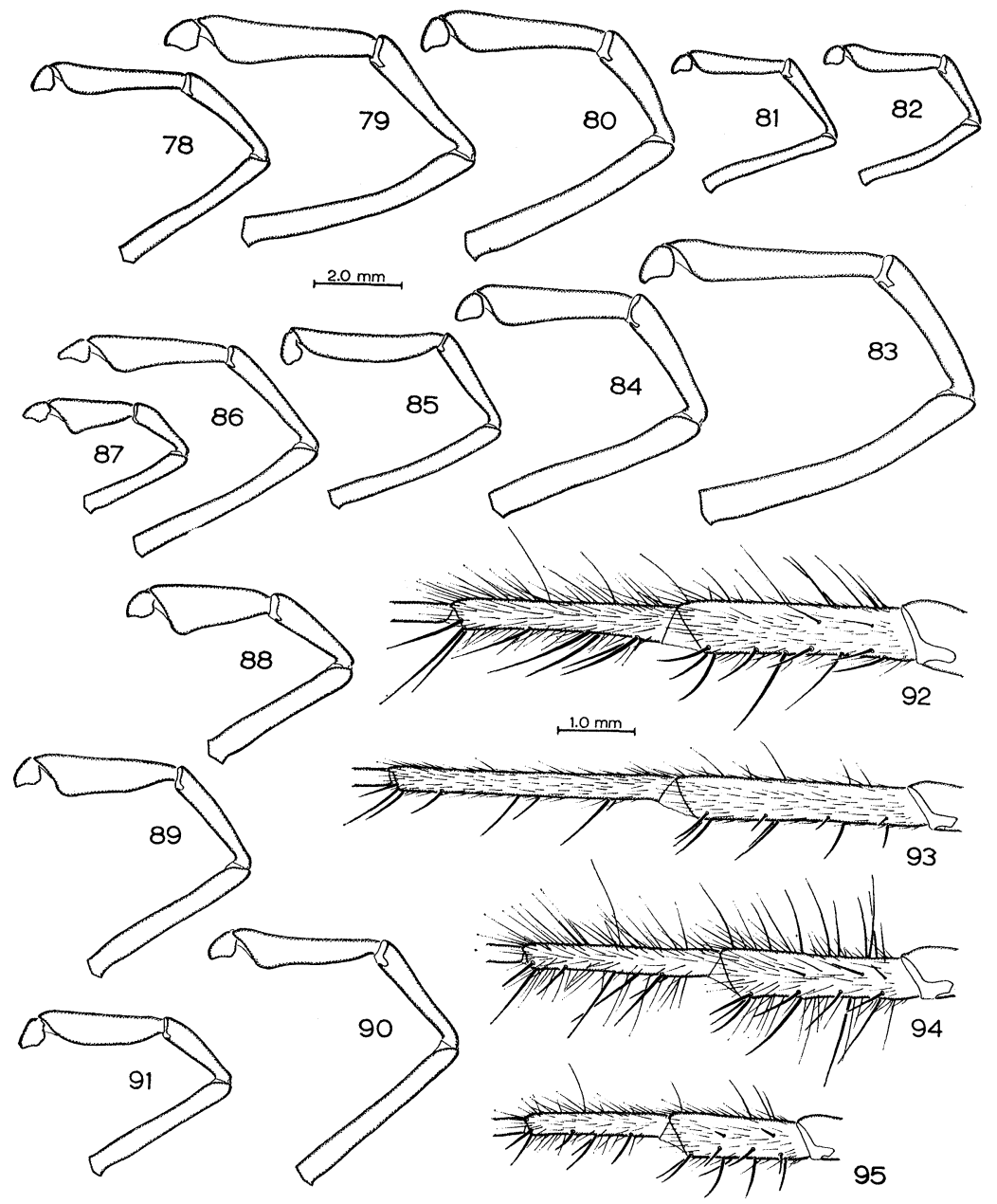

Figures 78-91: Aliatypus male pedipalps. (Retrolateral view of left pedipalps.) 78-79: A californicus. 78: Coloma. 79: Montebello Rd. 80: $A$. isolatus, holotype. 81: $A$. aquilonius, holotype. 82: $A$. gnomus, holotype. 83-84: $A$. janus. 83: Yosemite Nat'l Park. 84: Glenville. 85: $A$. gulosus, holotype. 86: $A$. thompsoni, holotype. 87: A. trophonius, holotype. 88: A. erebus, holotype. 89-90: $A$. plutonis. 89: Banning. 90: holotype. 91: $A$. torridus, holotype. Figures 92-95: Tibia and metatarsus of leg I of Aliatypus males. (Retrolateral view of left leg.) 92: $A$. californicus, Alum Rock Park. 93: $A$. thompsoni, holotype. 94: $A$. plutonis, holotype. 95: A. trophonius, holotype. 


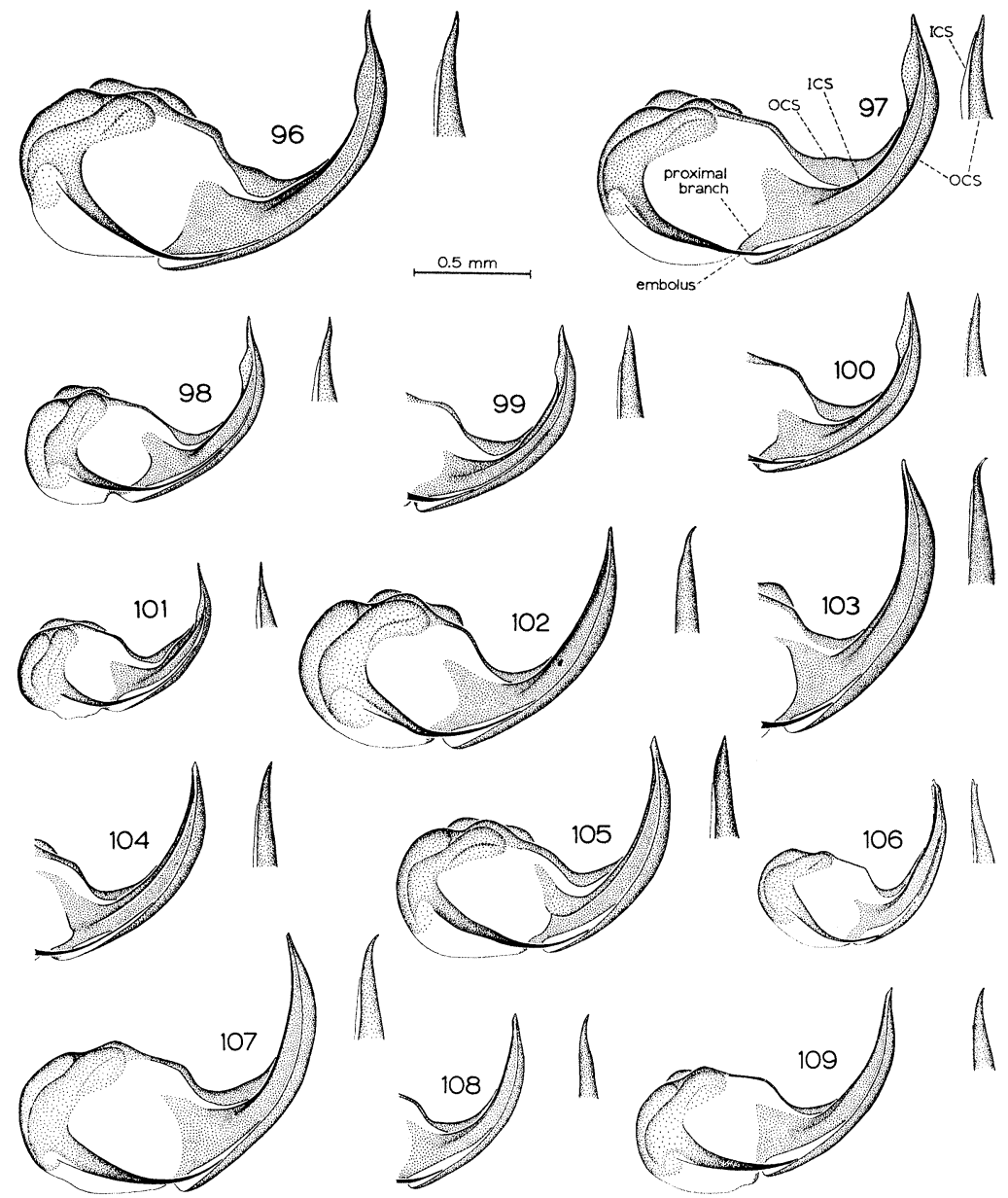

Figures 96-109: Aliatypus palpi. (Prolateral view of left palpus and view of tip after palpus rotated $90^{\circ}$ on longitudinal axis of distal part of conductor.) 96-100: $A$. californicus. 96: Montebello Rd. 97: Alum Rock Park. 98: Coloma. 99-100: Mariposa. 101: A. gnomus, holotype. 102-105: A. janus. 102: holotype. 103: Yosemite Nat'l Park. 104: Pinehurst. 105: Glenville. 106: A aquilonius, Briceland. 107-109: A. isolatus. 107: holotype. 108-109: Santa Catalina Mtns. 


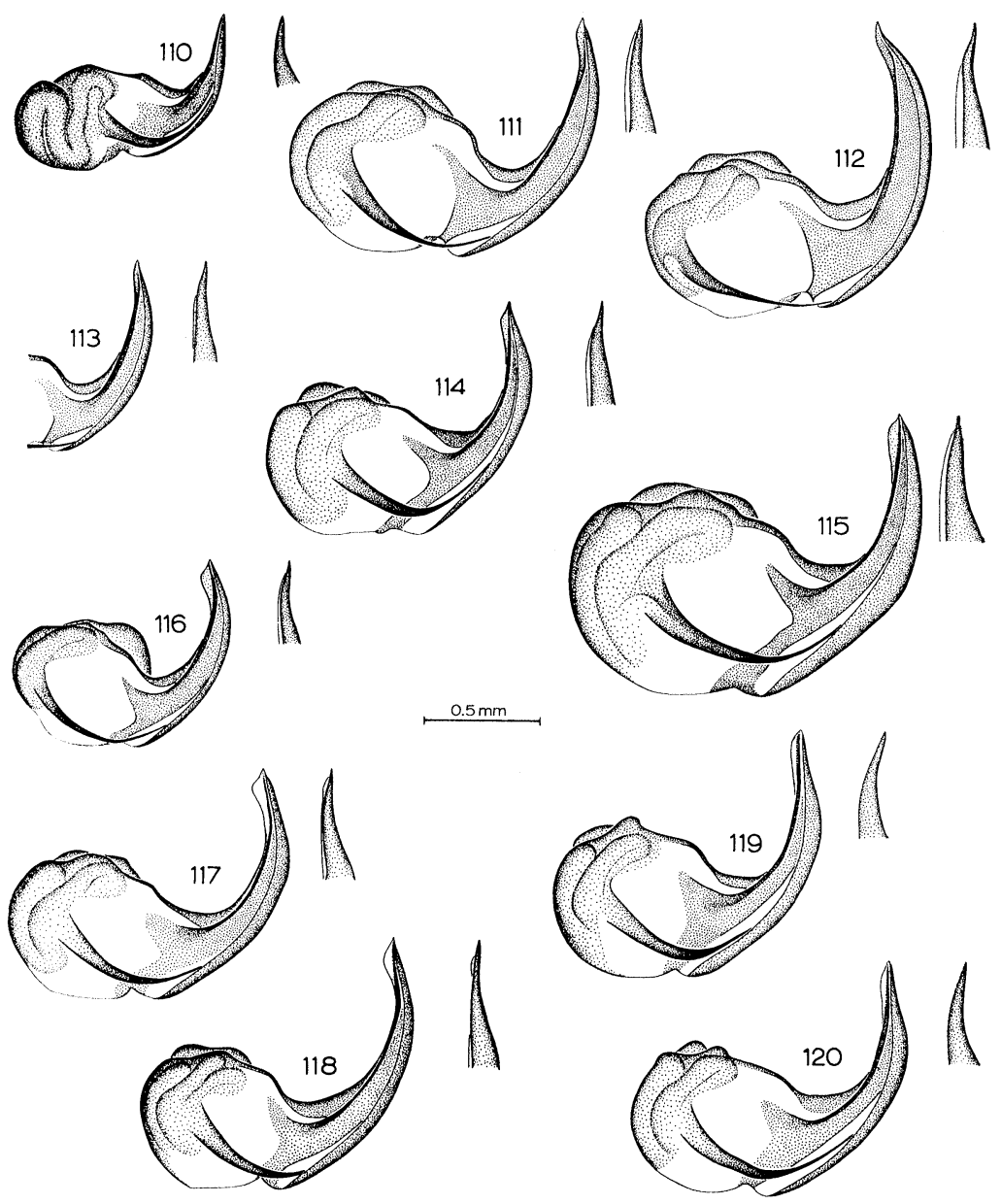

Figures 110-120: Aliatypus palpi. (Same views as previous plate.) 110: A. gulosus, holotype. 111-113: A. thompsoni. 111: Tehachapi Mtns. 112: holotype. 113: Henninger Flats. 114-115: A. erebus. 114: holotype. 115: Sonora. 116: A. trophonius, holotype. 117-118: A. plutonis. 117: Palomar Mtn. 118: Banning. 119-120: A. torridus. 119: El Paso Mtns. 120: holotype. 


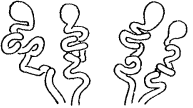

121

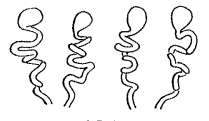

122

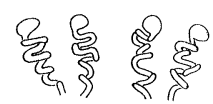

123

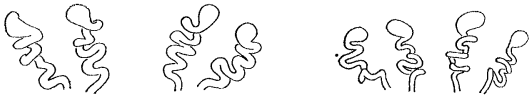
124
125

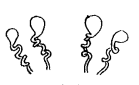

126

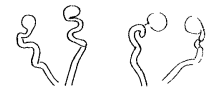

127

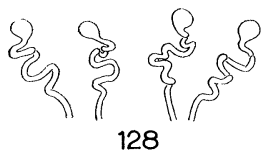<smiles>O=C(O)COS(=O)(=O)O</smiles><smiles>CC(C)Sc1ccccc1</smiles>

130
य)

131

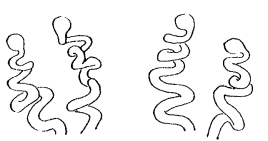

132

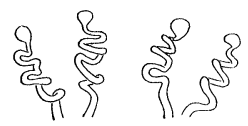

133
है? की की

134

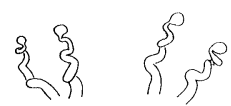

135

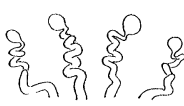

136

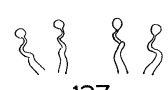
137

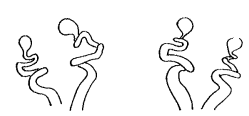

138

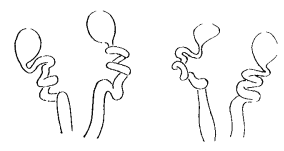

139

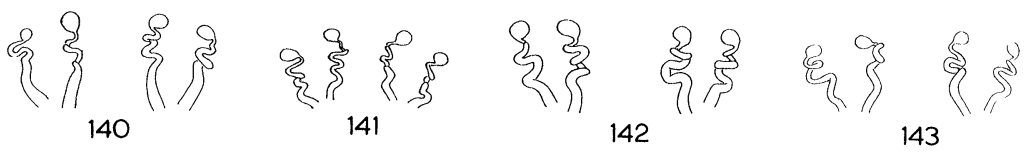

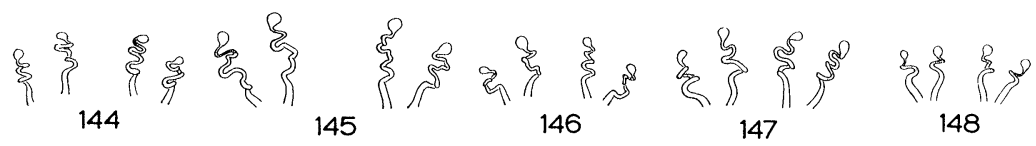

Figures 121-148: Aliatypus seminal receptacles. (Dorsal view.) 121-131: A. californicus. 121: Montebello Rd. 122: Bates Creek. 123: Henry Cowell Redwoods State Park. 124: Alum Rock Park. 125: Mt. Diablo State Park. 126: Sutter Buttes (immature). 127: Coloma. 128-129: Aukum. 130-131: Mariposa. 132-143: A. janus. 132: Briceburg. 133: Yosemite Nat'l Park. 134-135: Mammoth Lakes. 136-137: paratypes. 138-139: Pinehurst. 140141: Sequoia. 142: Woodlake. 143: Glenville. 144-146: $A$. isolatus. 144: paratype. 145-146: Santa Catalina Mtns. 147-148: A. aquilonius. 147: paratype. 148: Redway. 


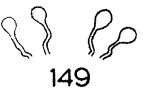
149

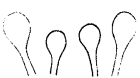

153

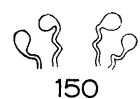

150
90

15

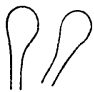

MI) 9

152

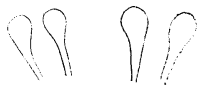

154

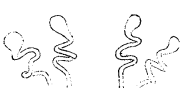

155

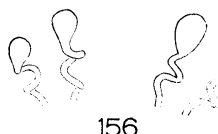

156

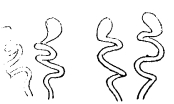

157
数畩

158

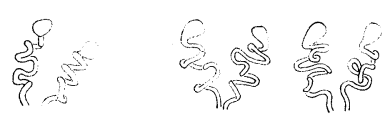

159

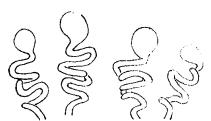

160

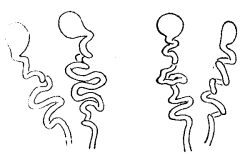

161

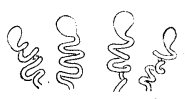

162

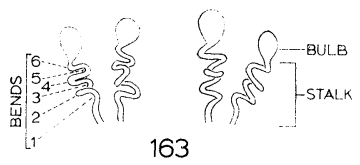<smiles>CC(C)CC(C)C</smiles>

164

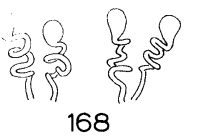

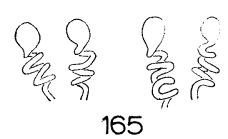

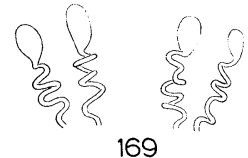

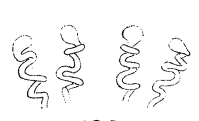

166

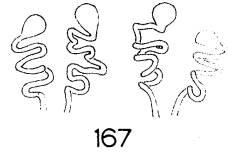

167

Figures 149-171: Aliatypus seminal receptacles. (Dorsal view.) 149-150: A. gnomus paratypes. 151-154: A. gulosus. 151: Eaton Canyon. 152: Sierra Madre. 153-154: paratypes. 155-171: A. thompsoni. 155: Kernville. 156-157: Tehachapi Mtns. 158: Santa Ynez. 159: Squaw Flats. 160-161: Placerita Canyon. 162: Baldwin Hills. 163: Limekiln Canyon. 164-166: paratypes. 167: I.as Barras Canyon. 168: Honninger Flats. 169170: Eaton Canyon. 171: Sierra Madre. 


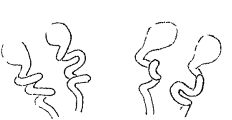

172

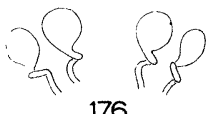

176

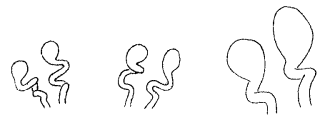

173

174
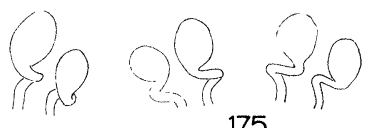

175

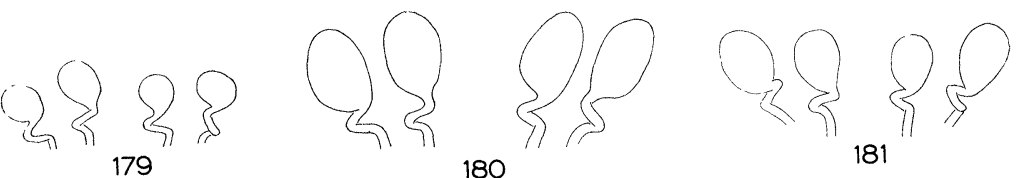

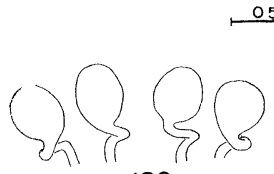

182

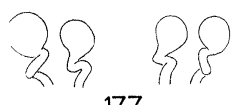

177

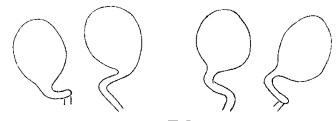

178

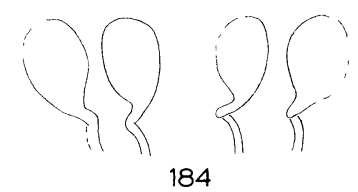

183

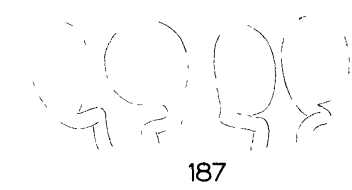

186

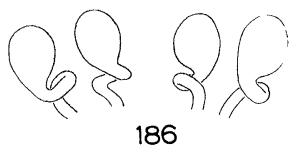

187

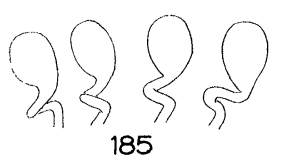

पूरी

188<smiles>OC(O)(O)C1CCCCC1</smiles>

189

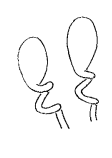

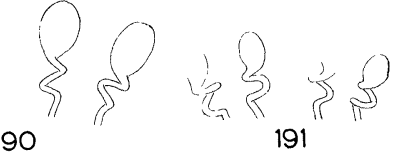

191

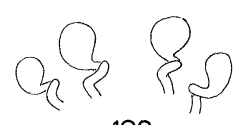

192

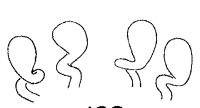

193

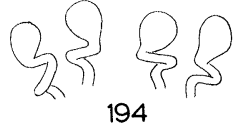

194

Figures 172-194: Aliatypus seminal receptacles. (Dorsal view.) 172-173: A. trophonius paratypes. 174-187: A erebus. 174-175: paratypes. 176-177: Wilbur Springs. 178-179: Nevada City. 180-181: Sonora. 182-183: Mariposa. 184-185: Shaver Lake. 186: Pinehurst. 187: Miramonte. 188-191: A. plutonis. 188-189: paratypes. 190-191: Banning. 192-194: A. torridus. 192: El Paso Mtns. 193: Yucaipa. 194: paratype. 

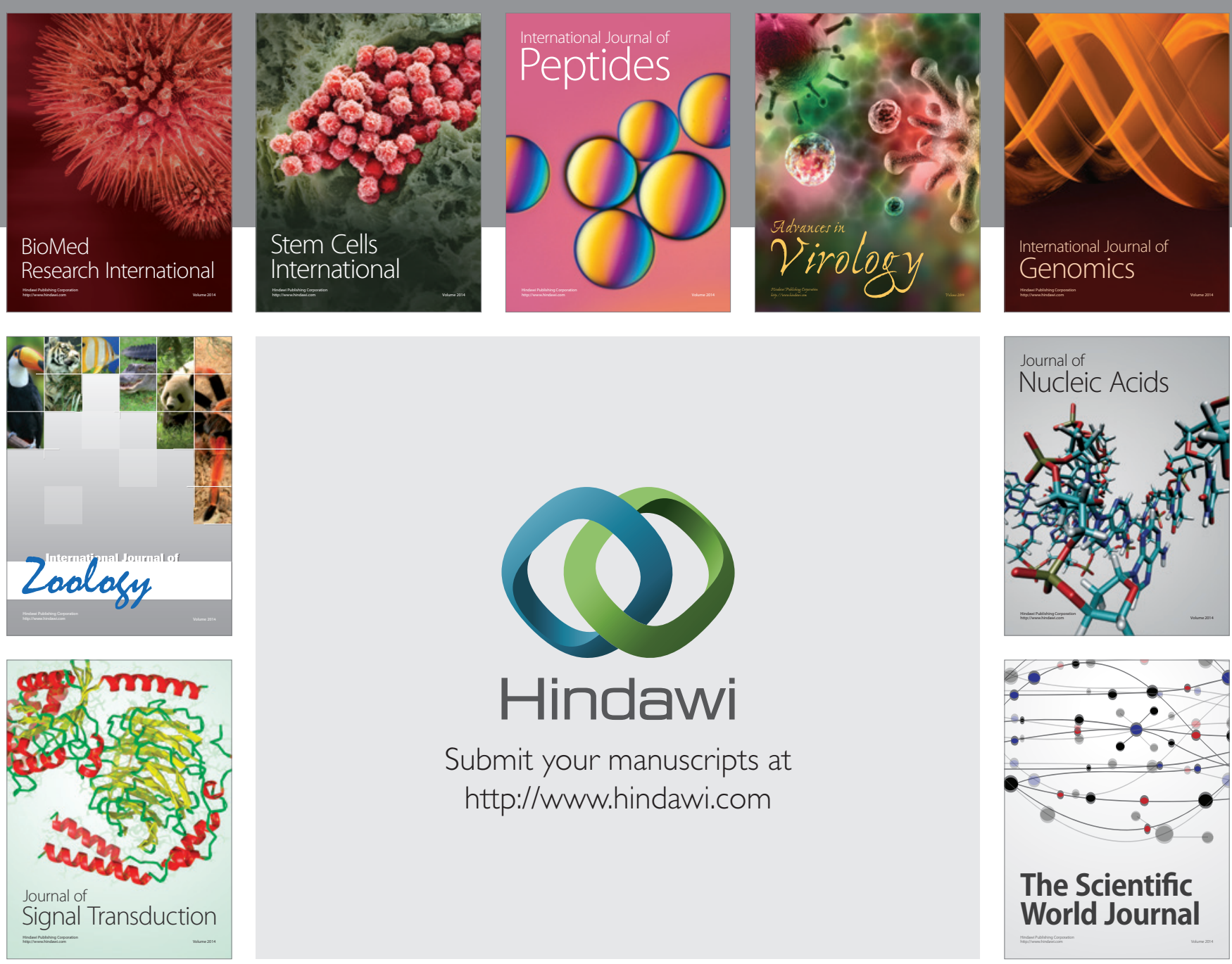

Submit your manuscripts at

http://www.hindawi.com
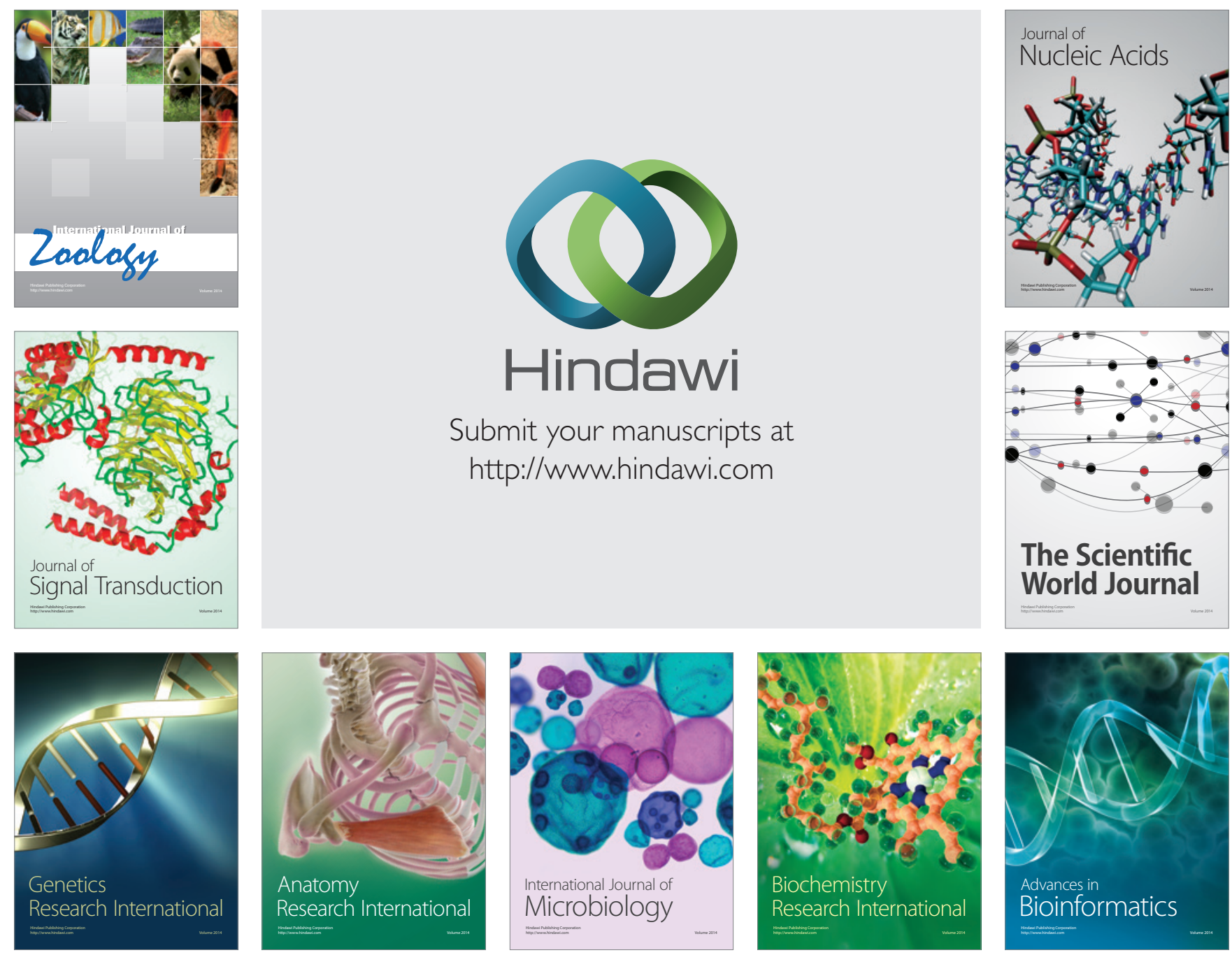

The Scientific World Journal
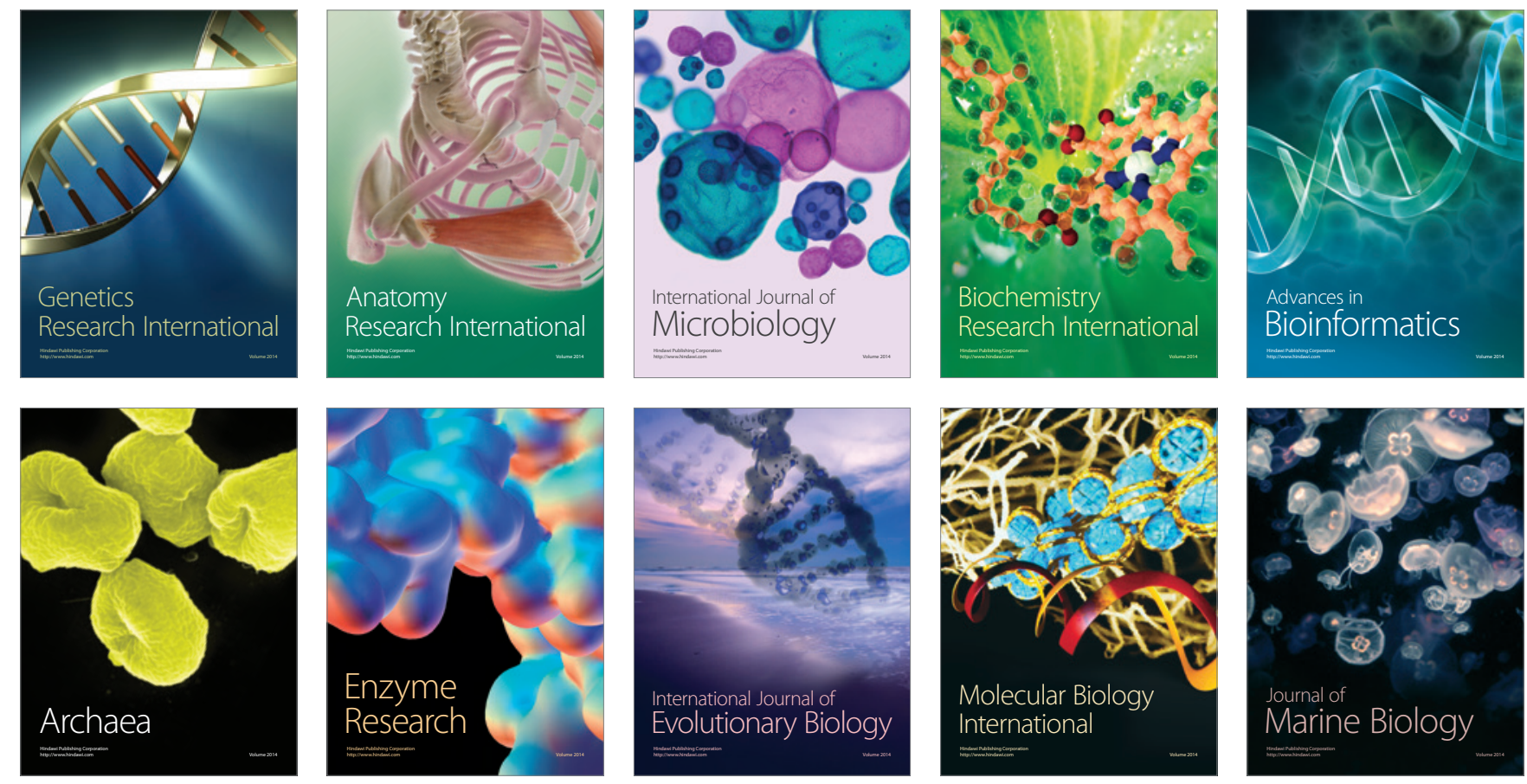